\title{
Homo medicus: The transition to meat eating, increased pathogen pressure, and the use of pharmacological plants in Homo
}

\author{
Edward H. Hagen, Aaron D. Blackwell, Aaron D. Lightner, Roger J. Sullivan
}

2022-08-28

\begin{abstract}
The human lineage transitioned to a more carnivorous niche 2.6 mya, likely increasing zoonotic pathogen pressure. Evidence for this increase includes increased zoonotic infections in modern hunter-gatherers and bushmeat hunters, exceptionally low stomach pH compared to other primates, and exceptional human immune responses to lipopolysaccharide compared to other primates. These all point to change, and likely intensification, in the disease environment of Homo compared to earlier hominins and other apes. At the same time, the brain, an organ in which immune responses are constrained, began to triple in size. We propose that the combination of increased zoonotic pathogen pressure and the challenges of defending a large brain and body from pathogens in a long-lived mammal, selected for intensification of the plant-based self-medication strategies already in place in apes and other primates. In support, there is evidence of medicinal plant use by hominins in the middle Paleolithic, and all cultures today have sophisticated, plant-based medical systems, add spices to food, and regularly consume psychoactive substances that are harmful to helminths and other pathogens. The computational challenges of discovering effective plant-based treatments, the consequent ability to consume more energy-rich animal foods, the reduced reliance on energetically costly immune responses, and the economic challenges of benefiting from costly-to-acquire medical knowledge that would be more often useful to others than oneself, helped select for increased cognitive abilities and unique exchange relationships in Homo. In the story of human evolution, which has long emphasized hunting skills, medical knowledge had an equal role to play.
\end{abstract}

\section{Introduction}

Every day, most adults deliberately consume plant substances that contain few, if any, macronutrients but that have potent pharmacological properties. Globally, farmers grow over one million tons of black pepper (Piper nigrum) and other Piper species every year, for example, along with 6.5 million tons of tea (Camellia sinensis), 10 million tons of coffee (Coffea spp.), 6.7 million tons of tobacco (Nicotiana tabacum), and 1.7 million tons of areca nuts (Areca catechu) (Food and Agriculture Organization, 2019). See Figure 1. 


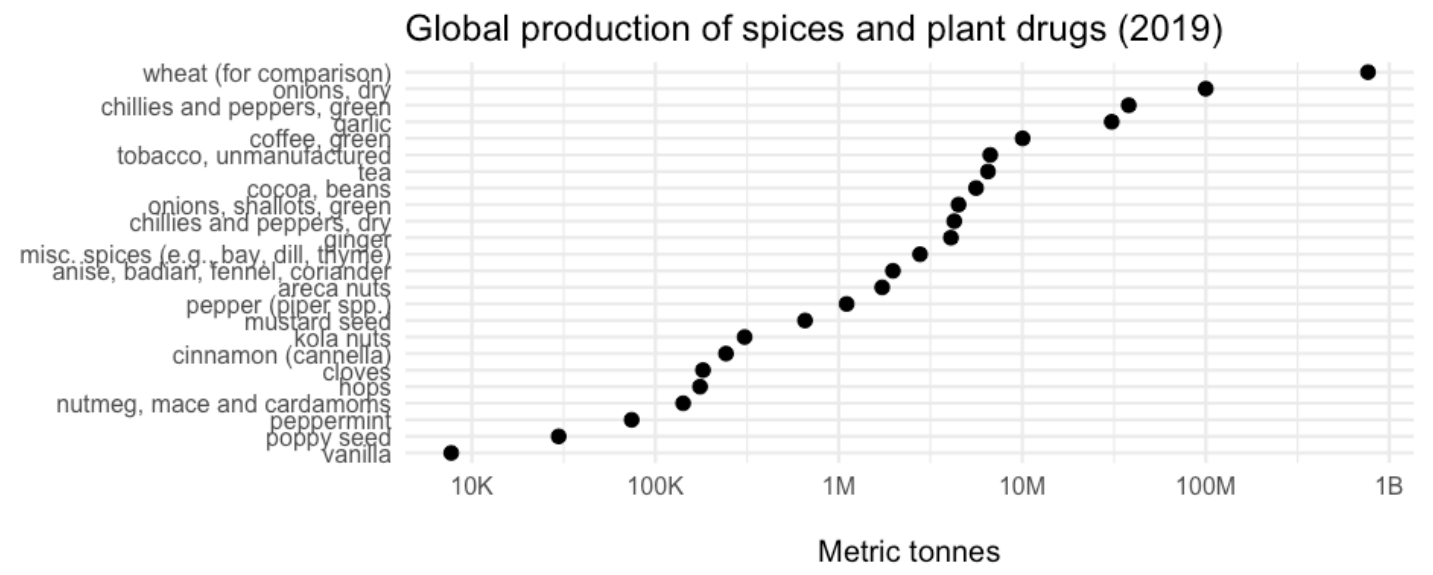

Figure 1: Global production of spice and drug plants in 2019. Wheat production for comparison. Axis on a log scale. Data from Food and Agriculture Organization (2019).

Apparently mundane black pepper contains numerous bioactive compounds that are effective against a wide range of pathogens and have other medically useful effects. Many of these effects are linked to the alkaloid piperine (Takooree et al., 2019), which is also psychoactive, crossing the blood brain barrier and modulating $\gamma$-aminobutyric acid (GABA) type A receptors (Eigenmann et al., 2016). Tea, the world's most popular beverage after water, has about 700 bioactive compounds, including catechins, theanine, caffeine, and volatiles (Wei et al., 2018), with numerous health and psychoactive effects and antimicrobial activity (Bansal et al., 2013; Nonthakaew et al., 2015; Zhang et al., 2019). Over $90 \%$ of a large representative US population sample had urinary biomarkers of caffeine (Rybak et al., 2015). Beyond these substances, other plant-based "recreational" drugs such as cannabis, cocaine, and opioids, as well as hundreds of additional spices, are widely consumed on a daily basis for their psychoactive and other effects.

Traditional medicine, a cross-cultural universal (Brown, 1991), also involves the consumption of pharmaceutical plant substances administered by specialists such as healers and shamans. Because access to Western medicine is limited in low- and middleincome countries (LMICs), where about $85 \%$ of the global population resides, most people depend on traditional medicinal knowledge when sick (Johns, 1990; Kim, Kim, et al., 2020; WHO, 2019). Traditional medicine even informs drug discovery in Western medicine (Atanasov et al., 2015, 2021; Porras et al., 2021; Silva et al., 2016). Willow bark, for instance, has been used to treat pain for thousands of years. The active ingredient, isolated in the nineteenth century, is aspirin (Desborough \& Keeling, 2017). The 2015 Nobel Prize in Medicine was awarded to Chinese scientist Tu Youyou for isolating the antimalarial compound artemisinin from sweet wormwood, a traditional Chinese medicine used to treat fevers (Nobel Prize, 2015). Traditional plant-based medicines often work.

Although Westerners classify some of these substances as foods (black pepper), some as recreational drugs (tobacco), and some as medicines (willow bark and sweet wormwood), all of them are plant substances rich in pharmacological compounds. We will argue here that the ubiquitous use of these substances is a behavior that evolved from the selfmedication strategies of ape ancestors (Huffman, 2003). These behaviors permitted greater 
consumption of energy-rich meat and reduced energetically expensive immune responses in response to a shift, and perhaps increase, in pathogen pressure in the human lineage as it transitioned from a mostly plant-based diet to a more carnivorous one c. 2.6 mya.

\section{Epidemiological transitions}

Most mammal species, including humans and other primates, are infected with one or more species of microparasites (viruses, bacteria, fungi, protozoa) and macroparasites (helminths, arthropods). Currently, 9149 pathogen species are known to infect 1835 mammal host species (Farrell et al., 2020), with humans infected by the greatest number (2064). See Figure 2. These numbers, especially for humans, are biased by research effort and other factors (for details, see Farrell et al., 2020; for modes of transmission among primates, see Pedersen et al., 2005).

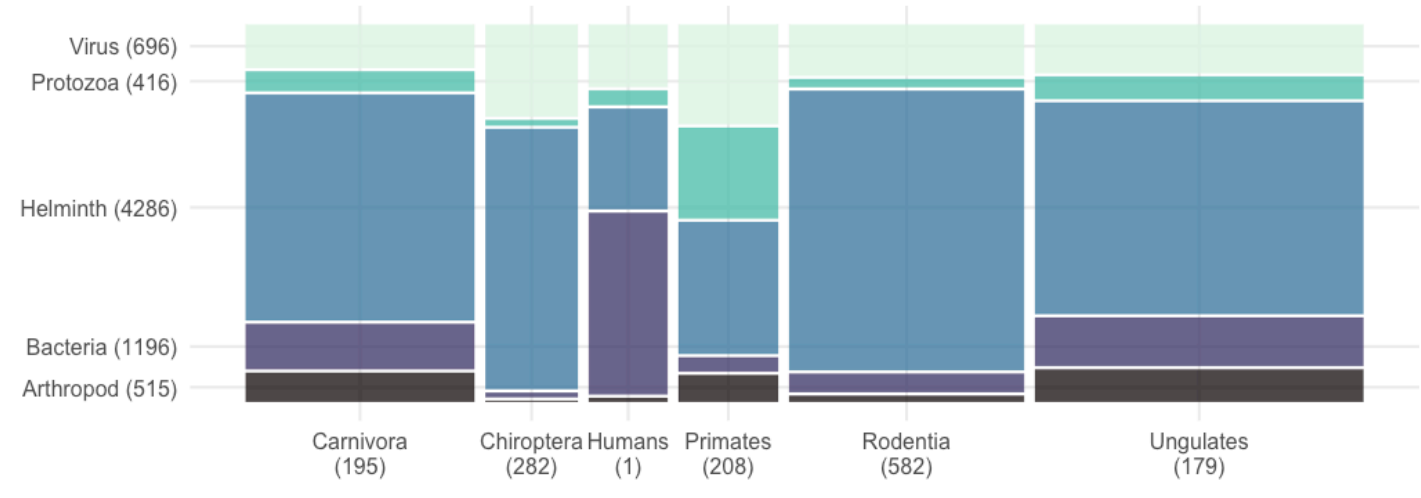

Modern

humans are currently undergoing two epidemiological transitions that are shifting our exposure to the pathogens that have impacted us throughout our evolution. One is the unprecedented decline in morbidity and mortality from infectious diseases following the 19th century discovery of the germ theory of disease and the resulting development of sanitation technologies, vaccines, and antibiotics. The other involves the rapid discovery of new human infectious diseases and the evolution of antimicrobial drug resistant pathogen strains (Barrett et al., 1998).

The first epidemiological transition, according to Barrett et al. (1998) and others, occurred during the Neolithic, c. 10 thousand years ago (kya). Greater sedentism, population size, population density, and animal domestication increased human exposure to zoonotic pathogens and created conditions required for sustained human-to-human transmission (for some genetic evidence, see Domínguez-Andrés et al., 2021). Prior to this, it has been thought, small nomadic populations of dispersed Pleistocene hunter-gatherers could not sustain the acute communicable pathogens common in large sedentary communities, though some argue that this transition might have started as modern humans colonized Eurasia (Houldcroft \& Underdown, 2016). Indeed, there is evidence of strong selection during the Upper Paleolithic on human proteins that interact with viruses (Enard \& Petrov, 2020; Souilmi et al., 2021). 
Following many other authors whose work we describe below, we focus on an epidemiological transition that likely occurred much earlier: a shift and perhaps increase in zoonotic pathogen pressure as the human lineage transitioned from a mostly plant-based diet to a more carnivorous niche, triggering changes in life history and social organization, near the beginning of the Pleistocene, c. 2.6 mya.

\section{Carnivory in Homo}

Although vertebrate meat eating is widespread across extant primates, with the most common prey species being, in order, birds (including eggs), reptiles, amphibians, mammals, and fish (Watts, 2020), meat is probably not an important source of either energy or protein even in chimpanzees, who are some of the most regular meat consumers among the non-human primates (invertebrates, on the other hand, are nutritionally important for many primate species, Rothman et al., 2014; Watts, 2020). African great apes, the closest living human relatives, subsist mostly on plants, primarily fruits and leaves (Berthaume \& Schroer, 2017; Pontzer \& Wood, 2021). The last common ancestor (LCA) of humans and chimpanzees, thought to have lived during the late Miocene, was therefore possibly a frugivore (Almécija et al., 2021; Young et al., 2015).

As African forests diminished, grasslands expanded, and seasonality intensified from the late Miocene into the Pliocene c. 6-5 mya, a new clade of apes - hominins - emerged with a more committed terrestrial lifestyle in open habitats. Craniodental traits, tooth wear patterns, and paleoecological contexts indicate a substantial shift in diet involving greater masticatory processing of food relative to extant apes, probably involving decreased consumption of C3 vegetation (e.g., fruits and leaves) and increased consumption of C4 vegetation (e.g., grasses, underground storage organs), albeit retaining dietary flexibility (considerable uncertainty remains in dietary reconstruction, however, Daegling et al., 2013; Lacruz et al., 2019; Quinn, 2019; Wynn et al., 2016).

The earliest fossil evidence of Homo coincides with the transition from the Pliocene to the Pleistocene 2.6 mya (Antón et al., 2014), when the Earth entered full glacial/interglacial cycles with hemispheric glaciations, strongly impacting African vegetation and herbivore communities (Couvreur et al., 2021). The brain and body of early Homo were somewhat bigger compared to australopithecines, and dentition reduced (Antón et al., 2014), indicating that our lineage had again entered a new dietary niche, this time involving less masticatory processing. A range of evidence, including stone tool cut marks on bones, leave little doubt that vertebrate meat, much of it from large mammalian prey like megaherbivores and grazers, was an important component of Homo diets (Antón et al., 2014). Although Homo might have acquired up to $70 \%$ of its calories from meat (Ben-Dor et al., 2021), the prevailing view is that it evolved as a diet generalist, able to flexibly adapt to different trophic levels as conditions required (e.g., Antón et al., 2014; Crittenden \& Schnorr, 2017; Pontzer \& Wood, 2021). Nevertheless, compared to $<5 \%$ meat in chimpanzee diets (Watts, 2020), the proportion of animals in the diet of contemporary hunter-gatherers is quite high, ranging from $40 \%-60 \%$ (Pontzer \& Wood, 2021). 


\section{$4 \quad$ Meat eating shifted, and might have increased zoonotic pathogen pressure}

Although plant foods are certainly often contaminated with animal pathogens, e.g., in feces, the threat from plant pathogens themselves seems to be relatively low. A few plant pathogens appear capable of cross-kingdom infections, but human infections with plant pathogens mostly occur in immunocompromised or physically injured individuals. In general, the substantial differences between plant and animal cell walls and immune systems are major barriers to pathogen spillover from plants to animals (Kim, Yoon, et al., 2020).

Meat, however, would often have been infected with pathogens adapted to primates and other mammals that had a high risk of spillover. Most human infectious diseases indeed originate in non-human animals (Han et al., 2016). Many zoonoses are enzootic (stably established) in animal populations and transmit from animals to people with little or no subsequent person-to-person transmission (Karesh et al., 2012). Rabies, for example, is a deadly zoonotic virus infecting the central nervous system (CNS) (Fisher et al., 2018) that humans acquire from infected carnivores or bats but do not transmit to other humans. Today, about 60,000 people die every year from rabies acquired from infected dogs (Hampson et al., 2015). Anthrax is another example of a deadly zoonotic pathogen that humans do not transmit to others (Kamal et al., 2011). Other diseases spread efficiently between people once introduced from an animal reservoir, leading to localized outbreaks (e.g., Ebola virus) or global spread (e.g., HIV, pandemic influenza) (Karesh et al., 2012). Between 1940 and 2004, over 300 infectious diseases emerged in the global human population, the majority of which (60\%) came from animals, mostly wildlife (the remainder were newly evolved strains and previously rare pathogens that increased in prevalence, Jones et al., 2008). See Figure 3.

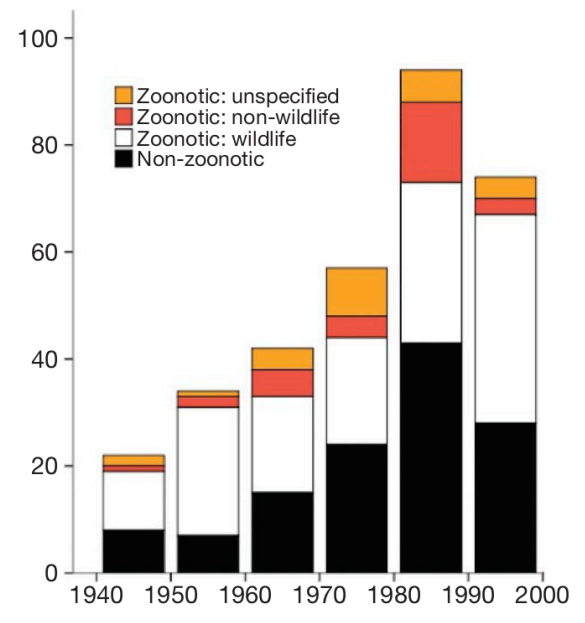

Figure 3: Number of emerging infectious diseases per decade, by source. Non-zoonotic pathogens include newly evolved strains, e.g., drug-resistant pathogens, and previously rare pathogens that increased in prevalence. Figure from Jones et al. (2008). 
Several lines of evidence indicate that the entry of Homo into a more carnivorous niche lowered several of the barriers to spillover, increasing zoonotic spillover events and therefore increasing its exposure to zoonotic pathogens. In contrast to australopithecines, who appear to have subsisted primarily on plants, perhaps supplemented with the occasional bird, lizard, or small mammal, hunters/scavengers in genus Homo would have had intimate, near-daily contact with mammalian prey and predators, and their pathogens and arthropod disease vectors.

There are numerous well-documented examples of spillover from prey to predators, with some carnivore populations suffering catastrophic declines. Spillover outcomes in predators can vary from asymptomatic infections, such as feline immunodeficiency virus in pumas preying on bobcats, to variable clinical outcomes, such as anthrax in wolves preying on bison, to virulent infections, such as bovine tuberculosis in coyotes preying on whitetailed deer (Malmberg et al., 2021). There is even evidence that some chimpanzee and bonobo viruses spilled over from their primate prey (Calvignac-Spencer et al., 2021). Predators have evolved apparent resistance mechanisms to infections from prey, such as exceptionally low gastric $\mathrm{pH}$ and avoidance of closely related prey species (Malmberg et al., 2021). Carnivores frequently kill other carnivores, for example, but rarely eat them, probably due to the heightened risk of infection (Moleón et al., 2017).

\subsection{Increased zoonoses in commercial hunters (bushmeat), Congo Basin foragers, and workers in animal-related occupations}

Bushmeat - wildlife hunted for human consumption - is widely considered to be a major risk factor for zoonotic spillover. Bushmeat provides food for hundreds of millions of rural people living in poverty, and in the Congo Basin alone involves more than a million tons of meat per year (Saylors et al., 2021). Bushmeat activities have been linked to numerous virulent disease outbreaks, including Ebola, HIV, monkeypox, SARS-CoV-1, and possibly SARS-CoV-2 (Guan et al., 2003; Kurpiers et al., 2016; Peros et al., 2021). Pathogen spillover from bushmeat can occur through consumption, but major risks come from exposure to body fluids and feces during handling and butchering (Milbank \& Vira, 2022). A study investigating the origins of SARS-CoV-1 in a key market, for example, found that $31 \%$ of individuals involved in wild animal trade or slaughter had SARS-CoV-1 antibodies whereas only 5\% involved in trading vegetables did (Guan et al., 2003). A review found 133 reports of disease involving 60 pathogens in 58 bushmeat species, mostly mammals (95\%); the most common zoonotic pathogens were helminths (37\%) and bacteria (33\%), followed by viruses and protozoa (15\% each) (Peros et al., 2021). Although such spillovers are a global phenomenon, in only about half the cases was evidence linking specific spillovers to wild meat consumption of good quality (Milbank \& Vira, 2022).

Congo Basin foragers are at increased risk of acquiring zoonotic infections compared to neighboring farmers. A study of zoonotic human infections with simian foamy virus in a large Cameroon sample found that foragers were more likely to be infected than neighboring farmers, and that infections were strongly associated with severe bites from apes during hunting (Betsem et al., 2011). Another study similarly found that a severe bite from a non-human primate was a major risk factor for infection with Human Tlymphotropic virus type 1 (HTLV-1) in foragers in rural South Cameroon (HTLV-1 
originates from simian T-lymphotropic virus type 1, Filippone et al., 2015). There is a higher prevalence of antibodies to monkeypox among Aka foragers compared to neighboring farmers (Lederman et al., 2007), probably because Aka are more likely to engage in behaviors, such as visiting the forest and interacting with animals, that expose them to monkeypox (Guagliardo et al., 2019). In a population of Efe foragers, the prevalence of antibodies to Ebola virus, a zoonotic pathogen whose animal reservoir is probably bats, are among the highest ever reported (18.7\% vs $2-3.5 \%$ in the Republic of the Congo and the Democratic Republic of the Congo, Mulangu et al., 2016; Steffen et al., 2019).

In a more cosmopolitan perspective, veterinarians have a higher risk of zoonotic infections than control groups (Baker \& Gray, 2009), and members of other occupations that involve animals, including livestock farm laborers, livestock/dairy producers, slaughterhouse workers, and animal carers and forestry workers, also have higher infectious disease risk (albeit not all zoonoses, Acke et al., 2021; Vonesch et al., 2019).

\subsection{Traits of host species and their zoonotic pathogens}

In general, as the number of species within an order (e.g., Rodentia, Carnivora, Primates) increases, so does the number that are hosts for zoonotic diseases (Han et al., 2016; Mollentze \& Streicker, 2020). On average, about $10 \%$ of species within the most specious orders are zoonotic hosts, with rodents and bats being the most specious, and therefore hosting a large fraction of zoonotic diseases. Primates and ungulates - common human prey species - stand out, however, in that $21 \%$ and $32 \%$ of species are zoonotic hosts, as are a large fraction of carnivore species (Han et al., 2021; Han et al., 2016). See Figure 4. Modern hunter-gatherers tend to avoid hunting carnivores, primates, and rodents (Bugir et al., 2021), perhaps, among other factors, due to the higher risk of spillover.

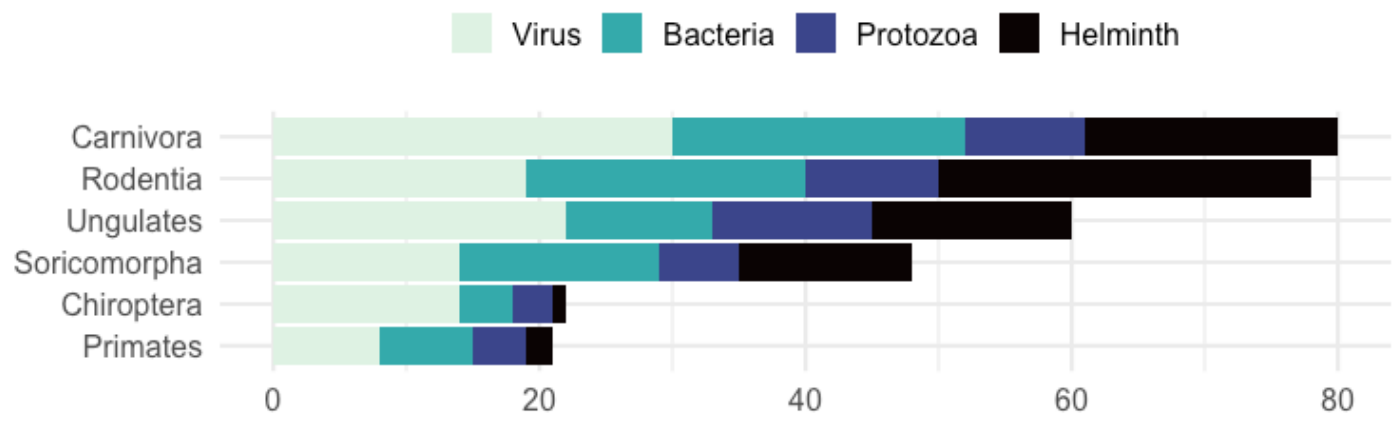

Number of unique zoonoses

Figure 4: The number of unique zoonoses caused by each pathogen type in the six most species-rich mammal groups: the carnivores, bats (Chiroptera), primates, rodents, shrews and moles (Soricomorpha), and the hoofed mammals (ungulates, which combine the orders Perissodactyla and Artiodactyla and exclude domesticated species). Data and caption from Han et al. (2016).

Most zoonotic diseases are caused by bacteria and viruses, followed by helminths, protozoa, and fungi (Han et al., 2016). Bacterial and viral traits associated with zoonotic 
status include host phylogenetic distance from humans (an effect driven largely but not entirely by primates), among others (Olival et al., 2017; Shaw et al., 2020). Diet class ("herbivore", "carnivore", "omnivore", or "invertebrate predator") is the strongest predictor of a wild species sharing a helminth species with a domestic species, compared to numerous other traits. Herbivores and carnivores are more likely to share parasites with humans, specifically, than are wild omnivorous and insectivorous mammals, probably because the lifecycles of many helminths depend on trophic interactions - consumption of their eggs and cysts, or by contact with larvae (Wells et al., 2018).

\subsection{Evidence of carnivory-related spillovers into hominins}

Taeniid tapeworms, characteristic parasites in carnivorous mammals, are one of the clearest examples of carnivory-related spillover to early Homo. Cestodes (tapeworms) are parasites that, as adults, live and produce eggs in their definitive host(s). The eggs are shed (e.g., in feces) and enter an intermediate host in which the larvae develop. The life cycle completes when the intermediate host is eaten by a definitive host. Humans are the definitive host for Taenia saginata, T. asiatica and T. solium, with domesticated ruminants as intermediate hosts (see Figure 13). These species are responsible for considerable disease burden in contemporary human populations, especially when they infect the nervous system (Carabin et al., 2017), a topic to which we shall return. Two to three million years ago, some Taenia species apparently switched their definitive host, probably hyenas or lions, to hominins who were hunting the same ungulate prey species (Hoberg, 2006; Hoberg et al., 2001; Terefe et al., 2014).

Other possible examples of Pleistocene spillovers into humans include herpes simplex virus 2 (HSV-2), which infects about $11 \%$ of the population, causes most cases of genital herpes, and appears to have spilled over from bonobos into the human lineage around 1 mya, after bonobos diverged from chimpanzees c. 2.1 mya (Wertheim et al., 2021); Helicobacter pylori, which infects the stomachs of about half of all humans, causes inflammation and increased risk for stomach cancer, and appears to have spilled over into the human lineage from an unknown host c. 88-116 kya, just prior to human migration out of Africa (Linz et al., 2007; Moodley et al., 2012); the rare human T-cell lymphotropic virus type II, found mainly among some Congo Basin foragers, Native American populations, and intravenous drug users, which appears to have spilled over from a primate species at least 400 kya (Vandamme et al., 2000); various hepatitis viruses (A, B, C, and GB viruses); enteroviruses such as poliovirus; and Schistosoma spp (due to increasing use of open environments). For reviews, see Houldcroft \& Underdown (2016), Mitchell (2013), Ledger \& Mitchell (2019), Harkins \& Stone (2015), Reperant et al. (2013), Blerkom (2003), and Brinkworth \& Alvarado (2020).

\subsection{Meat spoilage and cooking}

Many who argue that increased carnivory increased pathogen exposure emphasize meat spoilage rather than the increased spillover risk that we emphasize. Indeed, in the US and Europe, about $60 \%$ of food-borne illness cases are associated with animal foods (meat, fish, milk, eggs) and most of the rest with plant foods contaminated with, e.g., feces (DeweyMattia et al., 2018; EFSA and ECDC, 2018). In ancestral populations, spoiling meat also 
likely harbored more pathogens than plant foods. Carrion is quickly colonized by pathogenic bacteria from the dead animal itself, the animals that fed on it (including insects), and the soil, water, and air (Ragir et al., 2000; Smith et al., 2015).

The use of fire for cooking reduces pathogens in meat prior to consumption and was likely an important anti-infective strategy (Attwell et al., 2015; Smith et al., 2015). Cooking would not have reduced exposure to potential zoonoses when tracking, killing, and butchering animals, however, or when scavenging meat. Moreover, even the earliest (but highly contested) dates for the possible controlled use of fire, 1.7-1.5 mya, are about 1 million years after evidence of increased meat eating c. 2.6 mya, and clear archaeological evidence for the regular, controlled use of fire use only appears after 1 mya, with most evidence after 500 kya (reviewed in Hlubik et al., 2019; MacDonald et al., 2021). Further, several ethnographically known hunter-gatherer populations eat raw animal foods (McCauley et al., 2020), and even in modern populations that regularly cook animal foods, those who hunt and butcher wildlife are at increased risk of zoonotic disease. Nevertheless, meat spoilage was another source of pathogen pressure fostered by the transition to carnivory, which could have been mitigated by cooking.

\subsection{Meat taboos}

Meat is seen as dangerous across cultures. A study of food taboos among horticulturalists and foragers in the Democratic Republic of the Congo, for example, found that nearly all involved animal foods, and many aimed to prevent illness and death (Aunger, 1994). A study of food taboos in 78 cultures found that $85 \%$ involved meat, likely due to the risk of pathogen transmission (Fessler \& Navarrete, 2003). Because spoilage risk is similar for animal foods, taboos regarding specific animal species are generally thought to be maladaptive (albeit imposing only a small nutritional cost, Aunger, 1994). It is possible, though, that the taboos are not due to spoilage risk but instead originated after spillover events from particular species, which would warrant avoiding those species. Pork taboos are common, for instance, perhaps because pigs are intermediate hosts for Taenia solium and harbor various zoonoses (cf. Harris, 1997). The immune system also "sees" meat as dangerous: animal foods are generally pro-inflammatory whereas plant foods are antiinflammatory (Alcock et al., 2012). See Figure 5. 


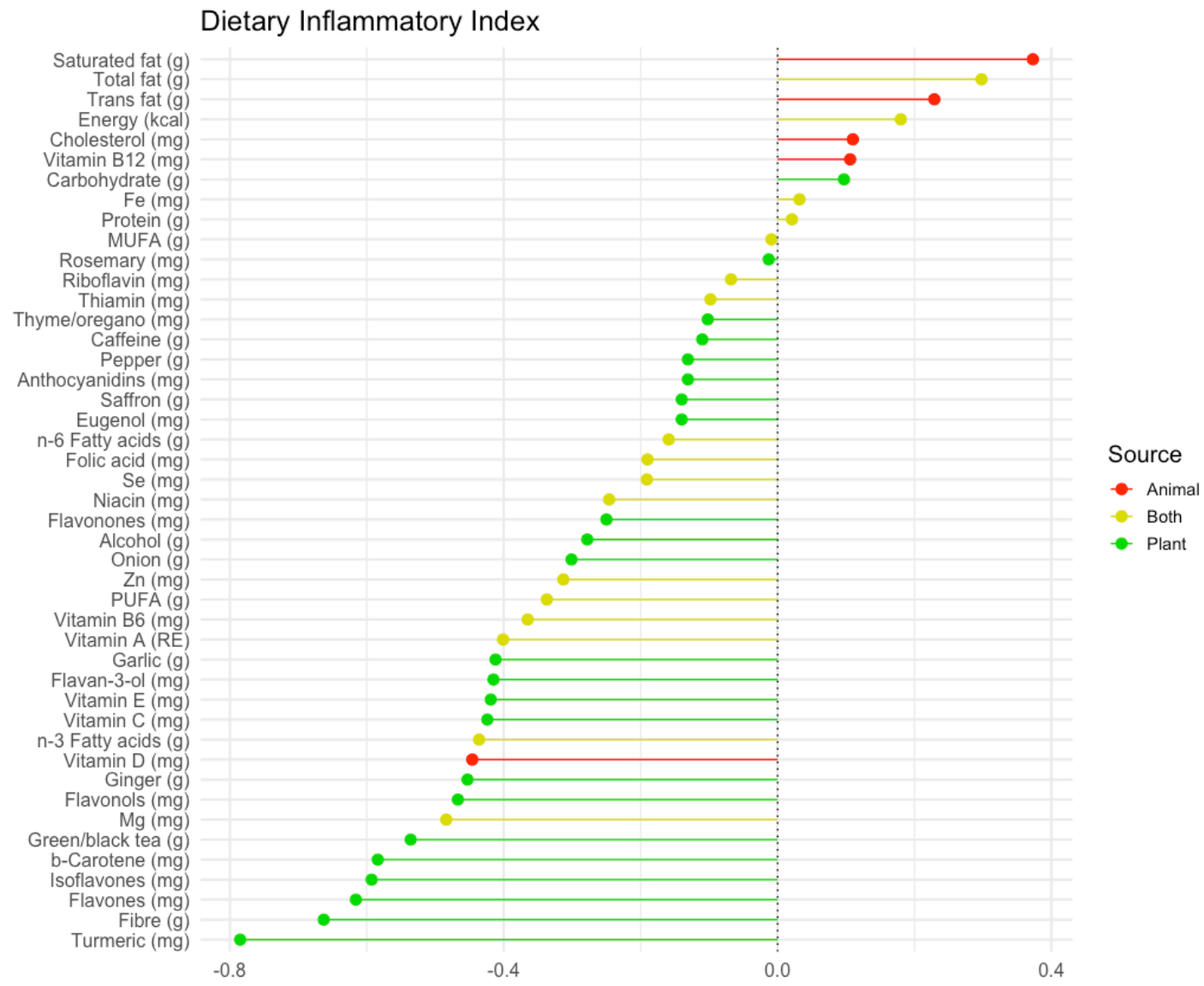

Figure 5: Overall inflammatory effect score from the Dietary Inflammatory Index. Positive values indicate the food component is pro-inflammatory; negative values indicate the food component is anti-inflammatory. Colors indicate primary source. MUFA: monounsaturated fatty acid. PUFA: polyunsaturated fatty acid. Saturated fat and Vitamin D are mostly (but not exclusively) from animal foods and are therefore coded as 'Animal'. Values from Shivappa et al. (2014).

\subsection{Virulence of newly emerged zoonotic pathogens}

Theoretical models of the evolution of virulence assume that there is a tradeoff between virulence and transmission: faster replicating pathogens create larger populations, increasing their transmission rate, but cause more host damage, increasing host mortality and thus decreasing the time for the infected host to contact susceptible hosts (reviewed in Cressler et al., 2016). Empirical evidence to date supports the existence of this tradeoff (albeit with complexities, Geoghegan \& Holmes, 2018; Visher et al., 2021). In human zoonotic viral infections, for instance, there is indeed a negative association between the capacity for human-to-human transmission and case fatality rate (CFR), an index of virulence (again, with caveats, Brierley et al., 2019; Geoghegan et al., 2016). Pathogens should therefore evolve to optimize virulence to maximize the number of hosts they can infect (Visher et al., 2021). 
Newly emerging zoonotic pathogens, however, are unlikely to have phenotypes that optimize the virulence-transmission tradeoff in the new host. They will therefore vary widely in their virulence and transmission rates (Brierley et al., 2019; Bull \& Ebert, 2008; Visher et al., 2021). An analysis of zoonotic viruses found that those with limited or no reported human-to-human transmission, suggesting they were poorly adapted to humans, had CFRs ranging from $0 \%$ to $100 \%$, with mean $=31.5 \%$. The highest CFRs after spillover were caused by zoonotic viruses from the hosts more distantly related to humans, and thus less well-adapted, such as viruses from ungulates, which were common prey species, and from bats, which inhabited the same caves as human ancestors (Guth et al., 2019). In addition, when the pool of susceptible hosts is large there can be transient selection for greater virulence in newly emerging pathogens (Berngruber et al., 2013; Bolker et al., 2010). Viruses with reported endemic transmission, however, suggesting they were better adapted to humans, all had relatively low CFRs, with mean $=2.5 \%$ (Guth et al., 2019). See Figure 6B.

Novel and thus poorly adapted pathogens might 'accidentally' infect host tissues that fail to support onward transmission of the pathogen. Nevertheless, the host immune system must defend those infected tissues. In a study of human RNA viruses, for example (Brierley et al., 2019), the most common primary tissue tropism for viruses with the highest transmission level was gastrointestinal and respiratory - tissues that can easily support onward transmission via feces, droplets, and aerosols. For viruses with the lowest transmission level, however, the primary tissue tropism was viraemic (only blood presence is known) and neural, followed by systemic, vascular, and circulatory. See Figure 6A. Onward transmission pathways from neural tissue are limited, but infection of neural tissue could be very costly to the host. Indeed, neural tropism in RNA viruses is associated with high virulence (Brierley et al., 2019). 


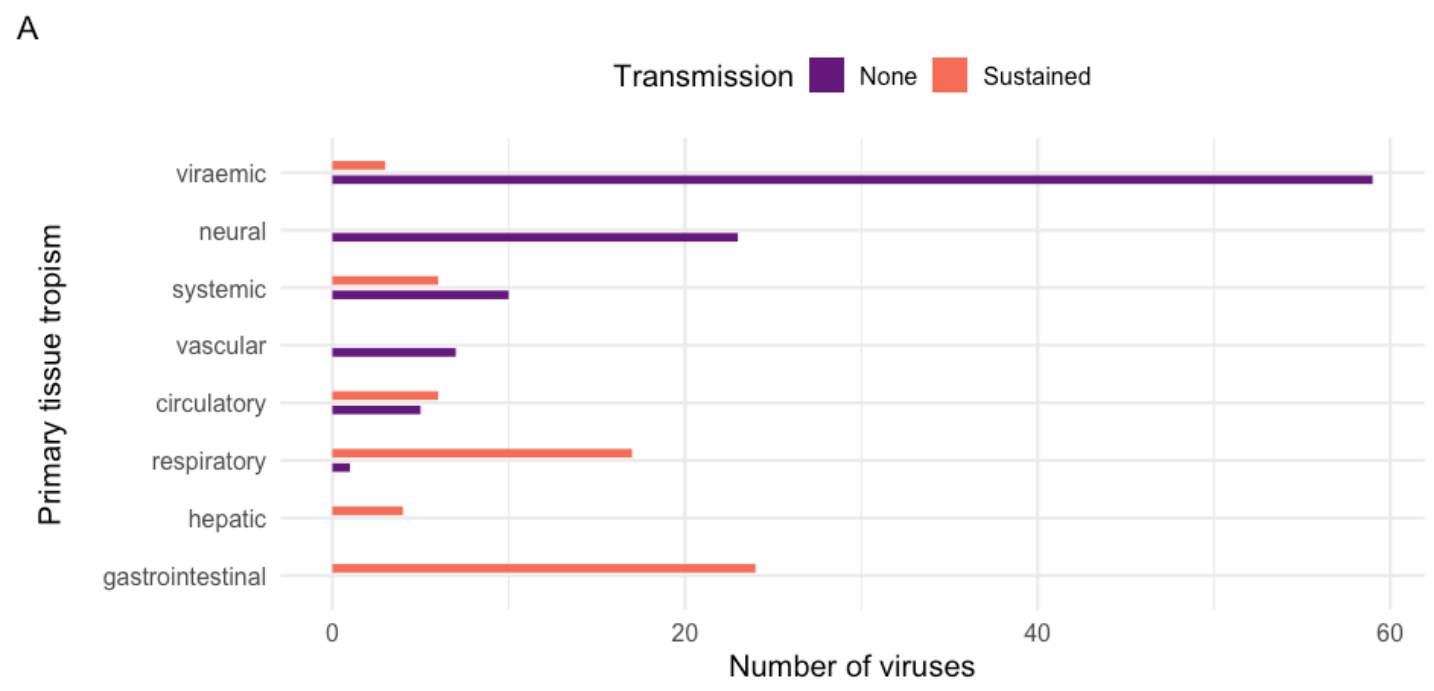

B

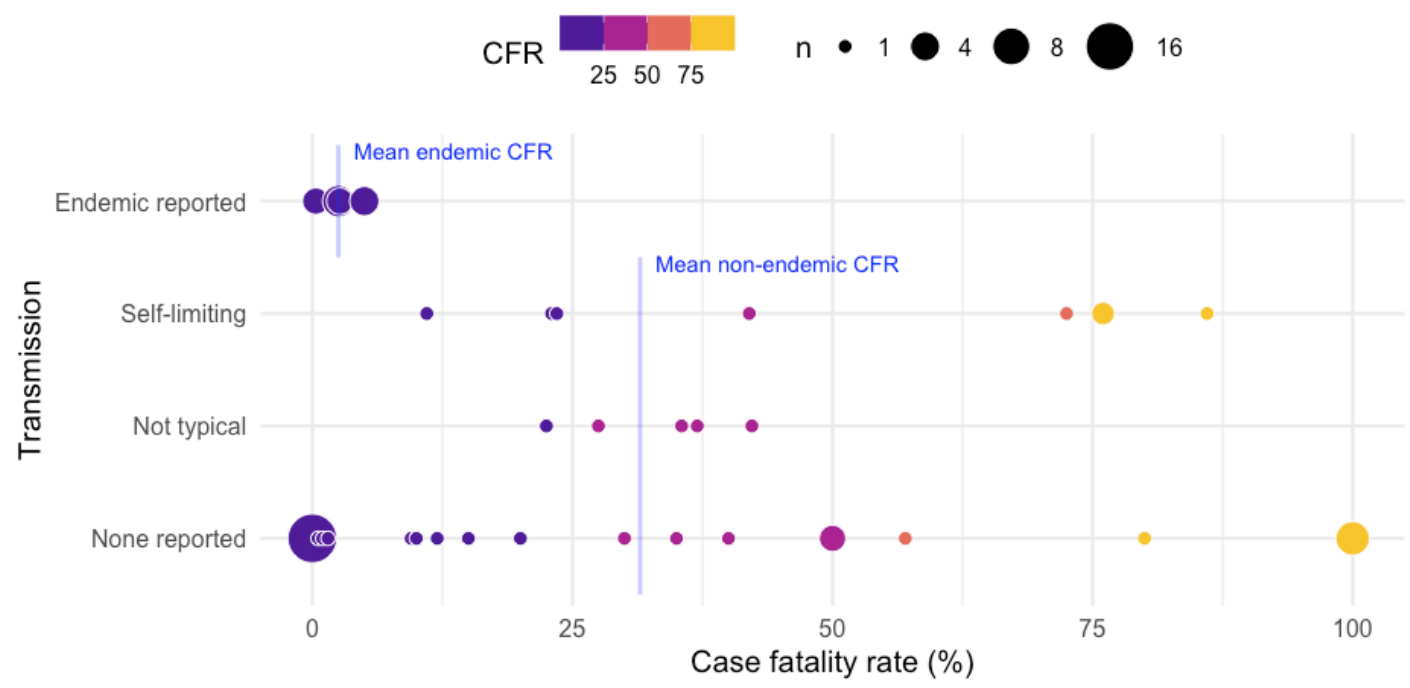

Figure 6: A. Human RNA virus primary tissue tropism vs. transmission. Primary tissue tropism indicates the dominant organ system the virus typically infects or targets (viraemic: only blood presence is known). No transmission: the virus infects humans but does not transmit to other humans. Sustained transmission: sustained human-to-human transmissibility. (Viruses with intermediate transmission not depicted.) Data from Brierley et al. (2019). B. Zoonotic virus case fatality rate (an index of virulence) versus degree of human-to-human transmission. Each dot is one virus species, or group of species with identical CFRs and degrees of transmission. Dot size represents the number of overlapping data points. Dot color represents the CFR. Blue vertical lines represent mean CFRs for viruses with endemic and nonendemic transmission. Data from Guth et al. (2019).

Increased zoonotic spillovers in Homo might therefore have selected for increased investment in immunity and increased defense of tissues such as neural tissue, through both immunological and behavioral mechanisms, a topic to which we shall return. 


\section{$5 \quad$ Carnivory-related shifts in human life history and social organization also affected pathogen pressure and investment in immunity}

The Plio-Pleistocene transition to carnivory in Homo was accompanied by increases in body size and longevity, and changes in range size, population size, population density, and social organization (Antón et al., 2014), all of which could have also altered pathogen pressure, thereby selecting for changes in investment in immunity, which provides the critical benefit of eliminating pathogens, but also causes tissue damage and has substantial energetic costs that must be traded off against other important energy-consuming investments, such as growth and reproduction (Blackwell et al., 2010; Demas et al., 1997; Garcia et al., 2020; Martin et al., 2011; McDade et al., 2016; Muehlenbein et al., 2010; Nystrand \& Dowling, 2020; Schulenburg et al., 2009; Shattuck-Heidorn et al., 2017; Urlacher et al., 2018).

\subsection{Increased body size and longevity in Homo might have increased exposure to pathogens, thereby selecting for increased immune investment}

Intuitively, large, long-lived animals would have greater lifetime exposure to pathogens and greater somatic investment, and should therefore invest more in immunity (although there are many complications, Banerjee et al., 2017; Donnelly et al., 2015, 2017; Downs, Schoenle, et al., 2020; Han et al., 2015; Kieft \& Simmons, 2015; van Boven \& Weissing, 2004). Empirically, body size is positively associated with the prevalence of viruses and bacteria in primates and ungulates, with macroparasites in primates and carnivores (Han et al., 2015), and with pathogen diversity, an index of pathogen pressure (Bordes \& Morand, 2009), across animal, plant, and fungal hosts (Kamiya et al., 2014).

Most studies of the fossil record conclude that body size in the human lineage increased in the evolutionary transition from Australopithecus to Homo, probably as a consequence of the higher quality diet (Grabowski et al., 2015; McHenry, 1992; Püschel et al., 2021; Will et al., 2017). Indeed, carnivores tend to have large body sizes (Cooke et al., 2022). Longevity is much harder to infer from the fossil record, but a reasonable conjecture is that increased body size in $H$. erectus entailed an increase in longevity (briefly reviewed in French \& Chamberlain, 2021). Modern humans fall toward the higher end of the distribution of mammalian body masses and have one of the longest lifespans, traits that are correlated across species (see Figure 7). Even given our large body size, the long lifespan of modern humans is an outlier among primates (Miller et al., 2019). 


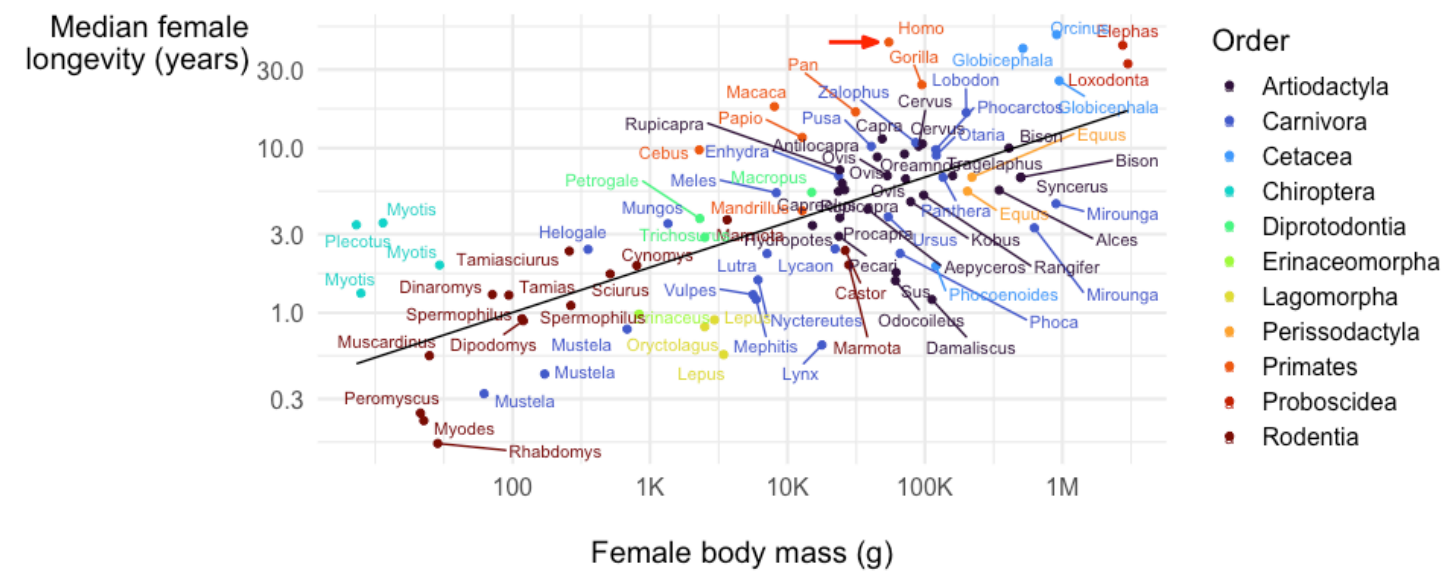

Figure 7: Log-log plot of mammal longevity vs. body mass. Each dot is one species (species names omitted to reduce clutter). Longevity estimates exclude juvenile mortality (i.e., deaths prior to the species-specific female age at first reproduction). The median female adult lifespan corresponds to the age when $50 \%$ of the females alive at the onset of adulthood were dead. Line fit by univariate regression. Modern humans, based on Ache forager data only, are indicated with an arrow. Data from Lemaître et al. (2020).

Empirical evidence that larger animals invest more in immunity is starting to emerge. Mammal metabolic rate scales hypometrically with body mass $\left(Y=a M^{b}, b<1\right)$, but neutrophils, part of the innate immune system, scale hypermetrically with body mass in over 250 mammalian species $(b>1)$, clear evidence of a size-related increase, and lymphocytes, which participate in both the innate and adaptive immune systems, scale nearly isometrically ( $b \sim 1$ ) (Downs, Dochtermann, et al., 2020; Cornelius Ruhs et al., 2021; see also Ruhs et al., 2020), as does antibacterial activity in serum in over 160 terrestrial mammals (Downs, Schoenle, et al., 2020). These patterns suggest size-related increases in immune investment. We will argue below that humans' large bodies and long lifespans are underwritten, in part, by increased investment in behavioral immune strategies.

\subsection{Increased range size and decreased population density in Homo likely had opposite effects on pathogen pressure}

Host range size and population density are both positive predictors of pathogen diversity across animal, plant, and fungal hosts (except range size in arthropods, Kamiya et al., 2014). These patterns have opposite implications for changes in pathogen pressure in early Homo. The population range sizes of early Homo species are estimated to be about seven to ten times larger than those of Australopithecus species (Antón et al., 2002), suggesting increased pathogen pressure.

Larger terrestrial vertebrates, including mammals, typically have lower population densities (Santini et al., 2018), on the other hand, suggesting Homo did too. Carnivory would have further reduced population density because transfer of energy and nutrients from lower to higher trophic levels is inefficient (Carbone \& Gittleman, 2002). As the proportion of meat in the diet increases, population density in ethnographically known hunter-gatherers decreases (Zhu et al., 2021). As Homo increased in trophic level its 
population density would therefore likely have decreased relative to its hominin predecessors. Decreasing population density would have decreased pathogen pressure in Homo; pathogen pressure could also limit population density. In high productivity environments (e.g., tropics, subtropics), the population density of ethnographically known hunter-gatherers is strongly associated with pathogen stress (Tallavaara et al., 2018; but see critique in Zhu et al., 2021).

\subsection{Climate variability and pathogen pressure}

Climate variability increased during the Pleistocene (Potts, 2012) because the distribution of the continents and low atmospheric greenhouse gas concentrations made the climate susceptible to changes in insolation due to the orbital forcing on $40 \mathrm{kyr}$ and later $100 \mathrm{kyr}$ cycles (von der Heydt et al., 2021). There is also evidence for more rapid, and sometimes abrupt unidirectional changes in the environment of early Homo (Lupien et al., 2020, 2021). During environmental change, many species survive by moving, bringing their pathogens into contact with new species (Carlson et al., 2022). Increased Pleistocene environmental variability might therefore have increased the frequency of spillovers into the human lineage.

\subsection{Mating system and pathogen pressure}

The reduced sexual dimorphism in Homo erectus compared to earlier Australopithecines suggests a shift in their mating system, perhaps toward greater monogamy (Villmoare et al., 2019). Monogamy is widespread in carnivores, probably because it increased cooperation and reproductive rate (Macdonald et al., 2019), rationales that could also apply to a more carnivorous Homo. Across primates and carnivores, mating promiscuity, such as seen in chimpanzees, is positively associated with investment in immunity, probably due to increased risk of sexually transmitted infections (STIs) (Nunn, 2002; Nunn et al., 2003). The shift in Homo toward monogamy might have reduced risk of STIs.

Theoretical results indicate that under various conditions, STIs can themselves select for a shift toward a monogamous mating system (e.g., Kokko et al., 2002; McLeod \& Day, 2014). Given that one of the today's most dangerous epidemic diseases, HIV, is a zoonotic STI, and that one of the most common STI's is from a Pleistocene spillover event (HSV-2 and genital herpes - see above), it is worth considering that increased zoonotic spillovers in Homo contributed to a shift toward monogamy.

\section{Possible human-specific physiological and immune defenses in response to changes in pathogen pressure}

If zoonotic spillover and changes in life history shifted, and perhaps increased pathogen pressure on hominins entering a more carnivorous niche, pathogen defenses should have evolved that differ from those seen in other, more herbivorous apes. 


\subsection{Divergent immune genes}

Genetic changes in humans relative to chimpanzees and other primates implicate divergence in immunological systems (as well as neuronal, and metabolic systems, Bitar et al., 2019). Genes coding for proteins that interact with viruses, for instance, diverged under positive selection in humans compared to chimpanzees. In fact, viruses appear to have driven $\sim 30 \%$ of all adaptive amino acid changes in the part of the human proteome conserved within mammals, and protein adaptation in mammals more generally (Enard et al., 2016). There is also human-chimpanzee divergence in regulatory sequences related to immune genes (He et al., 2016; Jin et al., 2018), including in microglia (brain immune cells, $\mathrm{Xu}$ et al., 2018), and there are even human-specific coding genes related to immunity (Costantini et al., 2019), including one expressed in microglia (Hayakawa et al., 2005).

Positive selection on immune-related genes is common in primates (van der Lee et al., 2017), so divergent evolution of immune genes could simply be due to Red Queen dynamics within the human lineage and not necessarily to a shift or intensification of the pathogen environment compared to other hominids. There is a range of phenotypic and genetic evidence, however, that does indicate carnivory-related shifts in pathogen pressure and immunity in the human lineage.

\subsection{Divergent low stomach $\mathrm{pH}$}

Stomach acid breaks down dietary proteins and functions as an important barrier to entry of pathogens into the gastrointestinal tract (Martinsen et al., 2005). Stomach pH is lower in animals feeding on closely related species (with higher pathogen risk), such as scavengers and generalist carnivores, than it is in species feeding on distantly related species (with lower pathogen risk), such as marine mammals feeding on fish or bats feeding on insects (Beasley et al., 2015). Stomach pH is also lower in meat eaters than herbivores (with some exceptions), presumably because herbivores have less risk from food-borne pathogens and actually require bacteria to digest plant foods (Beasley et al., 2015).

Human stomach $\mathrm{pH}$ is exceptionally low and is closer in value to scavengers and carnivores than it is to omnivores, supporting the view that humans had higher exposure to meatborne pathogens (Beasley et al., 2015). See Figure 8. It is not clear, however, if human stomach $\mathrm{pH}$ diverges from that of chimpanzees because there is only a single measurement of the latter, which found a neutral pH (Dunn et al., 2020). 
Primate (non-human)

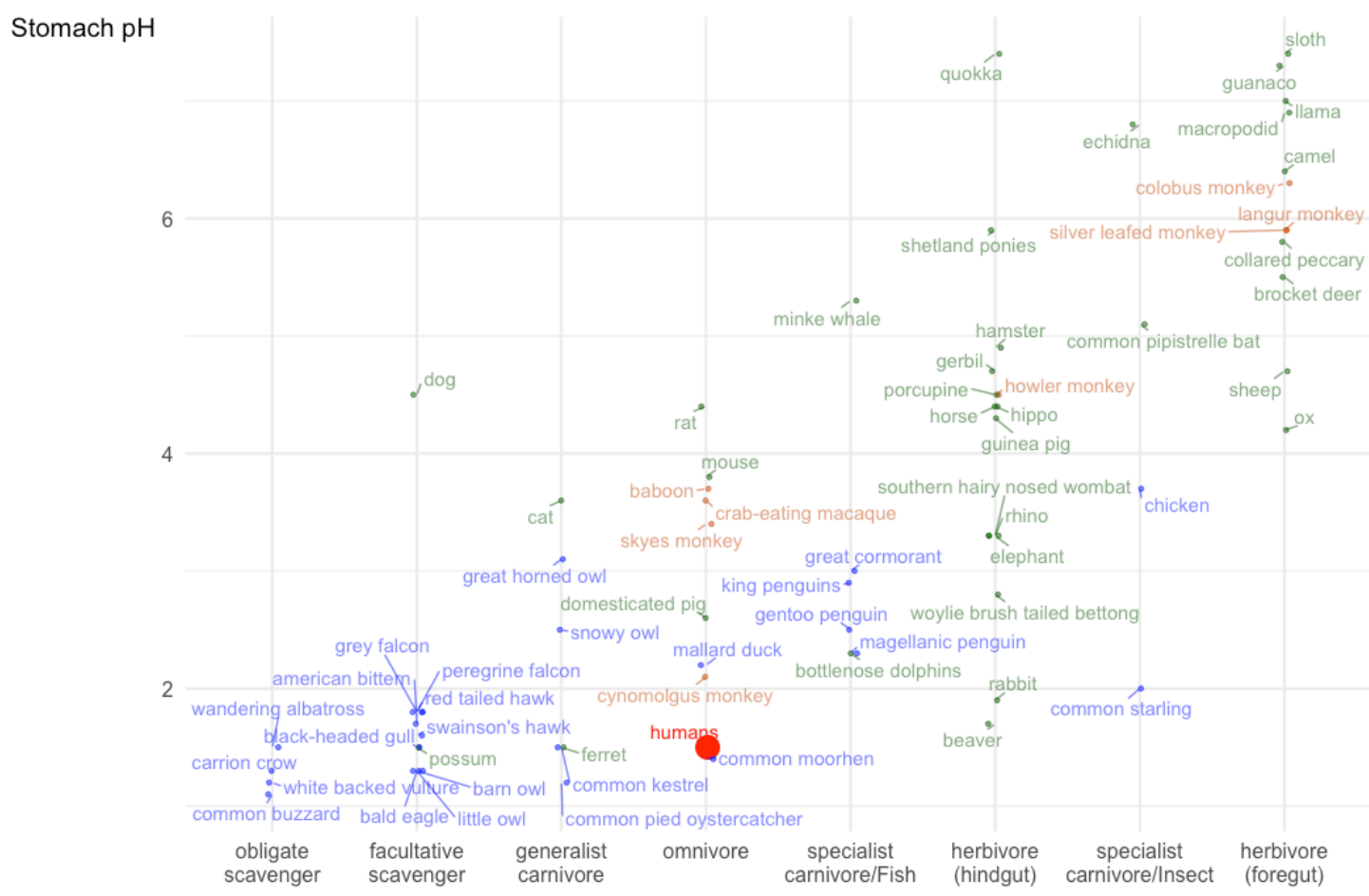

Figure 8: Stomach pH in mammal and bird species, organized by trophic group and labeled with common names (lower pH is more acidic). Data from Beasley et al. (2015).

\subsection{Divergent CMAH and SIGLEC biology}

Pathogens often infect hosts by exploiting host receptors, transporters, and other cellular pathways. Cells from all domains of life are covered with glycans. In vertebrates, glycan chains are often terminated with sialic acids, which are therefore involved in interactions between host cells and pathogens.

About 2 mya in the human lineage there was a loss-of-function mutation in CMAH that eliminated biosynthesis of the common mammalian sialic acid Neu5Gc, which was a target for pathogens such as Plasmodium, Escherichia coli, and coronaviruses. This mutation radically changed cell surface extracellular glycosylation throughout the body (Khan et al., 2020). Subsequently, there was a remarkable set of mutations in a cluster of siglec genes in the human lineage that postdate divergence with chimpanzees but predate divergence from Denisovans and Neanderthals. Siglec genes code for cell-surface proteins found primarily on the surface of immune cells that bind sialic acid. Siglecs appear to recognize endogenous sialylated glycans as self-associated molecular patterns, suppressing reactions of innate immune cells against self. In contrast, there are very few mutations in these genes in any great ape lineage (Khan et al., 2020), and little evidence for recent populationspecific selection in humans (Moon et al., 2018). 
Khan et al. (2020) suggest that the hominin CMAH null mutation 2 mya first altered sialic acids throughout the body, perhaps as a means to escape zoonotic pathogens encountered as Homo entered a more carnivorous niche. Loss of Neu5Gc then selected for changes in Siglec genes (for discussion, see Okerblom \& Varki, 2017). See Figure 9.

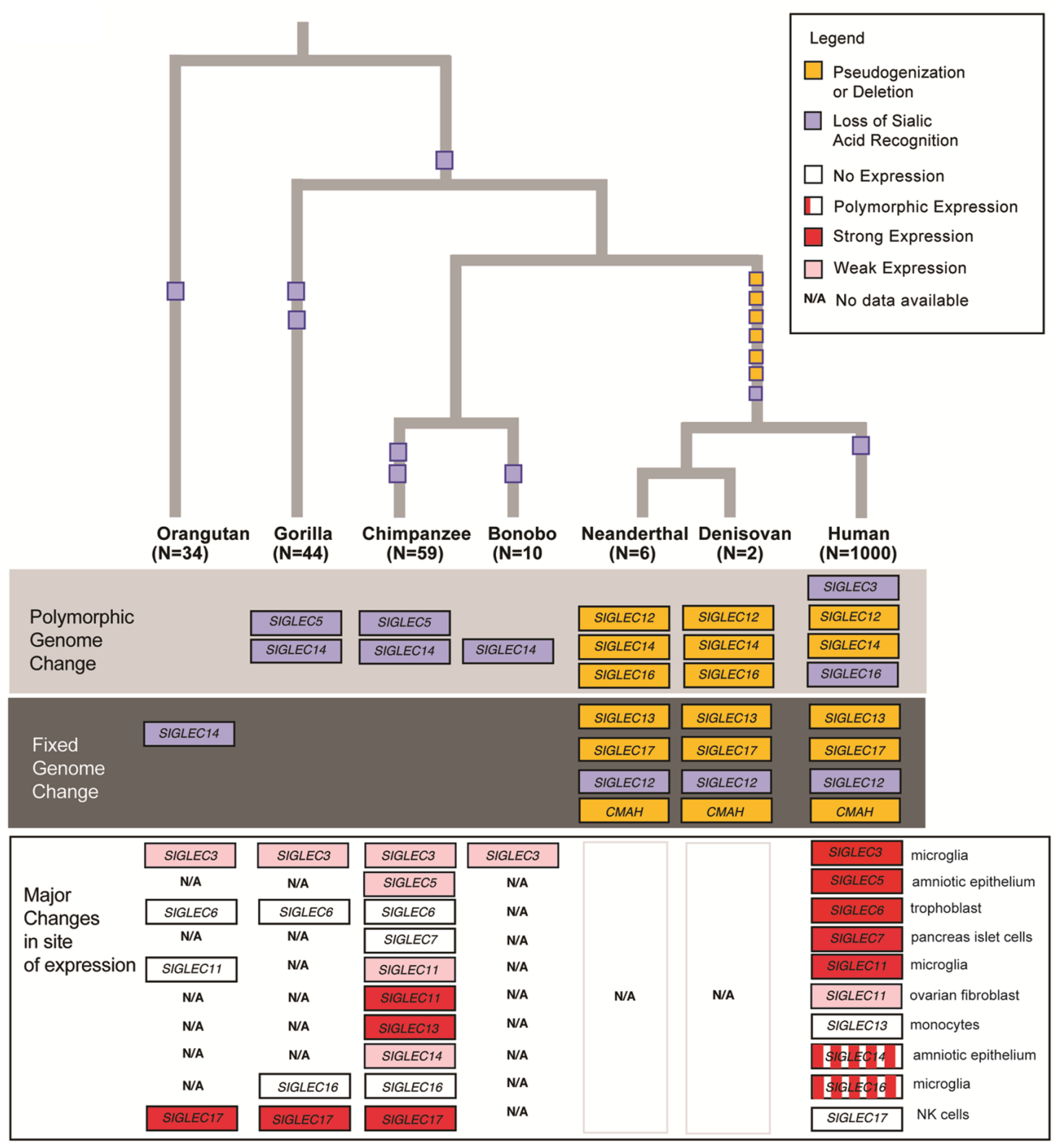

Figure 9: Evolutionary changes in hominid SIGLEC genes. The tree represents phylogenetic relatedness among hominids and different types of genomic events are depicted according to the color codes. Siglec expression differences are based on more limited comparisons. Figure and caption from Khan et al. (2020). 


\subsection{Divergent immune responses to bacterial and viral stimuli}

Mammals have multiple mechanisms to detect lipopolysaccharide (LPS), a component of the outer membrane of Gram-negative bacteria, which then activate further energy intensive mechanisms, involving upregulation of thousands of genes, that sequester and eliminate the bacteria. Compared to most other mammals, the human immune system is highly sensitive to LPS, mounting a robust immune response to quantities about $1 / 10$ of those needed to activate similar responses in other species (Brinkworth \& Valizadegan, 2021). Many more human genes are also differentially upregulated in response to LPS than in the macaques, baboons, and chimpanzees, and humans additionally exhibit markedly upregulated interferon gamma (IFN- $\gamma$ ) and the canonical T-cell costimulatory molecule CD80, which might mediate more effective killing of viral and bacterial pathogens compared to the other species (Hawash et al., 2021). Brinkworth \& Valizadegan (2021) attribute human's increased LPS sensitivity, in part, to increased exposure to microorganisms from increased butchering and eating of meat in early Homo, as does a study that links human sensitivity to LPS to the loss-of-function mutation in CMAH (Okerblom et al., 2017).

Bacillus anthracis, the bacterium that causes anthrax, primarily infects ruminants and is most commonly associated with arid ecosystems, particularly African savannas. Zoonotic spillovers have also caused considerable mortality in humans, however, as well as in chimpanzees and some other primates (Hoffmann et al., 2017). ANTXR2 encodes a widely expressed transmembrane receptor protein that aids entry of anthrax toxins into cells. ANTXR2 expression in human CD4+ T-cells is 8-fold downregulated compared to nonhuman primates, experimentally upregulating ANTXR2 increases cellular vulnerability to anthrax toxins, and the activity of cis-regulatory elements near ANTXR2 differs relative to orthologs in chimpanzees and macaques (Choate et al., 2021). Choate et al. (2021) conclude that the transition to hunting and scavenging increased exposure to B. anthracis in early humans, selecting for reduced ANTXR2 expression.

\subsection{Divergent microbiome}

The microbiomes of non-industrial human populations diverge from those of apes and are more similar to those of cercopithecines, particularly baboons, which, like hominins, inhabit more open habitats (Amato, Mallott, et al., 2019). Compared to ape gut microbiomes, the human microbiome possesses greater relative abundances of bacterial taxa associated with dietary animal fats and proteins, and lower relative abundances of taxa associated with degradation of complex plant polysaccharides (Moeller et al., 2014). In the human oral microbiome, on the other hand, including that of Neanderthals and Upper Paleolithic modern humans, Streptococcus amylase-binding taxa play a central role not seen in non-human primates, suggesting the importance of (possibly cooked) starch-rich diets in human evolution (Yates et al., 2021).

Commensal microbes can help deter pathogenic ones via niche exclusion and other mechanisms, a benefit that was likely important in human evolution (Amato, Jeyakumar, et al., 2019; Schnorr et al., 2016), but numerous uncertainties remain (Harris et al., 2019). Although the human microbiome undoubtedly adapted to an increasingly carnivorous diet, 
and helps protect against food-borne pathogens, we are not aware of evidence that the anti-infective properties of the human microbiome have increased relative to other primates, or that they can be linked to increased zoonotic spillover.

\subsection{Divergent apolipoprotein E}

APOE is the gene that codes for apolipoprotein E, a carrier of cholesterol in the blood that mediates the uptake of cholesterol and lipids by cells throughout the body (Finch \& Stanford, 2004). Unlike chimpanzees and other vertebrates, humans have three high frequency APOE alleles: E2, E3 and E4. E4 is considered the ancestral allele, evolving after divergence from chimpanzees; E3 evolved c. 200,000 years ago; and E2 evolved c. 80,000 years ago (Huebbe \& Rimbach, 2017). The evolution of APOE in humans has long been linked to meat-eating and the evolution of unique features of human life history (Finch \& Stanford, 2004), including improved defense against pathogens linked to meat-eating because APOE is an immune modulator, with E4 having the greatest pro-inflammatory effects (Vitek et al., 2009). Among Tsimane horticulturists, individuals carrying the E4 allele who had high pathogen load had better cognitive performance than non-carriers (Trumble et al., 2017). There are numerous hypotheses for the evolution of the human APOE alleles, however, based on their various beneficial and detrimental effects (Huebbe \& Rimbach, 2017).

\subsection{Divergent microglia}

Microglia are macrophages that are specific to the CNS. A study of microglia morphology and transcriptional programs across fish, birds, and mammals, including marmosets, macaques, and humans (but no non-human apes), found a conserved mammalian microglia core gene expression program, but also found considerable heterogeneity in human microglia that was not observed in other primates and mammals (Geirsdottir et al., 2019). There are also transcriptional differences between human microglia and those of chimpanzees and bonobos in certain brain regions (Khrameeva et al., 2020). Human immune defense of the CNS therefore apparently diverged from monkeys and apes, consistent with the possible link between increased zoonotic spillover and neurotropism we reviewed earlier.

\subsection{Increased meat-eating not associated with increased immune investment?}

In regression models of white blood cell counts across carnivore species (neutrophils, lymphocytes, monocytes, eosinophils - indices of immune investment), proportion of meat in the diet was only a weak positive predictor, and in the stepwise variable selection procedure, it dropped out of two of the four models (lymphocytes and eosinophils, Nunn et al., 2003).

Nunn et al. (2003) speculate that other carnivore adaptations to avoid pathogens in meat, such as gut physiology and behavioral avoidance, obviate the need for increased white blood cells. Nevertheless, proportion of meat was retained in models of neutrophils and monocytes. Moreover, the study data were from captive animals, and might not reflect the 
white blood cell counts these species would attain in the wild due to species differences in reaction norms for response to infection. Further comparative research on carnivore diets and immunity is warranted.

\section{The behavioral immune system includes constitutive and inducible consumption of pharmacological substances}

There is an important distinction between constitutive and inducible immune defenses. Constitutive defenses are always active, thereby incurring a fixed cost to develop and maintain whether they are needed or not. They pay substantial dividends, however, if they prevent pathogens from infecting and multiplying in the host, which would necessitate a much costlier immune response and risks severe illness and death. Inducible defenses, on the other hand, only incur a cost when activated upon contact with a pathogen, but the delay in efficacy enables the pathogen to multiply and cause damage, thereby requiring a substantial and costly immune response (Boots \& Best, 2018; Hamilton et al., 2008; Shudo \& Iwasa, 2001; van Loon et al., 2006; Westra et al., 2015).

In humans, the constitutive arm includes skin, saliva, stomach acid, restriction factors, basal autophagy, and proteasomal degradation, and the inducible arm includes the pattern recognition receptors of the innate immune system and the antigen-specific receptors of the adaptive immune system, which, among other things, activate costly proliferation of leukocytes and fever when detecting a pathogen (Paludan et al., 2021). Constitutive and inducible defenses overlap to some extent. Phagocytosis can be activated by Toll-like receptor (TLR) dependent and TLR-independent mechanisms, for example, and many restriction factors are expressed at basal levels to exert immediate antiviral activity, but are also induced transcriptionally (Paludan et al., 2021).

The behavioral immune system is a motivational system that reduces infection risk by promoting pathogen avoidance via changes in cognition, affect, and behavior (Ackerman et al., 2018, 2021; Buck et al., 2018; de Roode \& Lefèvre, 2012; Schaller \& Park, 2011). Some researchers note that behaviors after contact with pathogens, such as self-medication and grooming, also qualify as behavioral immune strategies (Amoroso, 2021; de Roode \& Lefèvre, 2012).

In analogy with the inducible and constitutive arms of the immune system, we propose that as Homo entered a more carnivorous niche and evolved a larger body size, increasing pathogen pressure, it increased investment in immunity by more intensively co-opting plant secondary compounds through consumption (Billing \& Sherman, 1998; Hagen et al., 2013; Hagen et al., 2009; Hardy, 2019; Huffman, 2003; Rodríguez et al., 1982; Sullivan \& Hagen, 2002; Sullivan et al., 2008). We conceptualize regular consumption of pharmacological plant substances, regardless of infection status, as a constitutive defense, and consumption upon infection as an inducible defense. 


\subsection{Plant chemical defenses as a "pharmacy" for animals}

The plant kingdom contains an estimated $10^{5}-10^{6}$ chemically unique structures, with 5000-15,000 structures per species, dwarfing all other major taxonomic categories for known specialized metabolites (Medema et al., 2021). Primary metabolic pathways - those producing compounds vital for plant survival such as proteins, lipids, and carbohydrates are widely conserved across plant lineages and therefore contribute little to this chemical diversity, most of which comprises lineage-specific secondary compounds - those involved in, e.g., plant-pollinator signaling and herbivore defense (Li \& Gaquerel, 2021). Even fruits and nectars, which evolved to attract seed and pollen dispersing animals, are chemically defended against unwanted consumers (Cipollini, 2000; Dalling et al., 2020; GonzálezTeuber \& Heil, 2009; Valenta et al., 2017). Plant defensive toxins typically target protein functions in plant consumers, including animal neural receptors and other steps in neural signaling (Wink, 2015).

Plants are attacked by the same classes of pathogens that attack humans and other animals: viruses, bacteria, protozoa, fungi, helminths, and arthropods. Plant chemical defenses might therefore also be effective against the pathogens of humans and other animals. Indeed, a substantial fraction of anti-infective drugs approved in the last four decades are either derived from plant or microbial products, or inspired by them (Cicka \& Quave, 2019; Harvey et al., 2015; Newman \& Cragg, 2020; Porras et al., 2021). The increase in antibiotic resistant strains of pathogenic bacteria in particular, combined with new high-throughput screening technologies, has renewed drug discovery efforts focused on plant products (Atanasov et al., 2021; Porras et al., 2021; Silva et al., 2016).

Over the course of evolution, local flora would have represented a "pharmacy" for members of the human lineage and other animals (Boppré, 1984). It is therefore plausible that there has been selection over deep time to not only extract macronutrients from plants but also to co-opt plant secondary compounds for their anti-infective effects. Such self-medication could also allow some energy to be redirected from immunity to growth, higher reproductive rate, or other fitness-enhancing processes and activities. In a model insect system, for example, use of antibiotics down-regulated immune-related genes, upregulated growth-related genes, and increased growth (Galarza et al., 2021). In humans, it would also have improved an ability to safely exploit energy-rich animal foods.

\subsection{Spices as a constitutive pharmaceutical toolkit to manage enteric pathogen risk}

Humans routinely add spices - plant substances high in secondary compounds but low in macronutrients - to food, typically meat-based dishes. Billing \& Sherman (1998) proposed that because spices have antimicrobial properties, and because foods, especially meat, contain dangerous microbes, this practice is adaptive, a hypothesis supported, in part, by a positive association between mean national temperature, a proxy of food-borne pathogen risk, and various indices of national spice use. On this view, the routine addition of spices and other medicinal substances to foods is a constitutive pathogen defense - it is always active, incurring the cost of potential interference with physiological functions but providing benefits by deterring infection and subsequent pathogen growth. 
A reanalysis of Billing \& Sherman (1998) that included additional data and appropriately controlled for autocorrelation from shared cultural ancestry and spatial proximity, and other potential confounds, found no significant association between temperature and spice use. Instead, spice use was associated with global patterns of poverty and health outcomes (Bromham et al., 2021). These authors went too far, though, in claiming "Patterns of spice use are not consistent with an infection-mitigation mechanism" (p. 1), especially since, accounting for autocorrelation, they found associations between mean spice use and incidence of foodborne illness and incidence of diarrhea in young children, as well as between use of spices and meat-based dishes. The problem with both studies is that their data are aggregated (mostly) at the nation level (36 countries in Billing \& Sherman, 1998; 70 cuisines in Bromham et al., 2021). These sample sizes are simply too small to tease apart the impact of what Bromham et al. (2021) themselves characterize as a "jungle of entangled variables that covary with culture, history and geography" (p. 6), such as temperature, poverty, biodiversity, and population.

In our opinion, the current adaptationist approach to spice use has placed undue emphasis on temperature and food spoilage, as there are major, temperature-independent risks of contaminated food that could be ameliorated by spices, such as zoonotic pathogens infecting the living animal, and fecal-oral transmission of pathogens (animal-to-human and human-to-human) via contaminated plant or animal foods. Despite some costs, there is considerable evidence for the beneficial biological activity of spices, especially against intestinal diseases (Rakhi et al., 2018), including evidence that spices can control pathogens already resident in the gut, such as H. pylori, which infects the stomachs of about half the world's population (Zaidi et al., 2015). See Figure 10.

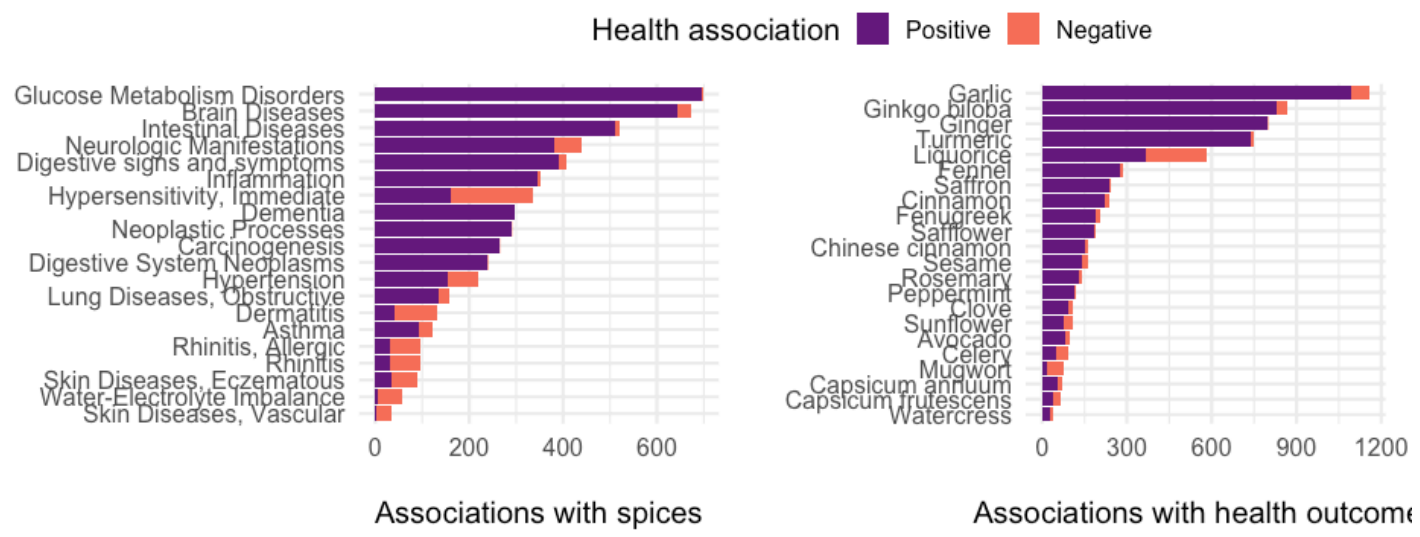

Figure 10: Top positive and negative health associations with spices (positive: spice associated with improved outcome; negative: spice associated with worse outcome). Left. Disease categories with the most positive and negative health associations with spices, ranked according to their total number of associations. Right: Spices with the most positive and negative health associations with diseases, ranked according to number of associations. The number of positive health associations for spices outnumber the number of negative associations, indicating that spices, in general, have been reported with beneficial health effects. Data from Rakhi et al. (2018). 
Although the extent to which prehistoric and contemporary hunter-gatherers have used spices is not clear, there is some evidence that it might be a longstanding practice. Chimpanzees have been observed to chew leaves when eating freshly killed animals(Krief et al., 2015), compounds in Neanderthal dental calculus that have been interpreted as "medicines" might be better conceptualized as "spices" (Krief et al., 2015), spices were combined with hunted foods by European foragers and early agriculturalists (Saul et al., 2013), and contemporary Congo Basin foragers use wild plants as spices (Fils et al., 2020; Gallois et al., 2020; Tanno, 1981). We propose an expanded adaptationist hypothesis that preferences for spices (and perhaps salt, which is also antimicrobial, Albarracin et al., 2011) evolved to constitutively manage overall enteric pathogen risk from whatever source.

\subsection{Self-medication as an inducible defense}

When constitutive defenses fail to prevent infections and illness, inducible (therapeutic) uses of plant substances could help bring infections under control, albeit with risk of poisoning. There is increasing evidence that invertebrates and vertebrates, including obligate carnivores, have evolved to co-opt plant and fungal toxins to prevent or treat their own infections, a phenomenon termed self-medication, zoopharmacognosy, or pharmacophagy (Boppré, 1984; de Roode et al., 2013; Huffman, 1997, 2017; Neco et al., 2019; Rodríguez \& Wrangham, 1993; Villalba \& Provenza, 2007; Wrangham \& Nishida, 1983; Yoshimura et al., 2021). A systematic review of self-medication in mammals found reports of self-medication in 71 species from 7 mammalian orders, with the most reports in Primates (46 species), Carnivores (10 species), and Rodents ( 5 species). Types of selfmedication included ingestion of whole leaves to expel parasites from the digestive system (mostly apes and elephants), rubbing fur with toxic plants (non-human primates), placement of bay foliage around the nest to reduce ectoparasites (rodents), and use of specific plants to attenuate negative effects of food ingestion (artiodactyls). Results suggest that self-medication evolved independently at least four times, and is associated with traits that increased in the human lineage in the Pleistocene: body size, brain size, and longevity (Neco et al., 2019).

\subsubsection{Possible self-medication by Middle Paleolithic Homo}

Middle Paleolithic hominins might have self-medicated, perhaps more intensively than other apes. An analysis of dental calculus from five Neanderthals found azulenes and coumarins in one, consistent with yarrow and chamomile, bitter-tasting plants with no nutritional value that might instead have been used as medicines (Hardy et al., 2012). An analysis of ancient DNA in the dental calculus of this same individual, who had a dental abscess, found sequences of poplar, which contains salicylic acid (the active ingredient in aspirin), a chronic gastrointestinal pathogen, and antibiotic-producing Penicillium rubens, suggesting this person might have been self-medicating both their abscess and a gastrointestinal infection (Weyrich et al., 2017).

Hardy (2019) classified plants from seven Near Eastern archaeological sites dating from the lower Paleolithic to the early Neolithic into edible, edible/medicinal, and medicinal/poisonous categories. Medicinal plants were quite common across sites $(>50 \%$ 
species), and much more common than in plants used by chimpanzees ( $30 \%)$ or among wild flora $(\sim 12.5 \%)$. Some of the medicinal plants might have been regularly added to food, i.e., they were "spices" (Krief et al., 2015). In modern populations, foods and medicines also overlap. Among the Hausa, for example, $30 \%$ of plant foods are used as medicines, and $89 \%$ of plants used to treat malaria are also part of the diet (Huffman, 2003; see also Roulette et al., 2018).

\subsection{Ethnopharmacology as a form of transgenerational immune memory}

Inducible immune responses have traditionally been divided into innate immune responses, which respond to pathogens rapidly and nonspecifically, and adaptive immune responses, which respond more slowly but are pathogen-specific and form immunological memory for rapid responses upon re-exposure. Innate responses also have some degree of specificity, however, and demonstrate increased resistance to reinfection, phenomena termed "trained immunity" or "innate immune memory" (Netea et al., 2016; Netea et al., 2019). There is even evidence that neurons encode and retrieve specific immune responses (Koren et al., 2021).

Transgenerational transmission of immunity is seen in invertebrates and vertebrates, which in mammals involves antibody provisioning via transplacental transfer and breastfeeding (Atyeo \& Alter, 2021; Clements et al., 2020; Erickson, 2022), maternal microchimerism, and antigen exposure in utero, phenomena termed "transgenerational immune priming" (Blackwell, n.d.; Roth et al., 2018). These patterns suggest that there is widespread selection for pathogen defense mechanisms that learn about specific pathogens and transmit this information to offspring.

We propose that, analogous to transmitted immune memory, increased pathogen pressure in the human lineage was a major selection pressure for the cognitive mechanisms underlying cultural transmission. Huffman (2003) proposed that ethnomedicine, such as culture-specific and traditional plant uses, is linked to hominid self-medication strategies in fact, some traditional plant medicines are used by both humans and African great apes (Huffman, 2003; Salali et al., 2016). Our proposal builds on his idea, arguing that in the context of social communication, transmitted information routinely includes locally adaptive medicinal knowledge, and can be viewed as a socially transmitted form of transgenerational immune memory (for related ideas, see Hurtado, 2021).

Medicine is a human universal (Brown, 1991), and traditional medicines and practices are still very widely used, especially in low- and middle-income countries (Porras et al., 2021). Although traditional medicine rarely outperforms Western medicine, Western medical services are often unavailable and traditional medical knowledge provides considerable value (Blackwell \& Purzycki, 2018; Kim, Kim, et al., 2020). Studies of Tsimane horticulturalists found that parental ethnobotanical knowledge was positively associated with child health (McDade et al., 2007), including increased BMI (Reyes-García et al., 2008), with some mixed results in a later study (Reyes-García et al., 2016). Similarly, in a study of Congo Basin foragers, mothers with greater knowledge of medicinal plants used to treat respiratory diseases had children with higher BMI (Salali et al., 2016). 
Traditional medicines, furthermore, have many advantages for drug discovery over other approaches (Atanasov et al., 2015). There are an estimated 374,000 plant species, 28,000 $(7.5 \%)$ of which are used in traditional medicine. This subset is likely enriched in compounds that are both effective against human diseases and also relatively safe for humans (Porras et al., 2021). Databases of plants used in traditional medicine are widely screened for medically useful compounds (Anand et al., 2019; Pushpangadan et al., 2018; Wink, 2015; Yeung et al., 2020). Although the "jungle medicine" narrative has its share of hype, Western romanticism, and exploitation (Voeks, 2018), and some systematic assays of ethnomedicines have been disappointing (e.g., Applequist et al., 2017), there have been about 60,000 publications on ethnopharmacology, with research increasing dramatically on inflammation, infection, pain, toxicity, cancer and diabetes (Yeung et al., 2020).

\subsection{The evolution of medical specialization}

Evolutionary theories of cultural transmission emphasize widespread knowledge that is used on a near-daily basis, such as locally adaptive subsistence practices (including spice use), toolmaking skills, and cooperative social norms (Henrich \& McElreath, 2003;

Richerson \& Boyd, 2008; Richerson \& Boyd, 2020). Medical problems are different. Because the immune system, perhaps combined with the constitutive behavioral defenses we described earlier, prevents most pathogens from causing serious illness, the substantial investment in individual and social learning required to effectively treat specific illnesses with specific plant substances would only occasionally be useful to the individual. The costs of acquiring medical knowledge would likely outweigh the benefits. Serious illnesses nevertheless unpredictably strike some individuals, who would benefit from diagnosis and treatment. To profit from a substantial investment in medicinal knowledge, it would be necessary for a few medical specialists to cultivate a large, medically naive clientele that is willing to "pay" for medical services on the rare occasions they need them.

In support of this perspective, medical knowledge, though clearly culturally evolved, is not evenly distributed within and across communities. Among Baka foragers in the Congo Basin, informants had almost the same amount of knowledge about plant uses for food and material culture, whereas knowledge of medicinal plants was mostly different, and some individuals had markedly more knowledge than others (Hattori, 2020). Similarly, among BaYaka Congo Basin foragers, knowledge of medicinal plants was primarily shared with families, unlike knowledge of food plants and social norms/beliefs, which was shared among camp members regardless of family ties (Salali et al., 2016). Medical knowledge also differs substantially across language groups, even within geographic regions (Cámara-Leret \& Bascompte, 2021).

In the ethnographic record, most knowledge specialists are medicinal knowledge specialists, such as shamans and traditional healers (Lightner et al., 2021b), whose expertise is often linked to other useful knowledge domains, such as botany, zoology, and psychology (see Figure 11). Medical specialists typically provide valuable medical services to a dedicated clientele, often in exchange for payments of various sorts (Lightner et al., 2021b; Sugiyama \& Sugiyama, 2003). Medicinal knowledge specialists therefore often treat their knowledge as a proprietary and secretive resource, in contrast to the prestigious 
mentorships provided by specialists in domains requiring commonly used skills, such as subsistence or toolmaking (Lightner et al., 2021a).

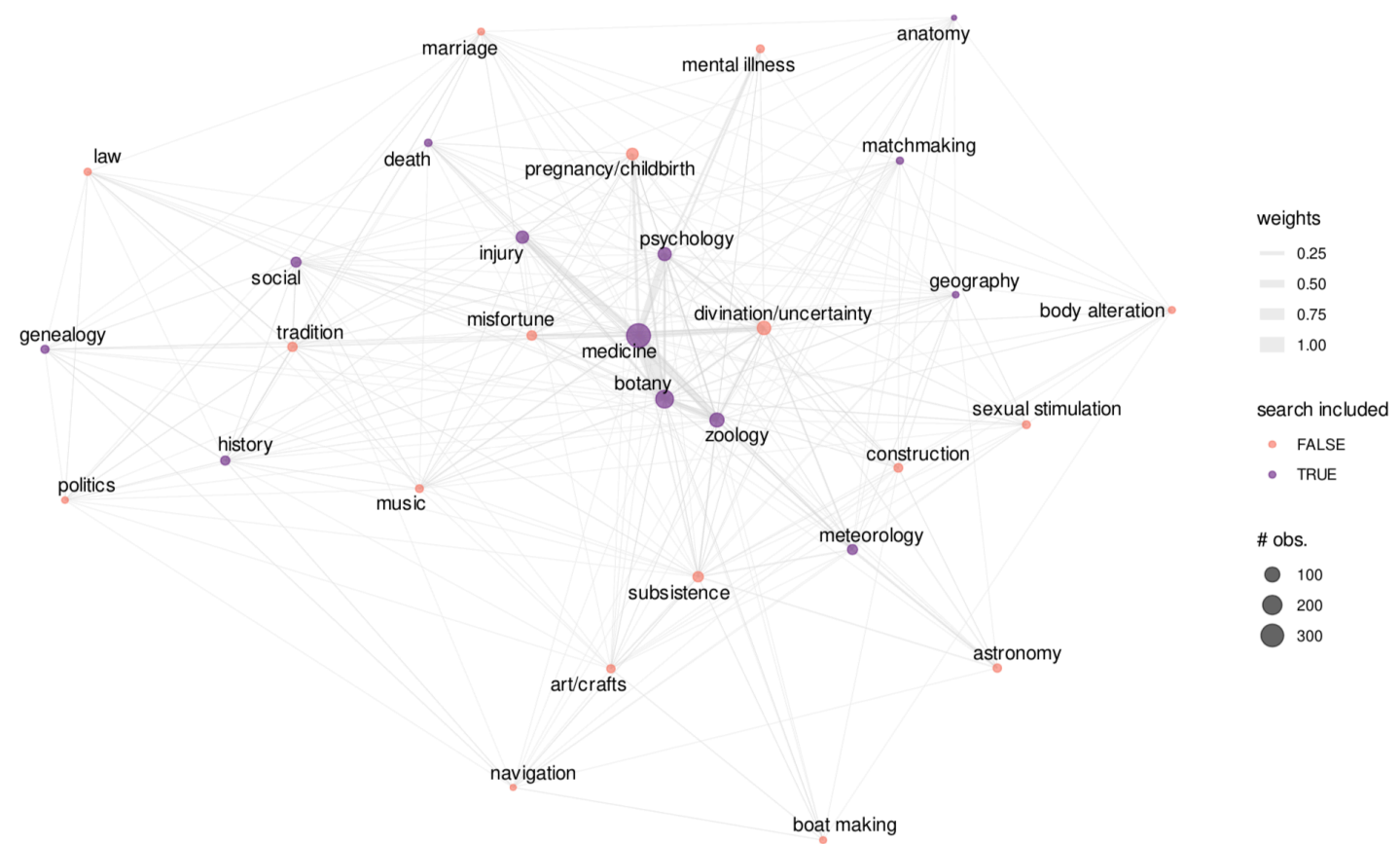

Figure 11: Commonly occurring domains of knowledge and skill that occurred in ethnographic text records of 55 traditional cultures. Vertices indicate domains that occurred in at least ten text records, and vertex size corresponds to the number of text records including that domain. Vertex colors indicate whether or not the domain was included in the original search query. Each edge indicates that a pair of knowledge/skill domains co-occurred in at least one text record. Edge widths correspond to the frequency with which each domain pair co-occurred (as determined by the number of text records describing them together, normalized by the maximum frequency =113). Figure from Lightner et al. (2021a).

We propose that in the human lineage, the self-medication behaviors seen in other apes evolved into widespread daily consumption of pharmacological plants, i.e., spices and "recreational" drugs (discussed next), that were behavioral analogs of constitutive defenses, and ethnomedical knowledge that was the behavioral analog of an inducible defense. Some ethnomedical knowledge to treat common infections, such as intestinal helminths, would have been widespread, but in modern humans, at least, much was probably possessed by shamans and traditional healers who treated specific but relatively uncommon illnesses in exchange for various sorts of payments.

\section{Defending the brain from pathogens}

The human brain tripled in size over the course of the Pleistocene. Much learned information, including language, is acquired in childhood and must be stored in neurons for a lifetime. Loss of neurons entails the loss of functionality and often irreplaceable 
information, such as in Alzheimer's disease where neuronal cell death causes permanent loss of memory and other cognitive dysfunctions (Arendt et al., 2015).

Most tissues have mechanisms to restore functionality when damaged or infected, which typically involves the destruction and removal of injured or infected cells (D'Arcy, 2019; Deretic et al., 2013), and the generation of new cells (Clevers \& Watt, 2018; Xia et al., 2018). Most human neurons, however, cannot be replaced in adulthood. Although adult neurogenesis has been reported in a wide range of vertebrates, including birds, rodents, and primates, in humans it is very limited and perhaps non-existent (Denoth-Lippuner \& Jessberger, 2021; Franjic et al., 2022; Gage, 2019; Lucassen et al., 2020; Moreno-Jiménez et al., 2019; Oppenheim, 2019; Sorrells et al., 2018). The unique value of neurons presents a conundrum to the immune system: how to defend the brain from pathogens if destroying infected neurons would cause permanent loss of critical learned information or other functionality? Constitutive defenses are one solution (Paludan et al., 2021).

\subsection{The blood-brain barrier, a constitutive defense}

The brain is defended by a physical blood brain barrier (BBB). Although originally conceptualized as a relatively static barrier protecting the CNS (Saunders et al., 2014), the BBB is now widely recognized as a key component in a dynamic neurovascular unit comprising, e.g., endothelial cells (the BBB), internal elastic lamina, vascular muscle, pericytes, perivascular nerves, neuropil, and astrocytes. The neurovascular unit matches blood flow to rapidly varying energetic demands in different parts of the brain, helps guide brain development, pumps glucose, amino acids, and other essential molecules into the brain via a variety of substrate-specific transporters, defends against neurotoxic xenobiotics, and conducts immune surveillance (Banks, 2016; Iadecola, 2017; VillabonaRueda et al., 2019).

The BBB prevents most blood-borne pathogens from infecting the brain. It also prevents most plant toxins and other xenobiotics from entering the brain, including most pharmaceuticals, which often chemically resemble plant toxins (Agúndez et al., 2014). These properties pose a considerable challenge to drug treatment of pathogens that do manage to infect the CNS (Pardridge, 2012; Terstappen et al., 2021). Certain small molecules can cross the BBB via lipid-mediated free diffusion, however, including oxygen, carbon dioxide, and widely used "recreational drugs" like nicotine and caffeine, a key point we take up later. See Figure 12. 


blood
channels
transport

Figure 12: Transport systems at the blood-brain barrier. (1) Small ions and water molecules can cross the blood-brain barrier through ion channels. (2) Small lipophilic molecules that are soluble in the hydrophobic core of the cell membrane can be transported passively across the cell. (3) Essential polar molecules that cannot diffuse through the cell membrane are shuttled across the cell membranes by carrier-mediated transport. These solute carriers may be directional, in or out of the cell, or bidirectional. Other molecules can be actively transported across endothelial cell membranes by carrier-mediated transporters, receptor-mediated transporters, adsorption-mediated transcytosis, or efflux pumps. Figure and caption from Wong et al. (2013).

\subsection{CNS immune privilege and defense}

Herpes simplex virus infection of skin cells results in massive immune- and virus-mediated cell death, followed by rapid replacement of the cells. If the immune system responded to infection of irreplaceable neurons in the same way, neural functions would be severely compromised (Miller et al., 2016; Solomos \& Rall, 2016). Moreover, CNS inflammatory responses interfere with CNS functions, sometimes permanently, even without neuronal death (Klein et al., 2017). For much of the last century, knowledge that the BBB prevented most pathogens from reaching the CNS and that tissue grafts implanted in the CNS parenchyma (functional tissue) did not provoke rejection, supported the view that the CNS 
was an "immune privileged" site. Recent discoveries that the brain parenchyma is connected to the peripheral immune system via meningeal lymphatic vessels have stimulated debate over the nature of immunity in the brain.

One mainstream view is that barriers establish compartments in the CNS that differ functionally in their access to the immune system and some are immune privileged and others are not (Engelhardt et al., 2017). The meninges surrounding the CNS parenchyma, for instance, contain a wide repertoire of immune cells, including monocytes and B cells from special skull and vertebral bone marrow reservoirs, that provide immune surveillance of the CNS (Alves de Lima et al., 2020; Brioschi et al., 2021; Cugurra et al., 2021). Although the CNS parenchyma can mount an inflammatory response to infection via resident microglia (brain-specific macrophages) and other cells, as well as cells migrating from the meninges, it is characterized by a dearth of adaptive and innate immune responses relative to peripheral tissues (Engelhardt et al., 2017). In fact, to maintain neuronal integrity, immune responses in the CNS might favor controlling pathogens rather than eliminating them (Matta et al., 2021; Miller et al., 2016).

\subsection{Infections of the CNS}

Despite formidable CNS defenses such as the BBB, pathogens do manage to infect the CNS. Immune privilege is a double-edged sword. The protection it provides to neurons also creates a niche in which pathogens that manage to infect the CNS can evade destruction by the immune system. There is increasing evidence that a number of pathogens establish latent infections in the CNS, i.e., survive but do not replicate until a later date. These include M. tuberculosis, T. gondii and HIV in microglia and other myeloid cells; T. gondii, HIV, and West Nile virus in astrocytes; T. gondii and herpes simplex virus in neurons; and Treponema pallidum (syphilis) in the CNS and meninges (Forrester et al., 2018).

Infection strategies include direct infection of brain endothelial cells (e.g., measles virus, Zika virus, T. gondii); free pathogen transcytosis through the BBB (perhaps West Nile virus); Trojan-horse-mediated pathogen entry into the CNS, in which infected leukocytes carry pathogens across the BBB (perhaps West Nile virus and T. gondii); paracellular entry at the BBB, in which pathogens secrete proteases and toxins that disrupt tight junctions (e.g., Bacillus anthracis); and axonal transport from peripheral neurons, in which pathogens enter the CNS by, e.g., entering vesicles in infected peripheral neurons that are then transmitted to CNS neurons (e.g., rabies, herpes simplex virus) (Cain et al., 2019; Forrester et al., 2018).

In a study of the global burden of 15 neurological disorders, encephalitis (inflammation of the brain parenchyma) ranked tenth (stroke, migraine, dementias, and meningitis ranked 1-4). In south Asia, however, a highly populated region, encephalitis ranked fifth (Feigin et al., 2019). The annual incidence of encephalitis is about 12 per 100,000 across all ages, but most cases occur in children. Mortality rates for encephalitis range from 5-15\% (Venkatesan et al., 2019). In only about half of the cases is a cause identified, which is usually an infectious agent, with an important minority of cases ( $20 \%)$ apparently due to immune activation alone (Boucher et al., 2017). In children, common infectious causes include enterovirus, parechovirus, bacterial meningoencephalitis, influenza, herpes 
simplex virus, and Mycoplasma pneumoniae (Britton et al., 2020). In adults, herpes simplex virus, Varicella-zoster virus, and Japanese encephalitis virus are the most common causes, followed by bacteria such as Mycobacterium tuberculosis and Listeria monocytogenes (Boucher et al., 2017). Arthropod-borne viruses such as Zika and chikungunya are also increasingly implicated (Venkatesan et al., 2019). Zoonotic SARS-CoV-2 seems to infect the brain, causing encephalitis in a few individuals but perhaps "long covid" symptoms in many more (Bauer et al., 2022). Rabies, as noted earlier, is a zoonotic virus that causes deadly encephalitis. More generally, neural tropism by zoonotic viruses is an important predictor of virulence (Brierley et al., 2019).

Larvae of T. solium, one of the tapeworm species that switched hosts from a carnivore into the human lineage c. 2-3 mya, can infect the brain, a condition termed neurocysticercosis. Ingested eggs hatch in the intestine, penetrate the intestinal wall and migrate to various tissues, including the CNS. See Figure 13. Once in the CNS the larval cyst might live and continue to grow, or die due to immune response or treatment and then degenerate and calcify (Sinha \& Sharma, 2009). The clinical manifestations of neurocysticercosis vary depending on the location and extent of CNS infection and the patient's immune response, and range from completely asymptomatic to headaches, seizures, increased intracranial pressure, focal deficits, meningitis, pressure on the spinal nerve, dementia and other mental changes, dizziness, stroke, and death (Sinha \& Sharma, 2009).

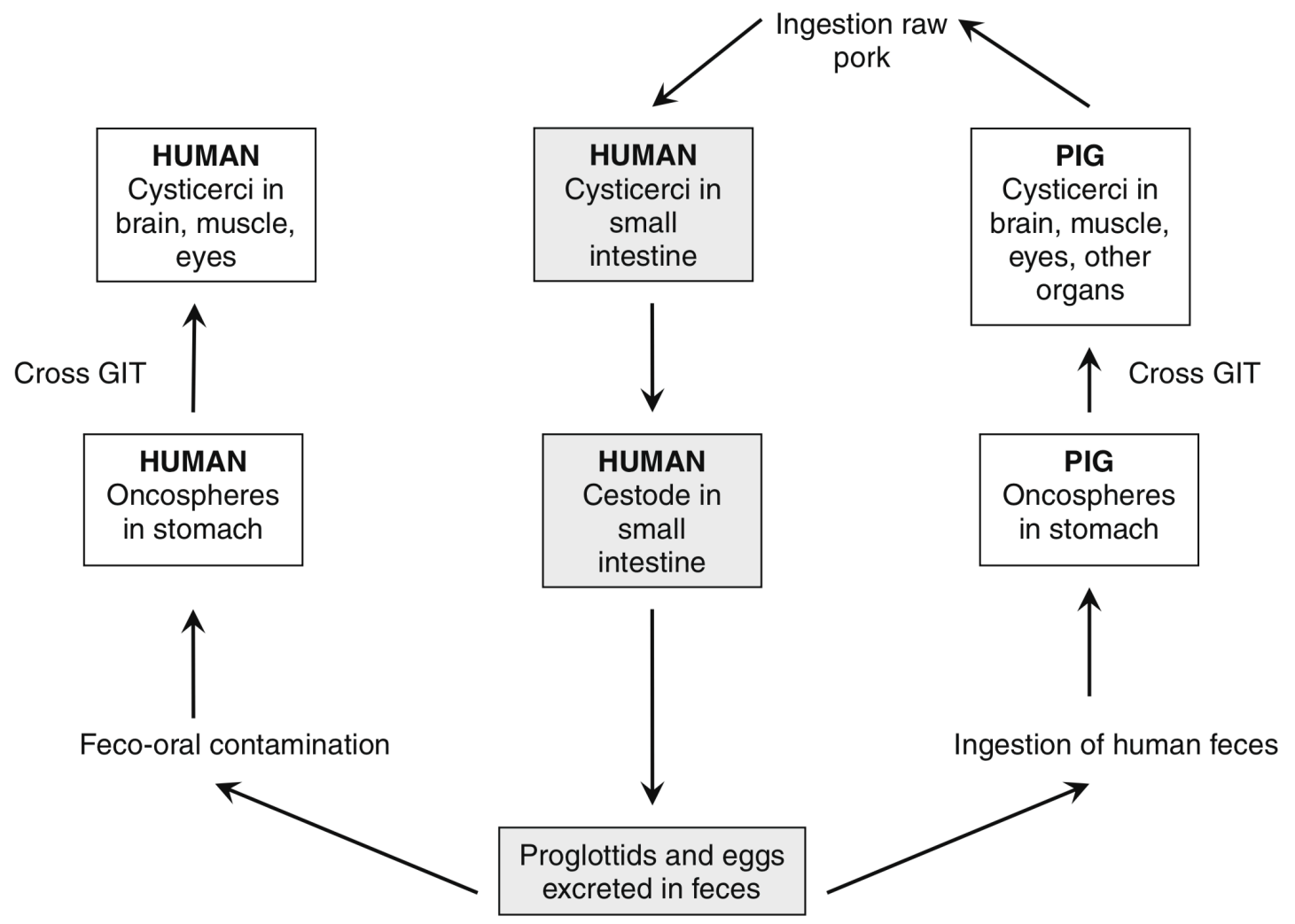

Figure 13: Life cycle of Taenia solium. Cysticerci are the larval cyst of the parasite, oncospheres are the embryonic form and the cestode is the adult form of the tapeworm. Proglottids are the segments of the tapeworm, which can detach and reproduce 
independently. Taeniasis is intestinal infection with the adult tapeworm (gray shaded boxes) while cysticercosis is systemic infection with larval cysts (unshaded boxes). GIT = gastrointestinal tract. Figure and caption from Sinha \& Sharma (2009).

Neurocysticercosis is a neglected tropical disease that has been difficult to diagnose (Gripper \& Welburn, 2017). Only now are MRI-based population studies beginning to emerge. In a study of a small rural Peruvian village where raising pigs is common, $37 \%$ of the population was seropositive for antibodies against T. solium cysticercosis and $19 \%$ of adults had brain calcifications consistent with neurocysticercosis. Of the latter, $17 \%$ reported a history of headaches or seizures. Thus, although about 1 in 5 villagers had brain infections of T. solium, most were asymptomatic (Moyano et al., 2016). In a population study of a rural Ecuadorian community where raising pigs is common, about 1 in 10 adults had lesions consistent with calcified brain cysticerci, with elevated rates in patients with epilepsy (Brutto et al., 2017). Even though, in these cross-sectional studies, most cases of neurocysticercosis appear to be asymptomatic, symptoms could appear over time, and there might be undetected cognitive deficits in apparently asymptomatic individuals.

Toxoplasma gondii is a protozoan parasite that infects more than one hundred species of vertebrates for which wild and domestic cats are the only known definite hosts (Johnson \& Johnson, 2021). The parasite reproduces in the feline host, which sheds oocytes in feces that are consumed by an intermediate host, such as rodent, that is subsequently eaten by a felid, completing the lifecycle (Dubey, 2020). T. gondii can infect the CNS and is one of the textbook examples of parasite manipulation: it appears to cause infected rodents to lose their fear of cats, increasing their likelihood of being eaten, thus enabling parasite reproduction. Humans can be infected with $T$. gondii by the fecal-oral route, but probably also by eating infected animals (Dubey, 2020). The seroprevalence of T. gondii in domestic and wild cats is 35\% and 59\%, respectively (Montazeri et al., 2020), and in humans ranges from 16\% in Asian countries to 61\% in African countries (Molan et al., 2019). T. gondii also appears to cause psychological and behavioral changes in humans, including less aversion to cat urine, although behavioral effects in humans are less certain (Johnson \& Johnson, 2021). A large population study found an association between seropositivity for T. gondii and schizophrenia (Burgdorf et al., 2019). A study of ancient DNA from a 2000-year-old hunter gatherer boy from South Africa found evidence that he died of complications of coinfection with T. gondii and typhus-like flea-borne rickettsioses (Rifkin et al., 2020). Interestingly, a study of $T$. gondii-infected chimpanzees found they had a morbid attraction to leopard urine, hinting that T. gondii has long manipulated hominids to lose fear of their felid predators and thus serve as viable intermediate hosts (Poirotte et al., 2016).

\subsection{Habitual recreational drug use as a constitutive pathogen defense}

Humans have evolved to be exceptionally reliant on learned information and other CNS functions across a lifespan that exceeds that of most other mammals, and they occupied a dietary niche with high exposure to potentially zoonotic pathogens, including those that infect the CNS. Yet immune defense of the CNS is constrained. Chemoprophylaxis and chemotherapy with compounds that are harmful to CNS pathogens but well-tolerated by the CNS would complement the immune system. Such an evolved chemoprotective strategy for the CNS requires antipathogenic compounds that can cross the BBB. 
Most common recreational drugs, including caffeine, nicotine, THC, and arecoline in betel nut, are plant defensive neurotoxins (ethanol, a yeast fermentation product, is the major exception). Sullivan, Hagen, and colleagues argued that the prevailing evolutionary "hijack hypothesis" of recreational drug use, in which evolutionarily novel substances incidentally activate dopamine reward circuits (Kelley \& Berridge, 2002; Wise, 1998), was implausible because similar compounds have been part of primate diets for millions of years (Hagen et al., 2013; Hagen et al., 2009; Sullivan \& Hagen, 2002; Sullivan et al., 2008).

Psychoactive substance seeking might instead be an evolved self-medication strategy to defend against intestinal helminths and other pathogens (Hagen et al., 2013; Hagen et al., 2009; Sullivan \& Hagen, 2002; Sullivan et al., 2008). All globally popular recreational drugs are toxic to helminths, as are some hallucinogenic plants used by Amazonian peoples (Rodríguez et al., 1982); nicotine was widely used to deworm livestock prior to the development of modern anthelmintics, and has the same mechanism of action as some commercial anthelmintics; an aqueous solution of tobacco is still used to deworm livestock in some low-income settings (efficacy quantitatively verified); tobacco is widely mentioned as an anthelmintic in ethnomedical texts; treatment of intestinal helminths in huntergatherers transiently reduces tobacco use, and tobacco and cannabis use is negatively associated with worm burden and reinfection; and there is a switch-like transition by virtually all humans to regular use of one or more of these pharmacologically potent substances in adolescence once teratogenic risks to the developing brain have dropped (Hagen et al., 2013; Hagen \& Sullivan, 2018; Hagen et al., 2009; Hagen \& Tushingham, 2019; Roulette, Kazanji, et al., 2016; Roulette et al., 2014; Sullivan \& Hagen, 2002; Sullivan et al., 2008). See Figures 14 and 15.
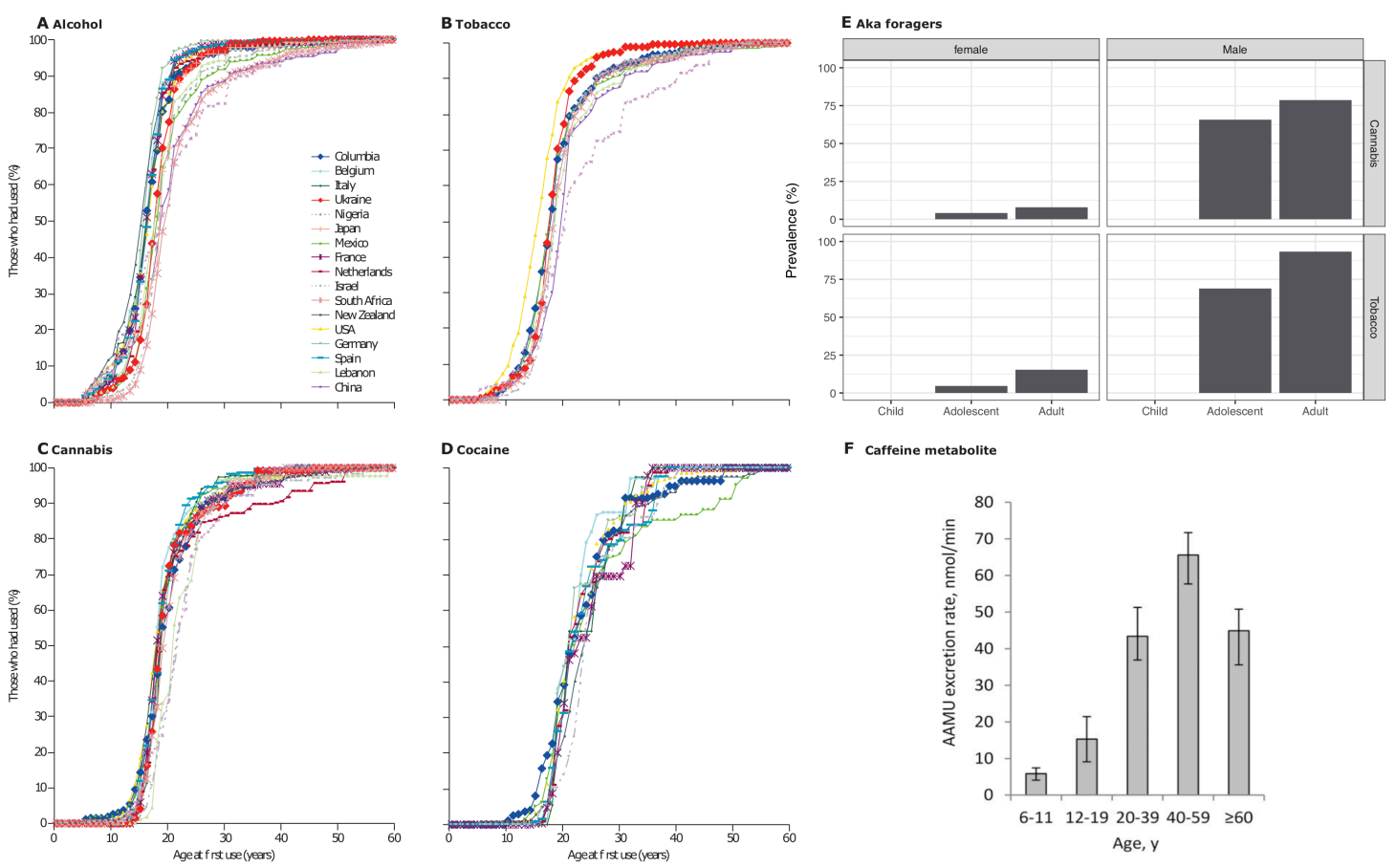

F caffeinemetabolit

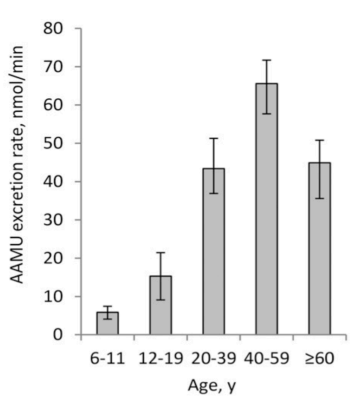

Figure 14: A-D: Cumulative distribution of self-reported age of first use of alcohol, tobacco, cannabis, and cocaine in a large $(N=85,052)$ cross-national sample of users of these 
substances. Figure from Degenhardt et al. (2016). E: Prevalence of tobacco and cannabis use among Aka forager children, adolescents, and adults, by sex (no children reported use). Data from Roulette, Hagen, et al. (2016). F: Urinary caffeine metabolite (AAMU: 5-acetylamino-6amino-3-methyluracil) excretion rate in a nationally representative US sample $(N=2714)$; 97.5\% had detectable AAMU. Self-reported caffeine intake in this sample exhibited the same age dependence, as did concentrations of urinary caffeine and other caffeine metabolites. Figure and data from Rybak et al. (2015). These patterns suggest the existence of a developmental 'switch' to psychoactive drug use during adolescence.

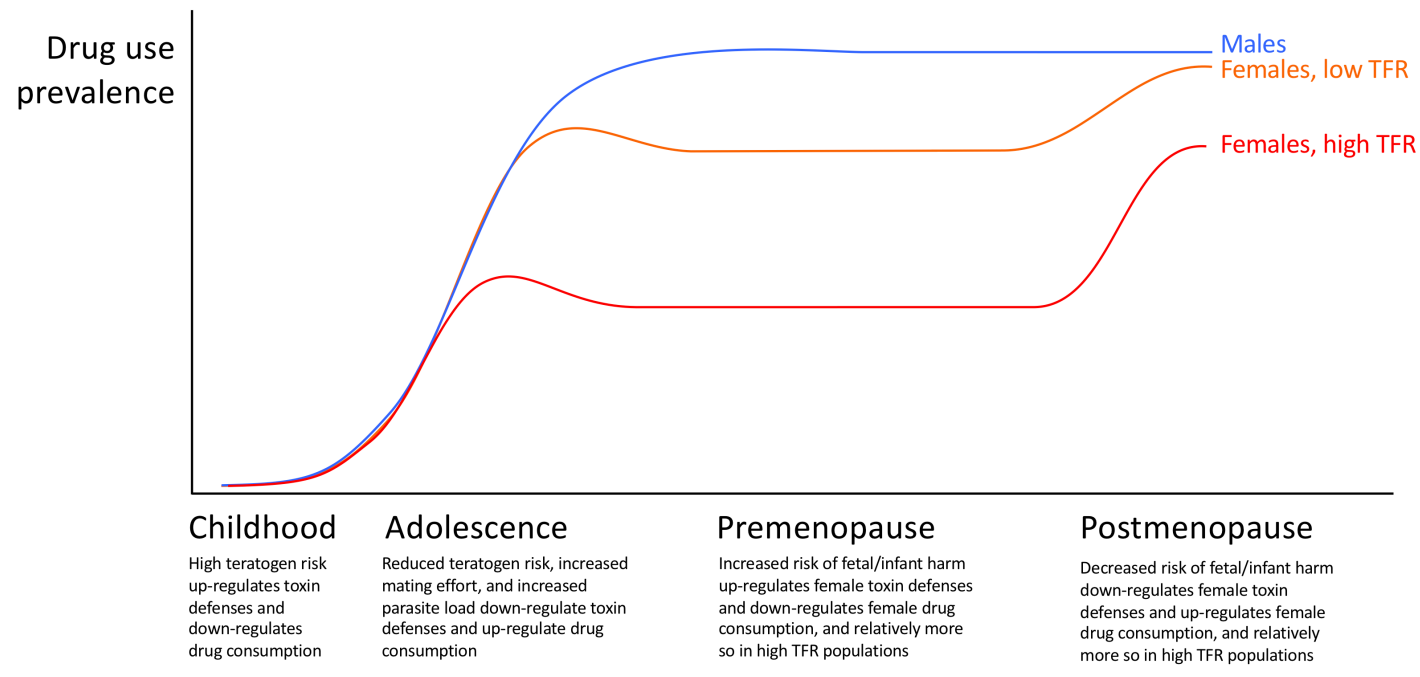

Figure 15: Theoretical model of recreational drug use as an evolved constitutive pathogen defense that varies by age, sex, and total fertility rate (TFR).

Helminths are an important class of CNS parasites, and of course all recreational drugs cross the BBB. Here we extend the antiparasite hypothesis of recreational drug use to pathogens that infect the CNS, focusing on the helminth T. solium as a key example. Humans, dogs, and other animals infected with Taenia and other tapeworm species have often been treated with arecoline hydrobromide (Gemmell, 1958; Li et al., 2012). Arecoline is an agonist of muscarinic acetylcholine receptors, which have numerous roles including in neuromuscular junctions. Arecoline's mechanism of action against cestodes is probably to induce paralysis (Liu et al., 2016). Arecoline readily crosses the BBB and is the primary psychoactive alkaloid in the seed of Areca catechu palm, which is typically chewed with the leaf of the Piper betle and slaked lime, a concoction termed betel quid or paan (Volgin et al., 2019). Betel quid is widely consumed in Asia and the Pacific and is probably the fourth most widely used psychoactive substance after caffeine, alcohol, and tobacco (Arora \& Squier, 2019; Gupta \& Warnakulasuriya, 2002; Mehrtash et al., 2017). Areca seeds, often combined with pumpkin seeds, were one of several frequently mentioned treatments of Taenia infections in Chinese medical texts dating back about 2000 years (Zou \& Ye, 2014). In a controlled study in humans this combination was found to be close to $90 \%$ effective at expelling Taenia tapeworms (Li et al., 2012). Whether arecoline also kills Taenia larvae in the brain is unknown, and killing larvae in the brain induces inflammation, potentially creating more problems than it solves. However, most of the medical community has 
accepted that the benefits of antiparasitic treatment of neurocysticercosis outweigh the risks (García et al., 2003).

It is intriguing that a pathogen that humans acquired from carnivores around the time they transitioned to increased meat eating, and which infects the CNS and other tissues, is potentially treatable with the active compound in one of the world's most popular "recreational" drugs, used on a daily basis by a sizable fraction of the world's population. It is also intriguing that caffeine, the world's most popular drug, inhibits growth of T. gondii (Munera López et al., 2019), another common neurotropic pathogen. Consumption of ethanol, like consumption of pharmacological plant substances, could also be a selfmedication strategy: it is a potent antimicrobial compound, and there is evidence that it mitigates infections of $H$. pylori in vitro and in vivo (Liu et al., 2016; Xia et al., 2020).

Extending previous work (Hagen et al., 2013; Hagen et al., 2009; Sullivan et al., 2008), we propose that when the benefits exceed the costs, humans, and perhaps other animals, have an evolved propensity to seek out and regularly consume psychoactive plant defensive chemicals, i.e., those that cross the BBB and interfere with neural signaling, so as to deter, control, and eliminate pathogen invasions of the immune privileged CNS parenchyma.

\section{Implications for the evolution of human cognition}

We propose that pathogens were an ecological selection pressure for increased cognitive capacity in the human lineage. Increased selection to co-opt anti-infective plant secondary compounds would have selected for the cognitive abilities necessary to identify a large variety of plant parts rich in various pharmaceutical compounds and then to determine which compounds best treated which illnesses. To illustrate: in order to evaluate the effects of each of 20 plant substances on 10 illnesses would require 200 "tests". Moreover, combinations of drugs can often outperform single drugs. Traditional Chinese medicine specifies treating Taenia with a combination of areca and pumpkin seeds, for instance, and this combination has been shown to outperform either plant substance alone (Li et al., 2012). There are 190 combinations of two plant substances chosen from 20; testing each combination against 10 illnesses would require 1900 tests. We are not proposing that humans evolved to systematically test every combination of plant substances against every illness; we are simply illustrating the complexity of discovering effective plant-based treatments of infectious diseases. Successful prevention and treatment of infections, in turn, especially zoonotic infections, would have enabled a heavier reliance on energy-rich meat and reduced the lifetime energetic cost of immune responses, thereby making more energy available to, among other things, support the evolution of a larger brain.

\section{Alternative hypotheses, caveats, and complications}

The hypotheses we have developed here are speculative and must be rigorously tested against plausible alternatives. We sketch some of those alternatives next, along with the types of evidence that could discriminate among them. 
Human's intensified use of medicinal plants could simply be a byproduct of a capacity for cumulative culture that evolved for other reasons (e.g., foraging or sociality). The motivation to use such plants could be common to all primates or mammals, with only the cognitive ability to do so increasing in humans. In addition, modern global trade would facilitate this usage by providing access to a much greater variety of plants than are available to other species.

One test would be to determine the extent to which patterns of medicinal and psychotropic plant use by chimpanzees and other apes converge or diverge from human patterns of use. For example, do chimpanzees or other apes exhibit a developmental shift to regular consumption of psychotropic substances that resembles the switch-like transition seen in human adolescents (Figure 14)? Chimpanzees do consume ethanol and fermented fruit under natural conditions (Amato et al., 2021; Hockings et al., 2019). Unlike tobacco and other psychotropic plants favored by humans, however, ethanol contains substantial calories, which might explain its use by chimpanzees and other primates (Dudley, 2014).

The effectiveness of psychotropic drugs against CNS infections is largely hypothetical and the possibility remains that psychotropic effects are merely a byproduct of the shared features of human and parasite nervous systems, and that the use of these drugs has more to do with their effects elsewhere in the body, for example in the gut, as argued previously (Hagen et al., 2013; Hagen et al., 2009; Sullivan et al., 2008).

Possible tests include investigations of the prophylactic effects of typical serum levels of nicotine, arecoline, caffeine, and other psychoactive drugs against CNS infections of Taenia and other helminths or pathogens in model organisms; evidence that regular psychoactive drug use protects against helminth or other infections of the CNS in humans; evidence that CNS infections were a significant selection pressure, and more so in humans than other apes (e.g., genetic evidence of selection on CNS-specific immune genes and regulatory elements that diverge from other apes); and evidence that clearing Taenia or other infections of the CNS in humans reduces psychoactive drug use (similar to Roulette et al., 2014).

If humans evolved to seek out some substances as prophylactics, they may continue to seek these substances even in the absence of immune challenges. Similarly, humans might seek out substances which present cues similar to medicinal plants, i.e. psychoactive effects, even if the particular plants chosen are not themselves medicinal. Both of these factors may make establishing the link between drug use and pathogen defense more challenging, particularly in modern, low-pathogen contexts.

If humans evolved a taste for plant secondary compounds for self-medication, this could have encouraged drug plant domestication and created runaway selection in which plants were selected for greater and greater amounts of these compounds (Alternately, this same process can also be seen as plants having been selected to manipulate humans by producing these compounds in order to encourage humans to spread and cultivate them, e.g., Pollan, 2002). Such a process could lead to selection for compounds with the strongest psychotropic effects, even if these are not the compounds with the greatest medicinal value. Similarly, once humans began regularly consuming and using these compounds, 
their use might have taken on social, ritual, and recreational significance. Medical specialists are often religious leaders, for instance (Lightner et al., 2021a). Such seeking out of drugs for reasons unrelated to parasite defense may have further selected for drug seeking in humans and psychotropic compounds in plants, further divorcing the cue from the original parasite defense function. Alternatively, religious leaders such as shamans might have emerged through the use of deceptive, subjectively appealing practices (Buckner, 2022; Hong, 2022). That is, shamans could gain prestige by professionalizing "plausible-seeming magical practices" that convince others of their superhuman qualities, independent of their ability to actually apply useful medicinal knowledge (Singh, 2018). This hypothesized origin of shamanism would reflect a more exploitative account than ours offers, but the two are not mutually exclusive: Deceptive practices might coexist with beneficial medicinal services (Blackwell \& Purzycki, 2018), and cross-culturally, shamans might only partially overlap with the traditional medicinal specialists we described here. Future research could test the social aspects of our proposal by investigating the efficacy of shamans' healing practices and comparing it to the efficacy of widespread folk alternatives. Consistent with alternative hypotheses, shamans' healing practices might also be integrated into a broader set of religious practices that serve separate functions that have little-to-no relevance to medicine.

\section{Concluding remarks}

The human lineage entered a more carnivorous dietary niche c. 2.6 mya, during a period of increasing climate variability, and subsequently experienced an increase in body size, brain size, longevity, and range size. As many researchers have suggested, it probably also experienced a shift, and perhaps an increase in zoonotic pathogen pressure. There is evidence of carnivory-related Plio-Pleistocene spillovers of pathogens that are still with us today. Hunting, range overlap, and climate change are associated with viral spillover into modern humans, and hunter-gatherers, bushmeat hunters, and veterinarians have increased zoonotic infections relative to others living in the same environments. The virulence of newly emerging zoonotic pathogens ranges widely, with many having exceptionally high case fatality rates, especially those that infect neural tissue.

In apparent response, the human lineage evolved a number of pathogen defenses that diverged from chimpanzees and other primates. Human's exceptionally low stomach $\mathrm{pH}$ compared to other primates is a pathogen defense that is closely related to carnivory. A loss-of-function mutation in $\mathrm{CMAH}$ that arose c. 2 mya in the human lineage, and subsequent evolution in Siglec genes that exceed those seen in other apes, plausibly protected against infections as the human lineage was transitioning to greater consumption of meat. Exceptional human immune responses to LPS compared to other primates, which is linked to the CMAH mutation, suggests greater costs of bacterial infections since divergence from chimpanzees. Human-specific downregulation in ANTXR2 would have protected against increased exposure to zoonotic anthrax. And divergent APOE is linked, among other things, to meat-eating and pathogen exposure. These all point to a shift, and perhaps an intensification, in the pathogen environment of Homo compared to earlier hominins and other apes and primates. At the same time, the brain, an organ in 
which inflammatory immune responses are highly constrained, begins to increase, eventually tripling in size.

We propose that, for three major reasons, selection intensified for the self-medication strategies already in place in apes and other primates (Huffman, 2003). The first was the carnivory-related shift and perhaps increase in zoonotic pathogen pressure. The second was the challenges of defending a large body and brain from pathogens across what would eventually become one of the longest lifespans of any mammal. And the third was the possible increase in infections of the CNS. See Figure 16. Local florae were continually evolving thousands of compounds to combat the same broad classes of continually evolving pathogens that infected human ancestors. The human lineage, entering a knowledge-based niche, began to evolve the cognitive mechanisms needed to determine which plant substances best prevented, reduced, or eliminated which infections. This resulted in an inducible defense system - treating specific illnesses with specific plants, i.e., medicine and medical specialization, and two constitutive defense strategies: routinely adding plants high in secondary compounds - spices - to foods, and habitually consuming psychoactive plant substances that entered systemic circulation and crossed the BBB. Each would have permitted a heavier reliance on energy-rich animal foods and reduced the need for energetically expensive immune responses.

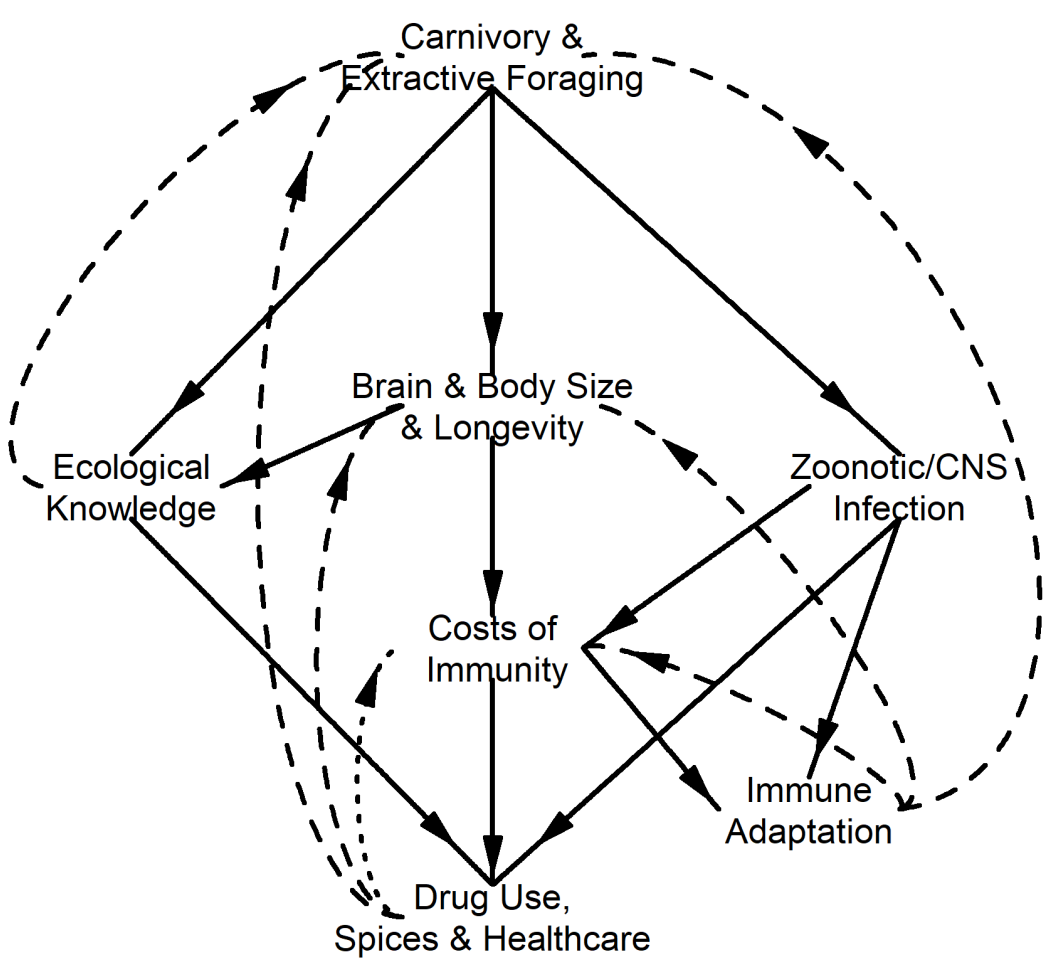

Figure 16: Homo medicus: As hominins entered a niche dependent on carnivory they encountered novel zoonotic diseases, some of which may have been more likely to infect the 
CNS. The new dietary niche also provided the caloric density necessary to evolve a large brain and body size, which was critical for the learning needed to acquire complex ecological knowledge. Ecological knowledge would have been useful not only when foraging for calories, but in acquiring knowledge of medicinal plants and spices, which may have provided both constitutive and inducible defenses. Selection would have particularly favored hominins who sought out compounds able to cross the BBS and supplement defense of the CNS. The evolution of drug use, spice use, and healthcare would have further reduced mortality risk and increased energy availability, by reducing immune costs and increasing the safety of carnivory, causing further feedback on selection for bigger brains, extended juvenile periods and longevity, allowing for even more acquisition of ecological knowledge and even greater payoffs from medicinal plant usage.

In support, there is evidence of medicinal plant use by hominins in the middle Paleolithic, and all cultures today have sophisticated, plant-based medical systems, incorporate plant components high in secondary compounds (spices) into food, and regularly consume psychoactive substances that are harmful to helminths and other pathogens. Protecting the immune privileged CNS parenchyma specifically, which was probably vulnerable to infection by Taenia and other pathogens throughout the Pleistocene, required substances that crossed the BBB. Psychoactivity is both a cue that a substance crosses the BBB and that it interferes with neural signaling, potentially harming helminths and other macroparasites with nervous systems. In previous publications Sullivan, Hagen, and colleagues developed the hypothesis that the near-universal adolescent transition to routine psychoactive substance use was an adaptation to protect against infections of helminths and other macroparasites (Hagen et al., 2013; Hagen \& Sullivan, 2018; Hagen et al., 2009; Hagen \& Tushingham, 2019; Roulette, Kazanji, et al., 2016; Roulette et al., 2014; Sullivan et al., 2008). We now extend this hypothesis to include protection against infections of the CNS.

Hunting provided the high quality meat-based diet necessary to support the evolution of a large brain while at the same time posing formidable cognitive challenges, thereby selecting for increased cognitive abilities (Kaplan et al., 2000). It also increased the risk of zoonotic spillover, a problem that if unsolved would have reduced the benefits of carnivory. Solving this problem involved the use of effective plant pharmaceuticals in the form of spices, medicines, and psychoactive drugs, discovery of which was also cognitively challenging, thereby also selecting for increased cognitive abilities. It also created demand for medical specialists. We propose that in the story of human evolution, which has long featured hunters, healers had an equal role to play.

\section{References}

Acke, S., Couvreur, S., Bramer, W. M., Schmickler, M.-N., De Schryver, A., \& Haagsma, J. A. (2021). Global infectious disease risks associated with occupational exposure among nonhealthcare workers: A systematic review of the literature. Occupational and Environmental Medicine, oemed-2020-107164. https://doi.org/10.1136/oemed-2020-107164 
Ackerman, J. M., Hill, S. E., \& Murray, D. R. (2018). The behavioral immune system: Current concerns and future directions. Social and Personality Psychology Compass, 12(2), e12371. https://doi.org/10.1111/spc3.12371

Ackerman, J. M., Tybur, J. M., \& Blackwell, A. D. (2021). What role does pathogen-avoidance psychology play in pandemics? Trends in Cognitive Sciences, 25(3), 177-186.

https://doi.org/10.1016/j.tics.2020.11.008

Agúndez, J. A. G., Jiménez-Jiménez, F. J., Alonso-Navarro, H., \& García-Martín, E. (2014). Drug and xenobiotic biotransformation in the blood-brain barrier: A neglected issue. Frontiers in Cellular Neuroscience, 8, 335. https://doi.org/10.3389/fncel.2014.00335

Albarracin, W., Sánchez, I. C., Grau, R., \& Barat, J. M. (2011). Salt in food processing; usage and reduction: A review. International Journal of Food Science \& Technology, 46(7), 13291336.

Alcock, J., Franklin, M. L., \& Kuzawa, C. W. (2012). Nutrient signaling: Evolutionary origins of the immune-modulating effects of dietary fat. The Quarterly Review of Biology, 87(3), 187-223. https://doi.org/10.1086/666828

Almécija, S., Hammond, A. S., Thompson, N. E., Pugh, K. D., Moyà-Solà, S., \& Alba, D. M. (2021). Fossil apes and human evolution. Science, 372(6542), eabb4363.

https://doi.org/10.1126/science.abb4363

Alves de Lima, K., Rustenhoven, J., \& Kipnis, J. (2020). Meningeal immunity and its function in maintenance of the central nervous system in health and disease. Annual Review of Immunology, 38(1), 597-620. https://doi.org/10.1146/annurev-immunol-102319-103410

Amato, K. R., Chaves, Ó. M., Mallott, E. K., Eppley, T. M., Abreu, F., Baden, A. L., ... Zeng, Y. (2021). Fermented food consumption in wild nonhuman primates and its ecological drivers. American Journal of Physical Anthropology, 1-18.

https://doi.org/10.1002/ajpa.24257

Amato, K. R., Jeyakumar, T., Poinar, H., \& Gros, P. (2019). Shifting climates, foods, and diseases: The human microbiome through evolution. BioEssays, 41(10), 1900034. https://doi.org/10.1002/bies.201900034

Amato, K. R., Mallott, E. K., McDonald, D., Dominy, N. J., Goldberg, T., Lambert, J. E., ... Knight, R. (2019). Convergence of human and Old World monkey gut microbiomes demonstrates the importance of human ecology over phylogeny. Genome Biology, 20(1), 201.

https://doi.org/10.1186/s13059-019-1807-z

Amoroso, C. R. (2021). Integrating concepts of physiological and behavioral resistance to parasites. Frontiers in Ecology and Evolution, 0. https://doi.org/10.3389/fevo.2021.635607

Anand, U., Jacobo-Herrera, N., Altemimi, A., \& Lakhssassi, N. (2019). A comprehensive review on medicinal plants as antimicrobial therapeutics: Potential avenues of biocompatible drug discovery. Metabolites, 9(11), 258.

https://doi.org/10.3390/metabo9110258 
Antón, S. C., Potts, R., \& Aiello, L. C. (2014). Evolution of early Homo : An integrated biological perspective. Science, 345(6192), 1236828.

https://doi.org/10.1126/science.1236828

Antón, S., Leonard, W. R., \& Robertson, M. L. (2002). An ecomorphological model of the initial hominid dispersal from Africa. Journal of Human Evolution, 43(6), 773-785. https://doi.org/10.1006/jhev.2002.0602

Applequist, W. L., Ratsimbason, M., Kuhlman, A., Rakotonandrasana, S., Rasamison, V., \& Kingston, D. G. I. (2017). Antimalarial use of Malagasy plants is poorly correlated with performance in antimalarial bioassays. Economic Botany, 71(1), 75-82.

https://doi.org/10.1007/s12231-017-9373-3

Arendt, T., Brückner, M. K., Morawski, M., Jäger, C., \& Gertz, H.-J. (2015). Early neurone loss in Alzheimer's disease: Cortical or subcortical? Acta Neuropathologica Communications, 3(1), 1-11.

Arora, S., \& Squier, C. (2019). Areca nut trade, globalisation and its health impact:

Perspectives from India and South-east Asia. Perspectives in Public Health, 139(1), 44-48. https://doi.org/10.1177/1757913918785398

Atanasov, A. G., Waltenberger, B., Pferschy-Wenzig, E.-M., Linder, T., Wawrosch, C., Uhrin, P., ... Stuppner, H. (2015). Discovery and resupply of pharmacologically active plant-derived natural products: A review. Biotechnology Advances, 33(8), 1582-1614.

https://doi.org/10.1016/j.biotechadv.2015.08.001

Atanasov, A. G., Zotchev, S. B., Dirsch, V. M., \& Supuran, C. T. (2021). Natural products in drug discovery: Advances and opportunities. Nature Reviews Drug Discovery, 20(3), 200 216. https://doi.org/10.1038/s41573-020-00114-Z

Attwell, L., Kovarovic, K., \& Kendal, J. (2015). Fire in the Plio-Pleistocene: The functions of hominin fire use, and the mechanistic, developmental and evolutionary consequences. Journal of Anthropological Sciences, (93), 1-20. https://doi.org/10.4436/JASS.93006

Atyeo, C., \& Alter, G. (2021). The multifaceted roles of breast milk antibodies. Cell, 184(6), 1486-1499. https://doi.org/10.1016/j.cell.2021.02.031

Aunger, R. (1994). Are food avoidances maladaptive in the Ituri Forest of Zaire? Journal of Anthropological Research, 277-310.

Baker, W. S., \& Gray, G. C. (2009). A review of published reports regarding zoonotic pathogen infection in veterinarians. Journal of the American Veterinary Medical Association, 234(10), 1271-1278. https://doi.org/10.2460/javma.234.10.1271

Banerjee, S., Perelson, A. S., \& Moses, M. (2017). Modelling the effects of phylogeny and body size on within-host pathogen replication and immune response. Journal of The Royal Society Interface, 14(136), 20170479. 
Banks, W. A. (2016). From bloodbrain barrier to bloodbrain interface: New opportunities for CNS drug delivery. Nature Reviews Drug Discovery, 15(4), 275-292.

https://doi.org/10.1038/nrd.2015.21

Bansal, S., Choudhary, S., Sharma, M., Kumar, S. S., Lohan, S., Bhardwaj, V., ... Jyoti, S. (2013). Tea: A native source of antimicrobial agents. Food Research International, 53(2), 568-584. https://doi.org/10.1016/j.foodres.2013.01.032

Barrett, R., Kuzawa, C. W., McDade, T., \& Armelagos, G. J. (1998). Emerging and re-emerging infectious diseases: The third epidemiologic transition. 27.

Bauer, L., Laksono, B. M., Vrij, F. M. de, Kushner, S. A., Harschnitz, O., \& Riel, D. van. (2022). The neuroinvasiveness, neurotropism, and neurovirulence of SARS-CoV-2. Trends in Neurosciences.

Beasley, D. E., Koltz, A. M., Lambert, J. E., Fierer, N., \& Dunn, R. R. (2015). The evolution of stomach acidity and its relevance to the human microbiome. PLOS ONE, 10(7), e0134116. https://doi.org/10.1371/journal.pone.0134116

Ben-Dor, M., Sirtoli, R., \& Barkai, R. (2021). The evolution of the human trophic level during the Pleistocene. American Journal of Physical Anthropology, $n / a(\mathrm{n} / \mathrm{a})$.

https://doi.org/10.1002/ajpa.24247

Berngruber, T. W., Froissart, R., Choisy, M., \& Gandon, S. (2013). Evolution of virulence in emerging epidemics. PLoS Pathogens, 9(3), e1003209.

https://doi.org/10.1371/journal.ppat.1003209

Berthaume, M. A., \& Schroer, K. (2017). Extant ape dental topography and its implications for reconstructing the emergence of early homo. Journal of Human Evolution, 112, 15-29. https://doi.org/10.1016/j.jhevol.2017.09.001

Betsem, E., Rua, R., Tortevoye, P., Froment, A., \& Gessain, A. (2011). Frequent and recent human acquisition of simian foamy viruses through apes' bites in central africa. PLOS Pathogens, 7(10), e1002306. https://doi.org/10.1371/journal.ppat.1002306

Billing, J., \& Sherman, P. W. (1998). Antimicrobial functions of spices: Why some like it hot. Q. Rev. Biol., 73(1), 3-49.

Bitar, M., Kuiper, S., O’Brien, E. A., \& Barry, G. (2019). Genes with human-specific features are primarily involved with brain, immune and metabolic evolution. BMC Bioinformatics, 20(9), 406. https://doi.org/10.1186/s12859-019-2886-2

Blackwell, A. D. (n.d.). Transgenerational inheritance of immunological knowledge: In utero exposure as a cue inducing tolerance to parasites and pathogens. 26.

Blackwell, A. D., \& Purzycki, B. G. (2018). Shamanism and efficacious exceptionalism. Behavioral and Brain Sciences, 41. https://doi.org/10.1017/S0140525X1700200X 
Blackwell, A. D., Snodgrass, J. J., Madimenos, F. C., \& Sugiyama, L. S. (2010). Life history, immune function, and intestinal helminths: Trade-offs among immunoglobulin $\mathrm{E}, \mathrm{C}$ reactive protein, and growth in an Amazonian population. American Journal of Human Biology, 22(6), 836-848.

Blerkom, L. M. V. (2003). Role of viruses in human evolution. American Journal of Physical Anthropology, 122(S37), 14-46. https://doi.org/10.1002/ajpa.10384

Bolker, B. M., Nanda, A., \& Shah, D. (2010). Transient virulence of emerging pathogens. Journal of The Royal Society Interface, 7(46), 811-822.

https://doi.org/10.1098/rsif.2009.0384

Boots, M., \& Best, A. (2018). The evolution of constitutive and induced defences to infectious disease. Proceedings of the Royal Society B: Biological Sciences, 285(1883), 20180658. https://doi.org/10.1098/rspb.2018.0658

Boppré, M. (1984). Redefining "pharmacophagy." Journal of Chemical Ecology, 10(7), 11511154.

Bordes, F., \& Morand, S. (2009). Parasite diversity: An overlooked metric of parasite pressures? Oikos, 118(6), 801-806.

Boucher, A., Herrmann, J. L., Morand, P., Buzelé, R., Crabol, Y., Stahl, J. P., \& Mailles, A. (2017). Epidemiology of infectious encephalitis causes in 2016. Médecine Et Maladies Infectieuses, 47(3), 221-235. https://doi.org/10.1016/j.medmal.2017.02.003

Brierley, L., Pedersen, A. B., \& Woolhouse, M. E. J. (2019). Tissue tropism and transmission ecology predict virulence of human RNA viruses. PLOS Biology, 17(11), e3000206. https://doi.org/10.1371/journal.pbio.3000206

Brinkworth, J. F., \& Alvarado, A. S. (2020). Cell-autonomous immunity and the pathogenmediated evolution of humans: Or how our prokaryotic and single-celled origins affect the human evolutionary story. The Quarterly Review of Biology, 95(3), 215-246.

https://doi.org/10.1086/710389

Brinkworth, J. F., \& Valizadegan, N. (2021). Sepsis and the evolution of human increased sensitivity to lipopolysaccharide. Evolutionary Anthropology: Issues, News, and Reviews, 30(2), 141-157. https://doi.org/10.1002/evan.21887

Brioschi, S., Wang, W.-L., Peng, V., Wang, M., Shchukina, I., Greenberg, Z. J., ... Colonna, M. (2021). Heterogeneity of meningeal B cells reveals a lymphopoietic niche at the CNS borders. Science, 373(6553), eabf9277. https://doi.org/10.1126/science.abf9277

Britton, P. N., Dale, R. C., Blyth, C. C., Clark, J. E., Crawford, N., Marshall, H., ... Jones, C. A. (2020). Causes and clinical features of childhood encephalitis: A multicenter, prospective cohort study. Clinical Infectious Diseases, 70(12), 2517-2526.

https://doi.org/10.1093/cid/ciz685 
Bromham, L., Skeels, A., Schneemann, H., Dinnage, R., \& Hua, X. (2021). There is little evidence that spicy food in hot countries is an adaptation to reducing infection risk. Nature Human Behaviour, 1-14. https://doi.org/10.1038/s41562-020-01039-8

Brown, D. E. (1991). Human universals. New York: McGraw-Hill.

Brutto, O. H. D., Arroyo, G., Brutto, V. J. D., Zambrano, M., \& García, H. H. (2017). On the relationship between calcified neurocysticercosis and epilepsy in an endemic village: A large-scale, computed tomography-based population study in rural ecuador. Epilepsia, 58(11), 1955-1961. https://doi.org/10.1111/epi.13892

Buck, J. C., Weinstein, S. B., \& Young, H. S. (2018). Ecological and evolutionary consequences of parasite avoidance. Trends in Ecology \& Evolution, 33(8), 619-632.

https://doi.org/10.1016/j.tree.2018.05.001

Buckner, W. (2022). A deceptive curing practice in hunter-gatherer societies. Humans, 2(3), 95-103.

Bugir, C. K., Peres, C. A., White, K. S., Montgomery, R. A., Griffin, A. S., Rippon, P., ... Hayward, M. W. (2021). Prey preferences of modern human hunter-gatherers. Food Webs, 26, e00183. https://doi.org/10.1016/j.fooweb.2020.e00183

Bull, J. J., \& Ebert, D. (2008). Invasion thresholds and the evolution of nonequilibrium virulence: Nonoptimal virulence. Evolutionary Applications, 1(1), 172-182.

https://doi.org/10.1111/j.1752-4571.2007.00003.x

Burgdorf, K. S., Trabjerg, B. B., Pedersen, M. G., Nissen, J., Banasik, K., Pedersen, O. B., ... Ullum, H. (2019). Large-scale study of Toxoplasma and Cytomegalovirus shows an association between infection and serious psychiatric disorders. Brain, Behavior, and Immunity, 79, 152-158. https://doi.org/10.1016/j.bbi.2019.01.026

Cain, M. D., Salimi, H., Diamond, M. S., \& Klein, R. S. (2019). Mechanisms of pathogen invasion into the central nervous system. Neuron, 103(5), 771-783.

https://doi.org/10.1016/j.neuron.2019.07.015

Calvignac-Spencer, S., Düx, A., Gogarten, J. F., Leendertz, F. H., \& Patrono, L. V. (2021). A great ape perspective on the origins and evolution of human viruses. In Advances in Virus Research (Vol. 110, pp. 1-26). https://doi.org/10.1016/bs.aivir.2021.06.001

Cámara-Leret, R., \& Bascompte, J. (2021). Language extinction triggers the loss of unique medicinal knowledge. Proceedings of the National Academy of Sciences, 118(24), e2103683118. https://doi.org/10.1073/pnas.2103683118

Carabin, H., Winkler, A. S., \& Dorny, P. (2017). Taenia solium cysticercosis and taeniosis: Achievements from the past 10 years and the way forward. PLOS Neglected Tropical Diseases, 11(4), e0005478. https://doi.org/10.1371/journal.pntd.0005478

Carbone, C., \& Gittleman, J. L. (2002). A common rule for the scaling of carnivore density. Science, 295(5563), 2273-2276. https://doi.org/10.1126/science.1067994 
Carlson, C. J., Albery, G. F., Merow, C., Trisos, C. H., Zipfel, C. M., Eskew, E. A., ... Bansal, S. (2022). Climate change increases cross-species viral transmission risk. Nature. https://doi.org/10.1038/s41586-022-04788-w

Choate, L. A., Barshad, G., McMahon, P. W., Said, I., Rice, E. J., Munn, P. R., ... Danko, C. G. (2021). Multiple stages of evolutionary change in anthrax toxin receptor expression in humans. Nature Communications, 12(1), 6590. https://doi.org/10.1038/s41467-02126854-Z

Cicka, D., \& Quave, C. (2019). Bioprospecting for pharmaceuticals: An overview and vision for future access and benefit sharing. In N. Joshee, S. A. Dhekney, \& P. Parajuli (Eds.), Medicinal plants (pp. 17-34). https://doi.org/10.1007/978-3-030-31269-5_2

Cipollini, M. L. (2000). Secondary metabolites of vertebrate-dispersed fruits: Evidence for adaptive functions. Revista Chilena de Historia Natural, 73(3).

https://doi.org/10.4067/S0716-078X2000000300006

Clements, T., Rice, T. F., Vamvakas, G., Barnett, S., Barnes, M., Donaldson, B., ... Holder, B. (2020). Update on transplacental transfer of IgG subclasses: Impact of maternal and fetal factors. Frontiers in Immunology, 11, 1920. https://doi.org/10.3389/fimmu.2020.01920

Clevers, H., \& Watt, F. M. (2018). Defining adult stem cells by function, not by phenotype. Annual Review of Biochemistry, 87(1), 1015-1027. https://doi.org/10.1146/annurevbiochem-062917-012341

Cooke, R., Gearty, W., Chapman, A. S. A., Dunic, J., Edgar, G. J., Lefcheck, J. S., ... Bates, A. E. (2022). Anthropogenic disruptions to longstanding patterns of trophic-size structure in vertebrates. Nature Ecology \& Evolution. https://doi.org/10.1038/s41559-022-01726-X

Cornelius Ruhs, E., Becker, D. J., Oakey, S. J., Ogunsina, O., Fenton, M. B., Simmons, N. B., ... Downs, C. J. (2021). Body size affects immune cell proportions in birds and non-volant mammals, but not bats. Journal of Experimental Biology, 224(13), jeb241109.

https://doi.org/10.1242/jeb.241109

Costantini, T. W., Chan, T. W., Cohen, O., Langness, S., Treadwell, S., Williams, E., ... Baird, A. (2019). Uniquely human CHRFAM7A gene increases the hematopoietic stem cell reservoir in mice and amplifies their inflammatory response. Proceedings of the National Academy of Sciences, 116(16), 7932-7940. https://doi.org/10.1073/pnas.1821853116

Couvreur, T. L. P., Dauby, G., Blach-Overgaard, A., Deblauwe, V., Dessein, S., Droissart, V., ... Sepulchre, P. (2021). Tectonics, climate and the diversification of the tropical African terrestrial flora and fauna. Biological Reviews, 96(1), 16-51.

https://doi.org/10.1111/brv.12644

Cressler, C. E., McLEOD, D. V., Rozins, C., Van Den Hoogen, J., \& Day, T. (2016). The adaptive evolution of virulence: A review of theoretical predictions and empirical tests. Parasitology, 143(7), 915-930. https://doi.org/10.1017/S003118201500092X 
Crittenden, A. N., \& Schnorr, S. L. (2017). Current views on hunter-gatherer nutrition and the evolution of the human diet. American Journal of Physical Anthropology, 162(S63), e23148. https://doi.org/10.1002/ajpa.23148

Cugurra, A., Mamuladze, T., Rustenhoven, J., Dykstra, T., Beroshvili, G., Greenberg, Z. J., ... Kipnis, J. (2021). Skull and vertebral bone marrow are myeloid cell reservoirs for the meninges and CNS parenchyma. Science, 373(6553), eabf7844.

https://doi.org/10.1126/science.abf7844

D'Arcy, M. S. (2019). Cell death: A review of the major forms of apoptosis, necrosis and autophagy. Cell Biology International, 43(6), 582-592. https://doi.org/10.1002/cbin.11137

Daegling, D. J., Judex, S., Ozcivici, E., Ravosa, M. J., Taylor, A. B., Grine, F. E., ... Ungar, P. S. (2013). Viewpoints: Feeding mechanics, diet, and dietary adaptations in early hominins. American Journal of Physical Anthropology, 151(3), 356-371.

https://doi.org/10.1002/ajpa.22281

Dalling, J. W., Davis, A. S., Arnold, A. E., Sarmiento, C., \& Zalamea, P.-C. (2020). Extending plant defense theory to seeds. Annual Review of Ecology, Evolution, and Systematics, 51(1), 123-141. https://doi.org/10.1146/annurev-ecolsys-012120-115156

de Roode, J. C., Lefevre, T., \& Hunter, M. D. (2013). Self-medication in animals. Science, 340(6129), 150-151. https://doi.org/10.1126/science.1235824

de Roode, J. C., \& Lefèvre, T. (2012). Behavioral immunity in insects. Insects, 3(3), 789-820. https://doi.org/10.3390/insects3030789

Degenhardt, L., Stockings, E., Patton, G., Hall, W. D., \& Lynskey, M. (2016). The increasing global health priority of substance use in young people. The Lancet Psychiatry, 3(3), 251264.

Demas, G. E., Chefer, V., Talan, M. I., \& Nelson, R. J. (1997). Metabolic costs of mounting an antigen-stimulated immune response in adult and aged C57BL/6J mice. American Journal of Physiology-Regulatory, Integrative and Comparative Physiology, 273(5), R1631-R1637.

Denoth-Lippuner, A., \& Jessberger, S. (2021). Formation and integration of new neurons in the adult hippocampus. Nature Reviews Neuroscience, 22(4), 223-236.

https://doi.org/10.1038/s41583-021-00433-z

Deretic, V., Saitoh, T., \& Akira, S. (2013). Autophagy in infection, inflammation and immunity. Nature Reviews Immunology, 13(10), 722-737.

https://doi.org/10.1038/nri3532

Desborough, M. J. R., \& Keeling, D. M. (2017). The aspirin story - from willow to wonder drug. British Journal of Haematology, 177(5), 674-683. https://doi.org/10.1111/bjh.14520

Dewey-Mattia, D., Manikonda, K., Hall, A. J., Wise, M. E., \& Crowe, S. J. (2018). Surveillance for foodborne disease outbreaks - United States, 2009-2015. MMWR Surveillance

Summaries, 67(10), 1-11. https://doi.org/10.15585/mmwr.ss6710a1 
Domínguez-Andrés, J., Kuijpers, Y., Bakker, O. B., Jaeger, M., Xu, C.-J., Van der Meer, J. W., ... Netea, M. G. (2021). Evolution of cytokine production capacity in ancient and modern European populations. eLife, 10, e64971. https://doi.org/10.7554/eLife.64971

Donnelly, R., White, A., \& Boots, M. (2015). The epidemiological feedbacks critical to the evolution of host immunity. Journal of Evolutionary Biology, 28(11), 2042-2053.

https://doi.org/10.1111/jeb.12719

Donnelly, R., White, A., \& Boots, M. (2017). Host lifespan and the evolution of resistance to multiple parasites. Journal of Evolutionary Biology, 30(3), 561-570.

https://doi.org/10.1111/jeb.13025

Downs, C. J., Dochtermann, N. A., Ball, R., Klasing, K. C., \& Martin, L. B. (2020). The effects of body mass on immune cell concentrations of mammals. The American Naturalist, 195(1), 107-114. https://doi.org/10.1086/706235

Downs, C. J., Schoenle, L. A., Goolsby, E. W., Oakey, S. J., Ball, R., Jiang, R. H. Y., ... Martin, L. B. (2020). Large mammals have more powerful antibacterial defenses than expected from their metabolic rates [Preprint]. https://doi.org/10.1101/2020.09.04.242107

Dubey, J. P. (2020). The history and life cycle of toxoplasma gondii. In Toxoplasma gondii (pp. 1-19). https://doi.org/10.1016/B978-0-12-815041-2.00001-3

Dudley, R. (2014). The drunken monkey. University of California Press.

Dunn, R. R., Amato, K. R., Archie, E. A., Arandjelovic, M., Crittenden, A. N., \& Nichols, L. M. (2020). The internal, external and extended microbiomes of hominins. Frontiers in Ecology and Evolution, 8. https://doi.org/10.3389/fevo.2020.00025

EFSA and ECDC. (2018). The european union summary report on trends and sources of zoonoses, zoonotic agents and food-borne outbreaks in 2017. EFSA Journal, 16(12), e05500. https://doi.org/10.2903/j.efsa.2018.5500

Eigenmann, D. E., Dürig, C., Jähne, E. A., Smieško, M., Culot, M., Gosselet, F., ... Oufir, M. (2016). In vitro bloodbrain barrier permeability predictions for GABAA receptor modulating piperine analogs. European Journal of Pharmaceutics and Biopharmaceutics, 103, 118-126. https://doi.org/10.1016/j.ejpb.2016.03.029

Enard, D., Cai, L., Gwennap, C., \& Petrov, D. A. (2016). Viruses are a dominant driver of protein adaptation in mammals. eLife, 25. https://doi.org/10.7554/eLife.12469

Enard, D., \& Petrov, D. A. (2020). Ancient RNA virus epidemics through the lens of recent adaptation in human genomes. Philosophical Transactions of the Royal Society B: Biological Sciences, 375(1812), 20190575. https://doi.org/10.1098/rstb.2019.0575

Engelhardt, B., Vajkoczy, P., \& Weller, R. O. (2017). The movers and shapers in immune privilege of the CNS. Nature Immunology, 18(2), 123-131. https://doi.org/10.1038/ni.3666 
Erickson, J. J. (2022). Pregnancy enables antibody protection against intracellular infection. Nature, 24.

Farrell, M. J., Elmasri, M., Stephens, D., \& Davies, T. J. (2020). Predicting missing links in global host-parasite networks [Preprint]. https://doi.org/10.1101/2020.02.25.965046

Feigin, V. L., Nichols, E., Alam, T., Bannick, M. S., Beghi, E., Blake, N., ... Vos, T. (2019). Global, regional, and national burden of neurological disorders, 1990-2016: A systematic analysis for the global burden of disease study 2016. The Lancet Neurology, 18(5), 459-480. https://doi.org/10.1016/S1474-4422(18)30499-X

Fessler, D. M., \& Navarrete, C. D. (2003). Meat is good to taboo: Dietary proscriptions as a product of the interaction of psychological mechanisms and social processes. Journal of Cognition and Culture, 3(1), 1-40.

Filippone, C., Betsem, E., Tortevoye, P., Cassar, O., Bassot, S., Froment, A., ... Gessain, A. (2015). A severe bite from a nonhuman primate is a major risk factor for HTLV-1 infection in hunters from central africa. Clinical Infectious Diseases, 60(11), 1667-1676.

https://doi.org/10.1093/cid/civ145

Fils, P. E. B., Nana, N. A., Betti, J. L., Njimbam, O. F., Womeni, S. T., Martin, E. Á., ... Funk, S. M. (2020). Ethnobotanical survey of wild edible plants used by Baka Pygmies in southeastern Cameroon. [Preprint]. https://doi.org/10.21203/rs.3.rs-42535/v1

Finch, C. E., \& Stanford, C. B. (2004). Meat-adaptive genes and the evolution of slower aging in humans. The Quarterly Review of Biology, 79(1), 3-50. https://doi.org/10.1086/381662

Fisher, C. R., Streicker, D. G., \& Schnell, M. J. (2018). The spread and evolution of rabies virus: Conquering new frontiers. Nature Reviews Microbiology, 16(4), 241-255.

https://doi.org/10.1038/nrmicro.2018.11

Food and Agriculture Organization. (2019). FAOSTAT.

http://www.fao.org/faostat/en/\#home.

Forrester, J. V., McMenamin, P. G., \& Dando, S. J. (2018). CNS infection and immune privilege. Nature Reviews Neuroscience, 19(11), 655-671. https://doi.org/10.1038/s41583018-0070-8

Franjic, D., Skarica, M., Ma, S., Arellano, J. I., Tebbenkamp, A. T. N., Choi, J., ... Sestan, N. (2022). Transcriptomic taxonomy and neurogenic trajectories of adult human, macaque, and pig hippocampal and entorhinal cells. Neuron, 110(3), 452-469.e14.

https://doi.org/10.1016/j.neuron.2021.10.036

French, J. C., \& Chamberlain, A. T. (2021). Demographic uniformitarianism: The theoretical basis of prehistoric demographic research and its cross-disciplinary challenges.

Philosophical Transactions of the Royal Society B: Biological Sciences, 376(1816), 20190720. https://doi.org/10.1098/rstb.2019.0720 
Gage, F. H. (2019). Adult neurogenesis in mammals. Science, 364(6443), 827-828.

https://doi.org/10.1126/science.aav6885

Galarza, J. A., Murphy, L., \& Mappes, J. (2021). Antibiotics accelerate growth at the expense of immunity. Proceedings of the Royal Society B: Biological Sciences, 288(1961), 20211819. https://doi.org/10.1098/rspb.2021.1819

Gallois, S., Heger, T., van Andel, T., Sonké, B., \& Henry, A. G. (2020). From bush mangoes to bouillon cubes: Wild plants and diet among the Baka, forager-horticulturalists from Southeast Cameroon. Economic Botany, 74(1), 46-58. https://doi.org/10.1007/s12231020-09489-x

Garcia, A. R., Blackwell, A. D., Trumble, B. C., Stieglitz, J., Kaplan, H., \& Gurven, M. D. (2020). Evidence for height and immune function trade-offs among preadolescents in a high pathogen population. Evolution, Medicine, and Public Health, 2020(1), 86-99. https://doi.org/10.1093/emph/eoaa017

García, H. H., Gonzalez, A. E., Evans, C. A. W., \& Gilman, R. H. (2003). Taenia solium cysticercosis. Lancet, 362(9383), 547-556. https://doi.org/10.1016/S01406736(03)14117-7

Geirsdottir, L., David, E., Keren-Shaul, H., Weiner, A., Bohlen, S. C., Neuber, J., ... Prinz, M. (2019). Cross-species single-cell analysis reveals divergence of the primate microglia program. Cell, 179(7), 1609-1622.e16. https://doi.org/10.1016/j.cell.2019.11.010

Gemmell, M. A. (1958). Arecoline hydrobromide as a taentafuge in dogs, with special reference to its use in controlling hydatid disease. Australian Veterinary Journal, 34(7), 207-212. https://doi.org/10.1111/j.1751-0813.1958.tb05879.x

Geoghegan, J. L., \& Holmes, E. C. (2018). The phylogenomics of evolving virus virulence. Nature Reviews Genetics, 19(12), 756-769. https://doi.org/10.1038/s41576-018-0055-5

Geoghegan, J. L., Senior, A. M., Di Giallonardo, F., \& Holmes, E. C. (2016). Virological factors that increase the transmissibility of emerging human viruses. Proceedings of the National Academy of Sciences, 113(15), 4170-4175. https://doi.org/10.1073/pnas.1521582113

González-Teuber, M., \& Heil, M. (2009). Nectar chemistry is tailored for both attraction of mutualists and protection from exploiters. Plant Signaling \& Behavior, 4(9), 809-813. https://doi.org/10.4161/psb.4.9.9393

Grabowski, M., Hatala, K. G., Jungers, W. L., \& Richmond, B. G. (2015). Body mass estimates of hominin fossils and the evolution of human body size. Journal of Human Evolution, 85, 75-93. https://doi.org/10.1016/j.jhevol.2015.05.005

Gripper, L. B., \& Welburn, S. C. (2017). Neurocysticercosis infection and disease-a review. Acta Tropica, 166, 218-224. https://doi.org/10.1016/j.actatropica.2016.11.015

Guagliardo, S. A. J., Doshi, R. H., Reynolds, M. G., Dzabatou-Babeaux, A., Ndakala, N., Moses, C., ... Petersen, B. W. (2019). Do monkeypox exposures vary by ethnicity? Comparison of 
aka and bantu suspected monkeypox cases. The American Journal of Tropical Medicine and Hygiene, 102(1), 202-205. https://doi.org/10.4269/ajtmh.19-0457

Guan, Y., Zheng, B. J., He, Y. Q., Liu, X. L., Zhuang, Z. X., Cheung, C. L., ... Poon, L. L. M. (2003). Isolation and characterization of viruses related to the SARS coronavirus from animals in southern China. Science, 302(5643), 276-278. https://doi.org/10.1126/science.1087139

Gupta, P. C., \& Warnakulasuriya, S. (2002). Global epidemiology of areca nut usage. Addiction Biology, 7(1), 77-83.

Guth, S., Visher, E., Boots, M., \& Brook, C. E. (2019). Host phylogenetic distance drives trends in virus virulence and transmissibility across the animal-human interface. Philosophical Transactions of the Royal Society B: Biological Sciences, 374(1782), 20190296. https://doi.org/10.1098/rstb.2019.0296

Hagen, E. H., Roulette, C. J., \& Sullivan, R. J. (2013). Explaining human recreational use of "pesticides": The neurotoxin regulation model of substance use vs. The hijack model and implications for age and sex differences in drug consumption. Frontiers in Psychiatry, 4. https://doi.org/10.3389/fpsyt.2013.00142

Hagen, E. H., \& Sullivan, R. J. (2018). The evolutionary significance of drug toxicity over reward. In H. Pickard \& S. H. Ahmed (Eds.), The routledge handbook of philosophy and science of addiction (First, pp. 102-119). https://doi.org/10.4324/9781315689197-10

Hagen, E. H., Sullivan, R. J., Schmidt, R., Morris, G., Kempter, R., \& Hammerstein, P. (2009). Ecology and neurobiology of toxin avoidance and the paradox of drug reward. Neuroscience, 160(1), 69-84. https://doi.org/10.1016/j.neuroscience.2009.01.077

Hagen, E. H., \& Tushingham, S. (2019). The prehistory of psychoactive drug use. In T. B. Henley, M. J. Rossano, \& E. P. Kardas (Eds.), Handbook of cognitive archaeology (pp. 471498). https://doi.org/10.4324/9780429488818-25

Hamilton, R., Siva-Jothy, M., \& Boots, M. (2008). Two arms are better than one: Parasite variation leads to combined inducible and constitutive innate immune responses.

Proceedings of the Royal Society B: Biological Sciences, 275(1637), 937-945. https://doi.org/10.1098/rspb.2007.1574

Hampson, K., Coudeville, L., Lembo, T., Sambo, M., Kieffer, A., Attlan, M., ... Prevention, on behalf of the G. A. for R. C. P. for R. (2015). Estimating the global burden of endemic canine rabies. PLOS Neglected Tropical Diseases, 9(4), e0003709.

https://doi.org/10.1371/journal.pntd.0003709

Han, B. A., Castellanos, A. A., Schmidt, J. P., Fischhoff, I. R., \& Drake, J. M. (2021). The ecology of zoonotic parasites in the Carnivora. Trends in Parasitology, S147149222100204X. https://doi.org/10.1016/j.pt.2021.08.006

Han, B. A., Kramer, A. M., \& Drake, J. M. (2016). Global patterns of zoonotic disease in mammals. Trends in Parasitology, 32(7), 565-577.

https://doi.org/10.1016/j.pt.2016.04.007 
Han, B. A., Park, A. W., Jolles, A. E., \& Altizer, S. (2015). Infectious disease transmission and behavioural allometry in wild mammals. Journal of Animal Ecology, 84(3), 637-646.

https://doi.org/10.1111/1365-2656.12336

Hardy, K. (2019). Paleomedicine and the use of plant secondary compounds in the paleolithic and early neolithic. Evolutionary Anthropology, 28(2), 60-71.

https://doi.org/10.1002/evan.21763

Hardy, K., Buckley, S., Collins, M. J., Estalrrich, A., Brothwell, D., Copeland, L., ... Rosas, A. (2012). Neanderthal medics? Evidence for food, cooking, and medicinal plants entrapped in dental calculus. Naturwissenschaften, 99(8), 617-626. https://doi.org/10.1007/s00114012-0942-0

Harkins, K. M., \& Stone, A. C. (2015). Ancient pathogen genomics: Insights into timing and adaptation. Journal of Human Evolution, 79, 137-149.

https://doi.org/10.1016/j.jhevol.2014.11.002

Harris, E. V., Roode, J. C. de, \& Gerardo, N. M. (2019). Dietmicrobiomedisease: Investigating diet's influence on infectious disease resistance through alteration of the gut microbiome. PLOS Pathogens, 15(10), e1007891. https://doi.org/10.1371/journal.ppat.1007891

Harris, M. (1997). The abominable pig. In C. Counihan \& P. Van Esterik (Eds.), Food and culture: A reader (pp. 67-79). Routledge.

Harvey, A. L., Edrada-Ebel, R., \& Quinn, R. J. (2015). The re-emergence of natural products for drug discovery in the genomics era. Nature Reviews Drug Discovery, 14(2), 111-129. https://doi.org/10.1038/nrd4510

Hattori, S. (2020). Diversity and similarity relating to plant knowledge among baka huntergatherers in southeast cameroon. The Center for African Area Studies, Kyoto University.

Hawash, M. B. F., Sanz-Remón, J., Grenier, J.-C., Kohn, J., Yotova, V., Johnson, Z., ... Barreiro, L. B. (2021). Primate innate immune responses to bacterial and viral pathogens reveals an evolutionary trade-off between strength and specificity. Proceedings of the National Academy of Sciences, 118(13), e2015855118. https://doi.org/10.1073/pnas.2015855118

Hayakawa, T., Angata, T., Amanda, L., Lewis, Mikkelsen, T. S., Varki, N. M., \& Varki, A. (2005). A human-specific gene in microglia. Science, 1693.

He, D.-D., Lu, Y., Gittelman, R., Jin, Y., Ling, F., \& Joshua, A. (2016). Positive selection of the TRIM family regulatory region in primate genomes. Proceedings of the Royal Society $B$ : Biological Sciences, 283(1840), 20161602. https://doi.org/10.1098/rspb.2016.1602

Henrich, J., \& McElreath, R. (2003). The evolution of cultural evolution. Evolutionary Anthropology, 12(3), 123-135.

Hlubik, S., Cutts, R., Braun, D. R., Berna, F., Feibel, C. S., \& Harris, J. W. K. (2019). Hominin fire use in the okote member at koobi fora, kenya: New evidence for the old debate. Journal of Human Evolution, 133, 214-229. https://doi.org/10.1016/j.jhevol.2019.01.010 
Hoberg, E. P. (2006). Phylogeny of Taenia: Species definitions and origins of human parasites. Parasitology International, 55, S23-S30.

https://doi.org/10.1016/j.parint.2005.11.049

Hoberg, E. P., Alkire, N. L., Queiroz, A. D., \& Jones, A. (2001). Out of africa: Origins of the Taenia tapeworms in humans. Proceedings of the Royal Society of London. Series B: Biological Sciences, 268(1469), 781-787. https://doi.org/10.1098/rspb.2000.1579

Hockings, K. J., Ito, M., \& Yamakoshi, G. (2019). The importance of raffia palm wine to coexisting humans and chimpanzees. In K. J. Hockings \& R. I. M. Dunbar (Eds.), Alcohol and humans: A long and social affair (p. 45). Oxford University Press.

Hoffmann, C., Zimmermann, F., Biek, R., Kuehl, H., Nowak, K., Mundry, R., ... Leendertz, F. H. (2017). Persistent anthrax as a major driver of wildlife mortality in a tropical rainforest. Nature, 548(7665), 82-86. https://doi.org/10.1038/nature23309

Hong, Z. (2022). Ghost, divination, and magic among the Nuosu: An ethnographic examination from cognitive and cultural evolutionary perspectives. Human Nature.

Houldcroft, C. J., \& Underdown, S. J. (2016). Neanderthal genomics suggests a Pleistocene time frame for the first epidemiologic transition. American Journal of Physical Anthropology, 160(3), 379-388. https://doi.org/10.1002/ajpa.22985

Huebbe, P., \& Rimbach, G. (2017). Evolution of human apolipoprotein e (APOE) isoforms: Gene structure, protein function and interaction with dietary factors. Ageing Research Reviews, 37, 146-161. https://doi.org/10.1016/j.arr.2017.06.002

Huffman, M. A. (1997). Current evidence for self-medication in primates: A multidisciplinary perspective. American Journal of Physical Anthropology, 104(s 25), 171200.

Huffman, M. A. (2003). Animal self-medication and ethno-medicine: Exploration and exploitation of the medicinal properties of plants. Proceedings of the Nutrition Society, 62(2), 371-381. https://doi.org/10.1079/PNS2003257

Huffman, M. A. (2017). Primate self-medication, passive prevention and active treatment - a brief review. International Journal of Multidisciplinary Studies, 3(2), 1.

https://doi.org/10.4038/ijms.v3i2.1

Hurtado, M. (2021). HBES2021 Plenary Address. Retrieved from osf.io/725cz

Iadecola, C. (2017). The neurovascular unit coming of age: A journey through neurovascular coupling in health and disease. Neuron, 96(1), 17-42. https://doi.org/10.1016/j.neuron.2017.07.030

Jin, Y., Gittelman, R. M., Lu, Y., Liu, X., Li, M. D., Ling, F., \& Akey, J. M. (2018). Evolution of DNAase i hypersensitive sites in MHC regulatory regions of primates. Genetics, 209(2), 579589. https://doi.org/10.1534/genetics.118.301028 
Johns, T. (1990). With bitter herbs they shall eat it: Chemical ecology and the origins of human diet and medicine. University of Arizona Press.

Johnson, S. K., \& Johnson, P. T. J. (2021). Toxoplasmosis: Recent advances in understanding the link between infection and host behavior. Annual Review of Animal Biosciences, 9(1), 249-264. https://doi.org/10.1146/annurev-animal-081720-111125

Jones, K. E., Patel, N. G., Levy, M. A., Storeygard, A., Balk, D., Gittleman, J. L., \& Daszak, P. (2008). Global trends in emerging infectious diseases. Nature, 451(7181), 990-993. https://doi.org/10.1038/nature06536

Kamal, S., Rashid, A. M., Bakar, M., \& Ahad, M. (2011). Anthrax: An update. Asian Pacific Journal of Tropical Biomedicine, 1(6), 496-501. https://doi.org/10.1016/S22211691(11)60109-3

Kamiya, T., O’Dwyer, K., Nakagawa, S., \& Poulin, R. (2014). What determines species richness of parasitic organisms? A meta-analysis across animal, plant and fungal hosts. Biological Reviews, 89(1), 123-134. https://doi.org/10.1111/brv.12046

Kaplan, H., Hill, K., Lancaster, J., \& Hurtado, A. M. (2000). A theory of human life history evolution: Diet, intelligence, and longevity. Evolutionary Anthropology, 9(4), 156-185.

Karesh, W. B., Dobson, A., Lloyd-Smith, J. O., Lubroth, J., Dixon, M. A., Bennett, M., ... Heymann, D. L. (2012). Ecology of zoonoses: Natural and unnatural histories. The Lancet, 380(9857), 1936-1945. https://doi.org/10.1016/S0140-6736(12)61678-X

Kelley, A. E., \& Berridge, K. C. (2002). The neuroscience of natural rewards: Relevance to addictive drugs. Journal of Neuroscience, 22(9), 3306-3311.

Khan, N., de Manuel, M., Peyregne, S., Do, R., Prufer, K., Marques-Bonet, T., ... Varki, A. (2020). Multiple genomic events altering hominin SIGLEC biology and innate immunity predated the common ancestor of humans and archaic hominins. Genome Biology and Evolution, 12(7), 1040-1050. https://doi.org/10.1093/gbe/evaa125

Khrameeva, E., Kurochkin, I., Han, D., Guijarro, P., Kanton, S., Santel, M., et al.others. (2020). Single-cell-resolution transcriptome map of human, chimpanzee, bonobo, and macaque brains. Genome Research, 30(5), 776-789.

Kieft, T. L., \& Simmons, K. A. (2015). Allometry of animal-microbe interactions and global census of animal-associated microbes. Proceedings of the Royal Society B: Biological Sciences, 282(1810), 20150702. https://doi.org/10.1098/rspb.2015.0702

Kim, J. K., Kim, K. H., Shin, Y. C., Jang, B.-H., \& Ko, S.-G. (2020). Utilization of traditional medicine in primary health care in low- and middle-income countries: A systematic review. Health Policy and Planning, 35(8), 1070-1083. https://doi.org/10.1093/heapol/czaa022

Kim, J.-S., Yoon, S.-J., Park, Y.-J., Kim, S.-Y., \& Ryu, C.-M. (2020). Crossing the kingdom border: Human diseases caused by plant pathogens. Environmental Microbiology, 22(7), 2485-2495. https://doi.org/10.1111/1462-2920.15028 
Klein, R. S., Garber, C., \& Howard, N. (2017). Infectious immunity in the central nervous system and brain function. Nature Immunology, 18(2), 132-141.

https://doi.org/10.1038/ni.3656

Kokko, H., Ranta, E., Ruxton, G., \& Lundberg, P. (2002). Sexually transmitted disease and the evolution of mating systems. Evolution, 56(6), 1091-1100. https://doi.org/10.1111/j.00143820.2002.tb01423.x

Koren, T., Yifa, R., Amer, M., Krot, M., Boshnak, N., Ben-Shaanan, T. L., ... Rolls, A. (2021). Insular cortex neurons encode and retrieve specific immune responses. Cell, S009286742101223X. https://doi.org/10.1016/j.cell.2021.10.013

Krief, S., Daujeard, C., Moncel, M.-H., Lamon, N., \& Reynolds, V. (2015). Flavouring food: The contribution of chimpanzee behaviour to the understanding of neanderthal calculus composition and plant use in neanderthal diets. Antiquity, 89(344), 464-471.

https://doi.org/10.15184/aqy.2014.7

Kurpiers, L. A., Schulte-Herbrüggen, B., Ejotre, I., \& Reeder, D. M. (2016). Bushmeat and emerging infectious diseases: Lessons from africa. In F. M. Angelici (Ed.), Problematic wildlife: A cross-disciplinary approach (pp. 507-551). https://doi.org/10.1007/978-3-31922246-2_24

Lacruz, R. S., Stringer, C. B., Kimbel, W. H., Wood, B., Harvati, K., O’Higgins, P., ... Arsuaga, J.L. (2019). The evolutionary history of the human face. Nature Ecology \& Evolution, 3(5), 726-736. https://doi.org/10.1038/s41559-019-0865-7

Lederman, E. R., Reynolds, M. G., Karem, K., Mombouli, J.-V., Moundeli, O., Regnery, R., ... Learned-Orozco, L. A. (2007). Prevalence of antibodies against orthopoxviruses among residents of likouala region, republic of congo: Evidence for monkeypox virus exposure. The American Journal of Tropical Medicine and Hygiene, 77(6), 1150-1156.

https://doi.org/10.4269/ajtmh.2007.77.1150

Ledger, M. L., \& Mitchell, P. D. (2019). Tracing zoonotic parasite infections throughout human evolution. International Journal of Osteoarchaeology, $n / a(\mathrm{n} / \mathrm{a})$.

https://doi.org/10.1002/oa.2786

Lemaître, J.-F., Ronget, V., Tidière, M., Allainé, D., Berger, V., Cohas, A., ... Gaillard, J.-M. (2020). Sex differences in adult lifespan and aging rates of mortality across wild mammals. Proceedings of the National Academy of Sciences, 117(15), 8546-8553. https://doi.org/10.1073/pnas.1911999117

Li, D., \& Gaquerel, E. (2021). Next-generation mass spectrometry metabolomics revives the functional analysis of plant metabolic diversity. Annual Review of Plant Biology, 72(1), 867891. https://doi.org/10.1146/annurev-arplant-071720-114836

Li, T., Ito, A., Chen, X., Long, C., Okamoto, M., Raoul, F., ... Craig, P. S. (2012). Usefulness of pumpkin seeds combined with areca nut extract in community-based treatment of human 
taeniasis in northwest Sichuan Province, China. Acta Tropica, 124(2), 152-157.

https://doi.org/10.1016/j.actatropica.2012.08.002

Lightner, A. D., Heckelsmiller, C., \& Hagen, E. H. (2021a). Ethnomedical specialists and their supernatural theories of disease. Review of Philosophy and Psychology.

Lightner, A. D., Heckelsmiller, C., \& Hagen, E. H. (2021b). Ethnoscientific expertise and knowledge specialisation in 55 traditional cultures. Evolutionary Human Sciences, 1-52. https://doi.org/10.1017/ehs.2021.31

Linz, B., Balloux, F., Moodley, Y., Manica, A., Liu, H., Roumagnac, P., ... Achtman, M. (2007). An African origin for the intimate association between humans and Helicobacter pylori. Nature, 445(7130), 915-918. https://doi.org/10.1038/nature05562

Liu, S.-Y., Han, X.-C., Sun, J., Chen, G.-X., Zhou, X.-Y., \& Zhang, G.-X. (2016). Alcohol intake and Helicobacter pylori infection: A doseresponse meta-analysis of observational studies. Infectious Diseases, 48(4), 303-309. https://doi.org/10.3109/23744235.2015.1113556

Lucassen, P. J., Fitzsimons, C. P., Salta, E., \& Maletic-Savatic, M. (2020). Adult neurogenesis, human after all (again): Classic, optimized, and future approaches. Behavioural Brain Research, 381, 112458. https://doi.org/10.1016/j.bbr.2019.112458

Lupien, R. L., Russell, J. M., Grove, M., Beck, C. C., Feibel, C. S., \& Cohen, A. S. (2020). Abrupt climate change and its influences on hominin evolution during the early Pleistocene in the Turkana Basin, Kenya. Quaternary Science Reviews, 245, 106531.

https://doi.org/10.1016/j.quascirev.2020.106531

Lupien, R. L., Russell, J. M., Subramanian, A., Kinyanjui, R., Beverly, E. J., Uno, K. T., ... Potts, R. (2021). Eastern African environmental variation and its role in the evolution and cultural change of Homo over the last 1 million years. Journal of Human Evolution, 157, 103028. https://doi.org/10.1016/j.jhevol.2021.103028

Macdonald, D. W., Campbell, L. A. D., Kamler, J. F., Marino, J., Werhahn, G., \& Sillero-Zubiri, C. (2019). Monogamy: Cause, consequence, or corollary of success in wild canids? Frontiers in Ecology and Evolution, 7, 341. https://doi.org/10.3389/fevo.2019.00341

MacDonald, K., Scherjon, F., Veen, E. van, Vaesen, K., \& Roebroeks, W. (2021). Middle Pleistocene fire use: The first signal of widespread cultural diffusion in human evolution. Proceedings of the National Academy of Sciences, 118(31).

https://doi.org/10.1073/pnas.2101108118

Malmberg, J. L., White, L. A., \& VandeWoude, S. (2021). Bioaccumulation of pathogen exposure in top predators. Trends in Ecology \& Evolution, 36(5), 411-420.

https://doi.org/10.1016/j.tree.2021.01.008

Martin, L. B., Hawley, D. M., \& Ardia, D. R. (2011). An introduction to ecological immunology. Functional Ecology, 25(1), 1-4. https://doi.org/10.1111/j.13652435.2010.01820.x 
Martinsen, T. C., Bergh, K., \& Waldum, H. L. (2005). Gastric juice: A barrier against infectious diseases. Basic \& Clinical Pharmacology \& Toxicology, 96(2), 94-102. https://doi.org/10.1111/j.1742-7843.2005.pto960202.x

Matta, S. K., Rinkenberger, N., Dunay, I. R., \& Sibley, L. D. (2021). Toxoplasma gondii infection and its implications within the central nervous system. Nature Reviews Microbiology, 19(7), 467-480. https://doi.org/10.1038/s41579-021-00518-7

McCauley, B., Collard, M., \& Sandgathe, D. (2020). A cross-cultural survey of on-site fire use by recent hunter-gatherers: Implications for research on palaeolithic pyrotechnology. Journal of Paleolithic Archaeology, 3(4), 566-584. https://doi.org/10.1007/s41982-02000052-7

McDade, T. W., Georgiev, A. V., \& Kuzawa, C. W. (2016). Trade-offs between acquired and innate immune defenses in humans. Evolution, Medicine, and Public Health, 2016(1), 1-16. https://doi.org/10.1093/emph/eov033

McDade, T. W., Reyes-Garcia, V., Blackinton, P., Tanner, S., Huanca, T., \& Leonard, W. R. (2007). Ethnobotanical knowledge is associated with indices of child health in the Bolivian Amazon. Proceedings of the National Academy of Sciences, 104(15), 6134-6139.

https://doi.org/10.1073/pnas.0609123104

McHenry, H. M. (1992). Body size and proportions in early hominids. American Journal of Physical Anthropology, 87(4), 407-431. https://doi.org/10.1002/ajpa.1330870404

McLeod, D. V., \& Day, T. (2014). Sexually transmitted infection and the evolution of serial monogamy. Proceedings of the Royal Society B: Biological Sciences, 281(1796), 20141726. https://doi.org/10.1098/rspb.2014.1726

Medema, M. H., de Rond, T., \& Moore, B. S. (2021). Mining genomes to illuminate the specialized chemistry of life. Nature Reviews Genetics, 22(9), 553-571.

https://doi.org/10.1038/s41576-021-00363-7

Mehrtash, H., Duncan, K., Parascandola, M., David, A., Gritz, E. R., Gupta, P. C., ... Trimble, E. L. (2017). Defining a global research and policy agenda for betel quid and areca nut. The Lancet Oncology, 18(12), e767-e775. https://doi.org/10.1016/S1470-2045(17)30460-6

Milbank, C., \& Vira, B. (2022). Wildmeat consumption and zoonotic spillover:

Contextualising disease emergence and policy responses. The Lancet Planetary Health, 6(5), e439-e448. https://doi.org/10.1016/S2542-5196(22)00064-X

Miller, I. F., Churchill, S. E., \& Nunn, C. L. (2019). Speeding in the slow lane: Phylogenetic comparative analyses reveal that not all human life history traits are exceptional. Journal of Human Evolution, 130, 36-44. https://doi.org/10.1016/j.jhevol.2018.12.007

Miller, K. D., Schnell, M. J., \& Rall, G. F. (2016). Keeping it in check: Chronic viral infection and antiviral immunity in the brain. Nature Reviews Neuroscience, 17(12), 766-776.

https://doi.org/10.1038/nrn.2016.140 
Mitchell, P. D. (2013). The origins of human parasites: Exploring the evidence for endoparasitism throughout human evolution. International Journal of Paleopathology, 3(3), 191-198. https://doi.org/10.1016/j.ijpp.2013.08.003

Moeller, A. H., Li, Y., Mpoudi Ngole, E., Ahuka-Mundeke, S., Lonsdorf, E. V., Pusey, A. E., ... Ochman, H. (2014). Rapid changes in the gut microbiome during human evolution. Proceedings of the National Academy of Sciences, 111(46), 16431-16435. https://doi.org/10.1073/pnas.1419136111

Molan, A., Nosaka, K., Hunter, M., \& Wang, W. (2019). Global status of toxoplasma gondii infection: Systematic review and prevalence snapshots. Tropical Biomedicine, 36(4), 898925.

Moleón, M., Martínez-Carrasco, C., Muellerklein, O. C., Getz, W. M., Muñoz-Lozano, C., \& Sánchez-Zapata, J. A. (2017). Carnivore carcasses are avoided by carnivores. Journal of Animal Ecology, 86(5), 1179-1191. https://doi.org/10.1111/1365-2656.12714

Mollentze, N., \& Streicker, D. G. (2020). Viral zoonotic risk is homogenous among taxonomic orders of mammalian and avian reservoir hosts. Proceedings of the National Academy of Sciences, 117(17), 9423-9430. https://doi.org/10.1073/pnas.1919176117

Montazeri, M., Mikaeili Galeh, T., Moosazadeh, M., Sarvi, S., Dodangeh, S., Javidnia, J., ... Daryani, A. (2020). The global serological prevalence of toxoplasma gondii in felids during the last five decades (1967-2017): A systematic review and meta-analysis. Parasites \& Vectors, 13(1), 82. https://doi.org/10.1186/s13071-020-3954-1

Moodley, Y., Linz, B., Bond, R. P., Nieuwoudt, M., Soodyall, H., Schlebusch, C. M., ... Achtman, M. (2012). Age of the association between Helicobacter pylori and man. PLOS Pathogens, 8(5), e1002693. https://doi.org/10.1371/journal.ppat.1002693

Moon, J. M., Aronoff, D. M., Capra, J. A., Abbot, P., \& Rokas, A. (2018). Examination of signatures of recent positive selection on genes involved in human sialic acid biology. G3 Genes/Genomes/Genetics, 8(4), 1315-1325. https://doi.org/10.1534/g3.118.200035

Moreno-Jiménez, E. P., Flor-García, M., Terreros-Roncal, J., Rábano, A., Cafini, F., PallasBazarra, N., ... Llorens-Martín, M. (2019). Adult hippocampal neurogenesis is abundant in neurologically healthy subjects and drops sharply in patients with alzheimer's disease. Nature Medicine, 25(4), 554-560. https://doi.org/10.1038/s41591-019-0375-9

Moyano, L. M., O’Neal, S. E., Ayvar, V., Gonzalvez, G., Gamboa, R., Vilchez, P., ... Peru, T. C. W. G. in. (2016). High prevalence of asymptomatic neurocysticercosis in an endemic rural community in peru. PLOS Neglected Tropical Diseases, 10(12), e0005130.

https://doi.org/10.1371/journal.pntd.0005130

Muehlenbein, M. P., Hirschtick, J. L., Bonner, J. Z., \& Swartz, A. M. (2010). Toward quantifying the usage costs of human immunity: Altered metabolic rates and hormone levels during acute immune activation in men. American Journal of Human Biology, 22(4), 546-556. 
Mulangu, S., Borchert, M., Paweska, J., Tshomba, A., Afounde, A., Kulidri, A., ... Van der Stuyft, P. (2016). High prevalence of IgG antibodies to ebola virus in the efé pygmy population in the watsa region, democratic republic of the congo. BMC Infectious Diseases, 16(1), 263. https://doi.org/10.1186/s12879-016-1607-y

Munera López, J., Ganuza, A., Bogado, S. S., Muñoz, D., Ruiz, D. M., Sullivan Jr, W. J., ... Angel, S. 0. (2019). Evaluation of ATM kinase inhibitor KU-55933 as potential anti-Toxoplasma gondii agent. Frontiers in Cellular and Infection Microbiology, 9, 26.

Neco, L. C., Abelson, E. S., Brown, A., Natterson-Horowitz, B., \& Blumstein, D. T. (2019). The evolution of self-medication behaviour in mammals. Biological Journal of the Linnean Society, blz117. https://doi.org/10.1093/biolinnean/blz117

Netea, M. G., Joosten, L. A. B., Latz, E., Mills, K. H. G., Natoli, G., Stunnenberg, H. G., ... Xavier, R. J. (2016). Trained immunity: A program of innate immune memory in health and disease. Science, 352(6284), aaf1098-aaf1098. https://doi.org/10.1126/science.aaf1098

Netea, M. G., Schlitzer, A., Placek, K., Joosten, L. A. B., \& Schultze, J. L. (2019). Innate and adaptive immune memory: An evolutionary continuum in the host's response to pathogens. Cell Host \& Microbe, 25(1), 13-26. https://doi.org/10.1016/j.chom.2018.12.006

Newman, D. J., \& Cragg, G. M. (2020). Natural products as sources of new drugs over the nearly four decades from 01/1981 to 09/2019. Journal of Natural Products, 83(3), 770803. https://doi.org/10.1021/acs.jnatprod.9b01285

Nobel Prize. (2015). The Nobel Prize in Physiology or Medicine 2015. https://www.nobelprize.org/prizes/medicine/2015/tu/facts/.

Nonthakaew, A., Matan, N., Aewsiri, T., \& Matan, N. (2015). Caffeine in foods and its antimicrobial activity. International Food Research Journal, 22(1), 9-14.

Nunn, C. L. (2002). A comparative study of leukocyte counts and disease risk in primates. Evolution, 56(1), 177-190. https://doi.org/10.1111/j.0014-3820.2002.tb00859.x

Nunn, C. L., Gittleman, J. L., \& Antonovics, J. (2003). A comparative study of white blood cell counts and disease risk in carnivores. Proceedings of the Royal Society of London. Series B: Biological Sciences, 270(1513), 347-356. https://doi.org/10.1098/rspb.2002.2249

Nystrand, M., \& Dowling, D. K. (2020). Effects of immune challenge on expression of lifehistory and immune trait expression in sexually reproducing metazoansa meta-analysis. BMC Biology, 18(1), 135. https://doi.org/10.1186/s12915-020-00856-7

Okerblom, J. J., Schwarz, F., Olson, J., Fletes, W., Ali, S. R., Martin, P. T., ... Varki, A. (2017). Loss of CMAH during human evolution primed the monocyte-macrophage lineage toward a more inflammatory and phagocytic state. The Journal of Immunology, 198(6), 2366-2373. https://doi.org/10.4049/jimmunol.1601471 
Okerblom, J., \& Varki, A. (2017). Biochemical, cellular, physiological, and pathological consequences of human loss of $N$-glycolylneuraminic acid. ChemBioChem, 18(13), 11551171. https://doi.org/10.1002/cbic.201700077

Olival, K. J., Hosseini, P. R., Zambrana-Torrelio, C., Ross, N., Bogich, T. L., \& Daszak, P. (2017). Host and viral traits predict zoonotic spillover from mammals. Nature, 546(7660), 646650. https://doi.org/10.1038/nature22975

Oppenheim, R. W. (2019). Adult hippocampal neurogenesis in mammals (and humans): The death of a central dogma in neuroscience and its replacement by a new dogma. Developmental Neurobiology, 79(3), 268-280. https://doi.org/10.1002/dneu.22674

Paludan, S. R., Pradeu, T., Masters, S. L., \& Mogensen, T. H. (2021). Constitutive immune mechanisms: Mediators of host defence and immune regulation. Nature Reviews Immunology, 21(3), 137-150. https://doi.org/10.1038/s41577-020-0391-5

Pardridge, W. M. (2012). Drug transport across the blood-brain barrier. Journal of Cerebral Blood Flow \& Metabolism, 32(11), 1959-1972. https://doi.org/10.1038/jcbfm.2012.126

Pedersen, A. B., Altizer, S., Poss, M., Cunningham, A. A., \& Nunn, C. L. (2005). Patterns of host specificity and transmission among parasites of wild primates. International Journal for Parasitology, 35(6), 647-657. https://doi.org/10.1016/j.ijpara.2005.01.005

Peros, C. S., Dasgupta, R., Kumar, P., \& Johnson, B. A. (2021). Bushmeat, wet markets, and the risks of pandemics: Exploring the nexus through systematic review of scientific disclosures. Environmental Science \& Policy, 124, 1-11. https://doi.org/10.1016/j.envsci.2021.05.025

Poirotte, C., Kappeler, P. M., Ngoubangoye, B., Bourgeois, S., Moussodji, M., \& Charpentier, M. J. E. (2016). Morbid attraction to leopard urine in toxoplasma-infected chimpanzees. Current Biology, 26(3), R98-R99. https://doi.org/10.1016/j.cub.2015.12.020

Pollan, M. (2002). The botany of desire: A plant's-eye view of the world. Random House.

Pontzer, H., \& Wood, B. M. (2021). Effects of evolution, ecology, and economy on human diet: Insights from hunter-gatherers and other small-scale societies. Annual Review of Nutrition, 41(1), annurev-nutr-111120-105520. https://doi.org/10.1146/annurev-nutr111120-105520

Porras, G., Chassagne, F., Lyles, J. T., Marquez, L., Dettweiler, M., Salam, A. M., ... Quave, C. L. (2021). Ethnobotany and the role of plant natural products in antibiotic drug discovery. Chemical Reviews, 121(6), 3495-3560. https://doi.org/10.1021/acs.chemrev.0c00922

Potts, R. (2012). Evolution and environmental change in early human prehistory. Annual Review of Anthropology, 41(1), 151-167. https://doi.org/10.1146/annurev-anthro092611-145754

Püschel, H. P., Bertrand, O. C., O’Reilly, J. E., Bobe, R., \& Püschel, T. A. (2021). Divergencetime estimates for hominins provide insight into encephalization and body mass trends in 
human evolution. Nature Ecology \& Evolution, 5(6), 808-819.

https://doi.org/10.1038/s41559-021-01431-1

Pushpangadan, P., George, V., T P, I., \& Chithra, M. (2018). Biodiversity, bioprospecting, traditional knowledge, sustainable development and value added products: A review. Journal of Traditional Medicine \& Clinical Naturopathy, 07. https://doi.org/10.4172/25734555.1000256

Quinn, R. L. (2019). Isotopic equifinality and rethinking the diet of australopithecus anamensis. American Journal of Physical Anthropology, 169(3), 403-421.

https://doi.org/10.1002/ajpa.23846

Ragir, S., Rosenberg, M., \& Tierno, P. (2000). Gut morphology and the avoidance of carrion among chimpanzees, baboons, and early hominids. Journal of Anthropological Research, 56(4), 477-512.

Rakhi, N. K., Tuwani, R., Mukherjee, J., \& Bagler, G. (2018). Data-driven analysis of biomedical literature suggests broad-spectrum benefits of culinary herbs and spices. PLOS ONE, 13(5), e0198030. https://doi.org/10.1371/journal.pone.0198030

Reperant, L. A., Cornaglia, G., \& Osterhaus, A. D. M. E. (2013). The importance of understanding the humananimal interface. In J. S. Mackenzie, M. Jeggo, P. Daszak, \& J. A. Richt (Eds.), One health: The human-animal-environment interfaces in emerging infectious diseases: The concept and examples of a one health approach (pp. 49-81).

https://doi.org/10.1007/82_2012_269

Reyes-García, V., Guèze, M., Díaz-Reviriego, I., Duda, R., Fernández-Llamazares, Á., Gallois, S., ... Pyhälä, A. (2016). The adaptive nature of culture: A cross-cultural analysis of the returns of local environmental knowledge in three indigenous societies. Current Anthropology, 57(6), 761-784. https://doi.org/10.1086/689307

Reyes-García, V., McDade, T. W., Vadez, V., Huanca, T., Leonard, W. R., Tanner, S., \& Godoy, R. (2008). Non-market returns to traditional human capital: Nutritional status and traditional knowledge in a native amazonian society. The Journal of Development Studies, 44(2), 217232. https://doi.org/10.1080/00220380701789901

Richerson, P. J., \& Boyd, R. (2008). Not by genes alone: How culture transformed human evolution. University of Chicago press.

Richerson, P. J., \& Boyd, R. (2020). The human life history is adapted to exploit the adaptive advantages of culture. Philosophical Transactions of the Royal Society B: Biological Sciences, 375(1803), 20190498. https://doi.org/10.1098/rstb.2019.0498

Rifkin, R. F., Vikram, S., Ramond, J.-B. J., Cowan, D. A., Jakobsson, M., Schlebusch, C. M., \& Lombard, M. (2020). Ancient DNA of Rickettsia felis and Toxoplasma gondii implicated in the death of a hunter-gatherer boy from south africa, 2,000 years ago [Preprint].

https://doi.org/10.1101/2020.07.23.217141 
Rodríguez, E., Cavin, J. C., \& West, J. E. (1982). The possible role of Amazonian psychoactive plants in the chemotherapy of parasitic worms - a hypothesis. Journal of Ethnopharmacology, 6(3), 303-309.

Rodríguez, E., \& Wrangham, R. (1993). Zoopharmocognosy: The use of medicinal plants by animals. Recent Advances In Phytochemistry, 27, 89-89.

Roth, O., Beemelmanns, A., Barribeau, S. M., \& Sadd, B. M. (2018). Recent advances in vertebrate and invertebrate transgenerational immunity in the light of ecology and evolution. Heredity, 121(3), 225-238. https://doi.org/10.1038/s41437-018-0101-2

Rothman, J. M., Raubenheimer, D., Bryer, M. A. H., Takahashi, M., \& Gilbert, C. C. (2014). Nutritional contributions of insects to primate diets: Implications for primate evolution. Journal of Human Evolution, 71, 59-69. https://doi.org/10.1016/j.jhevol.2014.02.016

Roulette, C. J., Hagen, E., \& Hewlett, B. S. (2016). A biocultural investigation of gender differences in tobacco use in an egalitarian hunter-gatherer population. Human Nature, 27(2), 105-129. https://doi.org/10.1007/s12110-016-9255-x

Roulette, C. J., Kazanji, M., Breurec, S., \& Hagen, E. H. (2016). High prevalence of cannabis use among Aka foragers of the Congo Basin and its possible relationship to helminthiasis. American Journal of Human Biology, 28(1), 5-15. https://doi.org/10.1002/ajhb.22740

Roulette, C. J., Mann, H., Kemp, B. M., Remiker, M., Roulette, J. W., Hewlett, B. S., ... Hagen, E. H. (2014). Tobacco use vs. Helminths in congo basin hunter-gatherers: Self-medication in humans? Evolution and Human Behavior, 35(5), 397-407. https://doi.org/10.1016/j.evolhumbehav.2014.05.005

Roulette, C. J., Njau, E.-F. A., Quinlan, M. B., Quinlan, R. J., \& Call, D. R. (2018). Medicinal foods and beverages among maasai agro-pastoralists in northern tanzania. Journal of Ethnopharmacology, 216, 191-202. https://doi.org/10.1016/j.jep.2018.01.022

Ruhs, E. C., Martin, L. B., \& Downs, C. J. (2020). The impacts of body mass on immune cell concentrations in birds. Proceedings of the Royal Society B: Biological Sciences, 287, 9. https://doi.org/10.1098/rspb.2020.0655

Rybak, M. E., Sternberg, M. R., Pao, C.-I., Ahluwalia, N., \& Pfeiffer, C. M. (2015). Urine excretion of caffeine and select caffeine metabolites is common in the US population and associated with caffeine intake. The Journal of Nutrition, 145(4), 766-774.

https://doi.org/10.3945/jn.114.205476

Salali, G. D., Chaudhary, N., Thompson, J., Grace, O. M., van der Burgt, X. M., Dyble, M., ... Migliano, A. B. (2016). Knowledge-sharing networks in hunter-gatherers and the evolution of cumulative culture. Current Biology. https://doi.org/10.1016/j.cub.2016.07.015

Santini, L., Isaac, N. J. B., Maiorano, L., Ficetola, G. F., Huijbregts, M. A. J., Carbone, C., \& Thuiller, W. (2018). Global drivers of population density in terrestrial vertebrates. Global Ecology and Biogeography, 27(8), 968-979. https://doi.org/10.1111/geb.12758 
Saul, H., Madella, M., Fischer, A., Glykou, A., Hartz, S., \& Craig, O. E. (2013). Phytoliths in pottery reveal the use of spice in European prehistoric cuisine. PLOS ONE, 8(8), e70583. https://doi.org/10.1371/journal.pone.0070583

Saunders, N. R., Dreifuss, J.-J., Dziegielewska, K. M., Johansson, P. A., Habgood, M. D., Møllgård, K., \& Bauer, H.-C. (2014). The rights and wrongs of blood-brain barrier permeability studies: A walk through 100 years of history. Frontiers in Neuroscience, 8. https://doi.org/10.3389/fnins.2014.00404

Saylors, K. E., Mouiche, M. M., Lucas, A., McIver, D. J., Matsida, A., Clary, C., ... Tamoufe, U. (2021). Market characteristics and zoonotic disease risk perception in cameroon bushmeat markets. Social Science \& Medicine, 268, 113358.

https://doi.org/10.1016/j.socscimed.2020.113358

Schaller, M., \& Park, J. H. (2011). The behavioral immune system (and why it matters). Current Directions in Psychological Science, 20(2), 99-103.

https://doi.org/10.1177/0963721411402596

Schnorr, S. L., Sankaranarayanan, K., Lewis, C. M., \& Warinner, C. (2016). Insights into human evolution from ancient and contemporary microbiome studies. Current Opinion in Genetics \& Development, 41,14-26. https://doi.org/10.1016/j.gde.2016.07.003

Schulenburg, H., Kurtz, J., Moret, Y., \& Siva-Jothy, M. T. (2009). Introduction. Ecological immunology. Philosophical Transactions of the Royal Society B: Biological Sciences, 364(1513), 3-14. https://doi.org/10.1098/rstb.2008.0249

Shattuck-Heidorn, H., Reiches, M. W., Prentice, A. M., Moore, S. E., \& Ellison, P. T. (2017). Energetics and the immune system: Trade-offs associated with non-acute levels of CRP in adolescent Gambian girls. Evolution, Medicine, and Public Health, 2017(1), 27-38.

https://doi.org/10.1093/emph/eow034

Shaw, L. P., Wang, A. D., Dylus, D., Meier, M., Pogacnik, G., Dessimoz, C., \& Balloux, F. (2020). The phylogenetic range of bacterial and viral pathogens of vertebrates. Molecular Ecology, 29(17), 3361-3379. https://doi.org/10.1111/mec.15463

Shivappa, N., Steck, S. E., Hurley, T. G., Hussey, J. R., \& Hébert, J. R. (2014). Designing and developing a literature-derived, population-based dietary inflammatory index. Public Health Nutrition, 17(8), 1689-1696. https://doi.org/10.1017/S1368980013002115

Shudo, E., \& Iwasa, Y. (2001). Inducible defense against pathogens and parasites: Optimal choice among multiple options. Journal of Theoretical Biology, 209(2), 233-247.

https://doi.org/10.1006/jtbi.2000.2259

Silva, L. N., Zimmer, K. R., Macedo, A. J., \& Trentin, D. S. (2016). Plant natural products targeting bacterial virulence factors. Chemical Reviews, 116(16), 9162-9236.

https://doi.org/10.1021/acs.chemrev.6b00184

Singh, M. (2018). The cultural evolution of shamanism. Behavioral and Brain Sciences, 41. 
Sinha, S., \& Sharma, B. S. (2009). Neurocysticercosis: A review of current status and management. Journal of Clinical Neuroscience, 16(7), 867-876.

https://doi.org/10.1016/j.jocn.2008.10.030

Smith, A. R., Carmody, R. N., Dutton, R. J., \& Wrangham, R. W. (2015). The significance of cooking for early hominin scavenging. Journal of Human Evolution, 84, 62-70.

https://doi.org/10.1016/j.jhevol.2015.03.013

Solomos, A. C., \& Rall, G. F. (2016). Get it through your thick head: Emerging principles in neuroimmunology and neurovirology redefine central nervous system "immune privilege." ACS Chemical Neuroscience, 7(4), 435-441.

https://doi.org/10.1021/acschemneuro.5b00336

Sorrells, S. F., Paredes, M. F., Cebrian-Silla, A., Sandoval, K., Qi, D., Kelley, K. W., ... AlvarezBuylla, A. (2018). Human hippocampal neurogenesis drops sharply in children to undetectable levels in adults. Nature, 555(7696), 377-381.

https://doi.org/10.1038/nature25975

Souilmi, Y., Lauterbur, M. E., Tobler, R., Huber, C. D., Johar, A. S., Moradi, S. V., ... Enard, D. (2021). An ancient viral epidemic involving host coronavirus interacting genes more than 20,000 years ago in east asia. Current Biology, S0960982221007946.

https://doi.org/10.1016/j.cub.2021.05.067

Steffen, I., Kai Lu, Yamamoto, L. K., Hoff, N. A., Mulembakani, P., Wemakoy, E. O., ... Hackett, J. J. (2019). Serologic prevalence of ebola virus in equatorial africa. Emerging Infectious Diseases, 25(5), 911-918. https://doi.org/10.3201/eid2505.180115

Sugiyama, L. S., \& Sugiyama, M. S. (2003). Social roles, prestige, and health risk: Social niche specialization as a risk-buffering strategy. Human Nature, 14(2), 165-190.

https://doi.org/10.1007/s12110-003-1002-4

Sullivan, R. J., \& Hagen, E. H. (2002). Psychotropic substance-seeking: Evolutionary pathology or adaptation? Addiction, 97, 389-400.

Sullivan, R. J., Hagen, E. H., \& Hammerstein, P. (2008). Revealing the paradox of drug reward in human evolution. Proceedings of the Royal Society B: Biological Sciences, 275(1640), 1231-1241. https://doi.org/10.1098/rspb.2007.1673

Takooree, H., Aumeeruddy, M. Z., Rengasamy, K. R. R., Venugopala, K. N., Jeewon, R., Zengin, G., \& Mahomoodally, M. F. (2019). A systematic review on black pepper (Piper nigrum l.): From folk uses to pharmacological applications. Critical Reviews in Food Science and Nutrition, 59(sup1), S210-S243. https://doi.org/10.1080/10408398.2019.1565489

Tallavaara, M., Eronen, J. T., \& Luoto, M. (2018). Productivity, biodiversity, and pathogens influence the global hunter-gatherer population density. Proceedings of the National Academy of Sciences, 115(6), 1232-1237. https://doi.org/10.1073/pnas.1715638115 
Tanno, T. (1981). Plant utilization of the Mbuti pygmies: With special reference to their material culture and use of wild vegetable foods. The Research Committee for African Area Studies, Kyoto University.

Terefe, Y., Hailemariam, Z., Menkir, S., Nakao, M., Lavikainen, A., Haukisalmi, V., ... Ito, A. (2014). Phylogenetic characterisation of Taenia tapeworms in spotted hyenas and reconsideration of the "Out of Africa" hypothesis of Taenia in humans. International Journal for Parasitology, 44(8), 533-541. https://doi.org/10.1016/j.ijpara.2014.03.013

Terstappen, G. C., Meyer, A. H., Bell, R. D., \& Zhang, W. (2021). Strategies for delivering therapeutics across the blood-brain barrier. Nature Reviews Drug Discovery, 20(5), 362383. https://doi.org/10.1038/s41573-021-00139-y

Trumble, B. C., Stieglitz, J., Blackwell, A. D., Allayee, H., Beheim, B., Finch, C. E., ... Kaplan, H. (2017). Apolipoprotein $E 4$ is associated with improved cognitive function in amazonian forager-horticulturalists with a high parasite burden. The FASEB Journal, 31(4), 15081515. https://doi.org/10.1096/fj.201601084R

Urlacher, S. S., Ellison, P. T., Sugiyama, L. S., Pontzer, H., Eick, G., Liebert, M. A., ... Snodgrass, J. J. (2018). Tradeoffs between immune function and childhood growth among Amazonian forager-horticulturalists. Proceedings of the National Academy of Sciences, 115(17), E3914E3921. https://doi.org/10.1073/pnas.1717522115

Valenta, K., Nevo, O., Martel, C., \& Chapman, C. A. (2017). Plant attractants: Integrating insights from pollination and seed dispersal ecology. Evolutionary Ecology, 31(2), 249-267. https://doi.org/10.1007/s10682-016-9870-3

van Boven, M., \& Weissing, F. J. (2004). The evolutionary economics of immunity. The American Naturalist, 163(2), 277-294. https://doi.org/10.1086/381407

van der Lee, R., Wiel, L., van Dam, T. J. P., \& Huynen, M. A. (2017). Genome-scale detection of positive selection in nine primates predicts human-virus evolutionary conflicts. Nucleic Acids Research, 45(18), 10634-10648. https://doi.org/10.1093/nar/gkx704

van Loon, L. C., Rep, M., \& Pieterse, C. M. J. (2006). Significance of inducible defense-related proteins in infected plants. Annual Review of Phytopathology, 44(1), 135-162.

https://doi.org/10.1146/annurev.phyto.44.070505.143425

Vandamme, A.-M., Bertazzoni, U., \& Salemi, M. (2000). Evolutionary strategies of human Tcell lymphotropic virus type II. Gene, 261(1), 171-180. https://doi.org/10.1016/S03781119(00)00473-X

Venkatesan, A., Michael, B. D., Probasco, J. C., Geocadin, R. G., \& Solomon, T. (2019). Acute encephalitis in immunocompetent adults. The Lancet, 393(10172), 702-716. https://doi.org/10.1016/S0140-6736(18)32526-1

Villabona-Rueda, A., Erice, C., Pardo, C. A., \& Stins, M. F. (2019). The evolving concept of the blood brain barrier (BBB): From a single static barrier to a heterogeneous and dynamic 
relay center. Frontiers in Cellular Neuroscience, 13.

https://doi.org/10.3389/fncel.2019.00405

Villalba, J. J., \& Provenza, F. D. (2007). Self-medication and homeostatic behaviour in herbivores: Learning about the benefits of nature's pharmacy. Animal, 1(09), 1360-1370.

Villmoare, B., Hatala, K. G., \& Jungers, W. (2019). Sexual dimorphism in Homo erectus inferred from 1.5 Ma footprints near Ileret, Kenya. Scientific Reports, 9(1), 7687.

https://doi.org/10.1038/s41598-019-44060-2

Visher, E., Evensen, C., Guth, S., Lai, E., Norfolk, M., Rozins, C., ... Boots, M. (2021). The three ts of virulence evolution during zoonotic emergence. Proceedings of the Royal Society $B$.

https://doi.org/10.1098/rspb.2021.0900

Vitek, M. P., Brown, C. M., \& Colton, C. A. (2009). APOE genotype-specific differences in the innate immune response. Neurobiology of Aging, 30(9), 1350-1360.

https://doi.org/10.1016/j.neurobiolaging.2007.11.014

Voeks, R. A. (2018). The ethnobotany of eden: Rethinking the jungle medicine narrative. University of Chicago Press.

Volgin, A. D., Bashirzade, A., Amstislavskaya, T. G., Yakovlev, O. A., Demin, K. A., Ho, Y.-J., ... Kalueff, A. V. (2019). DARK classics in chemical neuroscience: arecoline. ACS Chemical Neuroscience, 10(5), 2176-2185. https://doi.org/10.1021/acschemneuro.8b00711

von der Heydt, A. S., Ashwin, P., Camp, C. D., Crucifix, M., Dijkstra, H. A., Ditlevsen, P., \& Lenton, T. M. (2021). Quantification and interpretation of the climate variability record. Global and Planetary Change, 197, 103399.

https://doi.org/10.1016/j.gloplacha.2020.103399

Vonesch, N., Binazzi, A., Bonafede, M., Melis, P., Ruggieri, A., Iavicoli, S., \& Tomao, P. (2019). Emerging zoonotic viral infections of occupational health importance. Pathogens and Disease, 77(2), ftz018. https://doi.org/10.1093/femspd/ftz018

Watts, D. P. (2020). Meat eating by nonhuman primates: A review and synthesis. Journal of Human Evolution, 149, 102882. https://doi.org/10.1016/j.jhevol.2020.102882

Wei, C., Yang, H., Wang, S., Zhao, J., Liu, C., Gao, L., ... Wan, X. (2018). Draft genome sequence of Camellia sinensis var. sinensis provides insights into the evolution of the tea genome and tea quality. Proceedings of the National Academy of Sciences, 115(18), E4151-E4158. https://doi.org/10.1073/pnas.1719622115

Wells, K., Gibson, D. I., Clark, N. J., Ribas, A., Morand, S., \& McCallum, H. I. (2018). Global spread of helminth parasites at the human-domestic animal-wildlife interface. Global Change Biology, 24(7), 3254-3265. https://doi.org/10.1111/gcb.14064

Wertheim, J. O., Hostager, R., Ryu, D., Merkel, K., Angedakin, S., Arandjelovic, M., ... Calvignac-Spencer, S. (2021). Discovery of novel herpes simplexviruses in wild gorillas, 
bonobos, and chimpanzees supports zoonotic origin of HSV-2. Molecular Biology and Evolution, 38(7), 2818-2830. https://doi.org/10.1093/molbev/msab072

Westra, E. R., van Houte, S., Oyesiku-Blakemore, S., Makin, B., Broniewski, J. M., Best, A., ... Buckling, A. (2015). Parasite exposure drives selective evolution of constitutive versus inducible defense. Current Biology, 25(8), 1043-1049.

https://doi.org/10.1016/j.cub.2015.01.065

Weyrich, L. S., Duchene, S., Soubrier, J., Arriola, L., Llamas, B., Breen, J., ... Cooper, A. (2017). Neanderthal behaviour, diet, and disease inferred from ancient DNA in dental calculus. Nature, 544(7650), 357-361. https://doi.org/10.1038/nature21674

WHO (Ed.). (2019). WHO global report on traditional and complementary medicine, 2019. Geneva, Switzerland: World Health Organization.

Will, M., Pablos, A., \& Stock, J. T. (2017). Long-term patterns of body mass and stature evolution within the hominin lineage. Royal Society Open Science, 4(11), 171339. https://doi.org/10.1098/rsos.171339

Wink, M. (2015). Modes of action of herbal medicines and plant secondary metabolites. Medicines, 2(3), 251-286. https://doi.org/10.3390/medicines2030251

Wise, R. A. (1998). Drug-activation of brain reward pathways. Drug Alcohol Depend, 51(12), 13-22.

Wong, A., Ye, M., Levy, A., Rothstein, J., Bergles, D., \& Searson, P. C. (2013). The blood-brain barrier: An engineering perspective. Frontiers in Neuroengineering, 6.

https://doi.org/10.3389/fneng.2013.00007

Wrangham, R. W., \& Nishida, T. (1983). Aspilia spp. Leaves: A puzzle in the feeding behavior of wild chimpanzees. Primates, 24(2), 276-282.

Wynn, J. G., Reed, K. E., Sponheimer, M., Kimbel, W. H., Alemseged, Z., Bedaso, Z. K., \& Campisano, C. J. (2016). Dietary flexibility of Australopithecus afarensis in the face of paleoecological change during the middle Pliocene: Faunal evidence from Hadar, Ethiopia. Journal of Human Evolution, 99, 93-106. https://doi.org/10.1016/j.jhevol.2016.08.002

Xia, H., Li, X., Gao, W., Fu, X., Fang, R. H., Zhang, L., \& Zhang, K. (2018). Tissue repair and regeneration with endogenous stem cells. Nature Reviews Materials, 3(7), 174-193.

https://doi.org/10.1038/s41578-018-0027-6

Xia, M., Chen, H., \& Liu, S. (2020). The synergy of resveratrol and alcohol against Helicobacter pylori and underlying anti- Helicobacter pylori mechanism of resveratrol. Journal of Applied Microbiology, 128(4), 1179-1190. https://doi.org/10.1111/jam.14531

Xu, C., Li, Q., Efimova, O., He, L., Tatsumoto, S., Stepanova, V., ... Go, Y. (2018). Humanspecific features of spatial gene expression and regulation in eight brain regions. Genome Research, 28(8), 1097-1110. https://doi.org/10.1101/gr.231357.117 
Yates, J. A. F., Velsko, I. M., Aron, F., Posth, C., Hofman, C. A., Austin, R. M., ... Menéndez, M. (2021). The evolution and changing ecology of the African hominid oral microbiome. Proceedings of the National Academy of Sciences, 118, 1-11.

Yeung, A. W. K., Heinrich, M., Kijjoa, A., Tzvetkov, N. T., \& Atanasov, A. G. (2020). The ethnopharmacological literature: An analysis of the scientific landscape. Journal of Ethnopharmacology, 250, 112414. https://doi.org/10.1016/j.jep.2019.112414

Yoshimura, H., Hirata, S., \& Kinoshita, K. (2021). Plant-eating carnivores: Multispecies analysis on factors influencing the frequency of plant occurrence in obligate carnivores. Ecology and Evolution, 11(16), 10968-10983. https://doi.org/10.1002/ece3.7885

Young, N. M., Capellini, T. D., Roach, N. T., \& Alemseged, Z. (2015). Fossil hominin shoulders support an african ape-like last common ancestor of humans and chimpanzees. Proceedings of the National Academy of Sciences, 112(38), 11829-11834.

https://doi.org/10.1073/pnas.1511220112

Zaidi, S. F., Muhammad, J. S., Usmanghani, K., \& Sugiyama, T. (2015). Pharmacological ins and outs of medicinal plants against Helicobacter pylori: A review. Pak. J. Pharm. Sci., 6.

Zhang, L., Ho, C.-T., Zhou, J., Santos, J. S., Armstrong, L., \& Granato, D. (2019). Chemistry and biological activities of processed camellia sinensis teas: A comprehensive review. Comprehensive Reviews in Food Science and Food Safety, 18(5), 1474-1495.

https://doi.org/10.1111/1541-4337.12479

Zhu, D., Galbraith, E. D., Reyes-García, V., \& Ciais, P. (2021). Global hunter-gatherer population densities constrained by influence of seasonality on diet composition. Nature Ecology \& Evolution, 5(11), 1536-1545. https://doi.org/10.1038/s41559-021-01548-3

Zou, X.-Y., \& Ye, B. (2014). Traditional chinese treatment of taeniasis. In H. Mehlhorn, Z. Wu, \& B. Ye (Eds.), Treatment of human parasitosis in traditional chinese medicine (pp. 155168). https://doi.org/10.1007/978-3-642-39824-7 